January 2000 • NREL/SR-570-27613

\title{
A Review of the Chemical and Physical Mechanisms of the Storage Stability of Fast Pyrolysis Bio-Oils
}

J.P. Diebold

Thermalchemie, Inc. Lakewood, Colorado

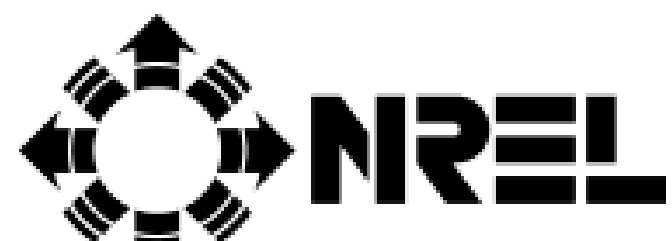

National Renewable Energy Laboratory

1617 Cole Boulevard Golden, Colorado 80401-3393

NREL is a U.S. Department of Energy Laboratory Operated by Midwest Research Institute $\bullet$ Battelle $\bullet$ Bechtel 


\title{
A Review of the Chemical and Physical Mechanisms of the Storage Stability of Fast Pyrolysis Bio-Oils
}

\author{
J.P. Diebold \\ Thermalchemie, Inc. \\ Lakewood, Colorado
}

NREL Technical Monitor: Stefan Czernik

Prepared under Purchase Order Number 165134

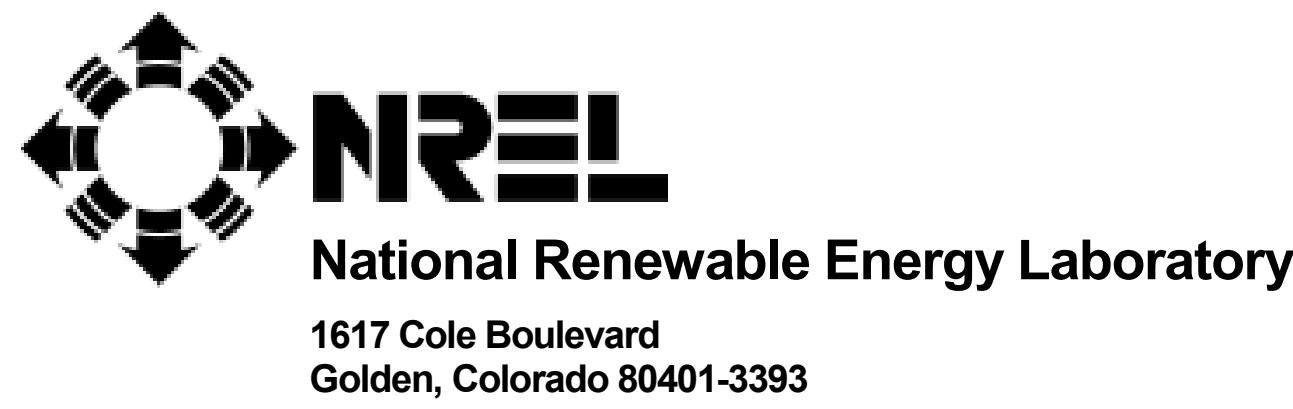

NREL is a U.S. Department of Energy Laboratory

Operated by Midwest Research Institute $\bullet$ Battelle $\bullet$ Bechtel

Contract No. DE-AC36-99-G010337 


\section{NOTICE}

This report was prepared as an account of work sponsored by an agency of the United States government. Neither the United States government nor any agency thereof, nor any of their employees, makes any warranty, express or implied, or assumes any legal liability or responsibility for the accuracy, completeness, or usefulness of any information, apparatus, product, or process disclosed, or represents that its use would not infringe privately owned rights. Reference herein to any specific commercial product, process, or service by trade name, trademark, manufacturer, or otherwise does not necessarily constitute or imply its endorsement, recommendation, or favoring by the United States government or any agency thereof. The views and opinions of authors expressed herein do not necessarily state or reflect those of the United States government or any agency thereof.

Available electronically at http://www.doe.gov/bridge

Available for a processing fee to U.S. Department of Energy

and its contractors, in paper, from:

U.S. Department of Energy

Office of Scientific and Technical Information

P.O. Box 62

Oak Ridge, TN 37831-0062

phone: 865.576.8401

fax: 865.576.5728

email: reports@adonis.osti.gov

Available for sale to the public, in paper, from:

U.S. Department of Commerce

National Technical Information Service

5285 Port Royal Road

Springfield, VA 22161

phone: 800.553.6847

fax: 703.605.6900

email: orders@ntis.fedworld.gov

online ordering: http://www.ntis.gov/ordering.htm

Printed on paper containing at least $50 \%$ wastepaper, including $20 \%$ postconsumer waste 


\section{PREFACE}

This literature review was suggested by the Pyrolysis Network (PyNe) and the National Renewable Energy Laboratory (NREL), as a necessary means to collect and compare the known chemistry and physical mechanisms of the storage instability of bio-oils. Because of the chemical similarities between bio-oils derived by fast pyrolysis with wood distillates and liquid smoke used for flavors, the author expanded the review to include these pyrolysis-derived condensates.

\section{ACKNOWLEDGMENTS}

The financial support to perform this review was provided equally by PyNe (managed by Prof. A.V. Bridgwater, Director of the Energy Research Group, Department of Chemical Engineering and Applied Chemistry, Aston University, Birmingham, UK) and by the Biomass Power Program (managed by Mr. Kevin Craig) at NREL, Golden, CO of the U.S. Department of Energy with purchase order 165134 of June 3, 1999. This support is gratefully acknowledged.

The encouragement of Dr. Stefan Czernik of NREL, Mr. Jan Piskorz of Resource Transforms International, Dr. Dietrich Meier of the Institute of Wood Chemistry, and Ms. Anja Oasmaa of the Technical Research Centre (VTT) of Finland is also gratefully acknowledged. 


\section{Contents}

Preface.

Page

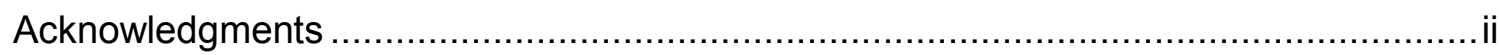

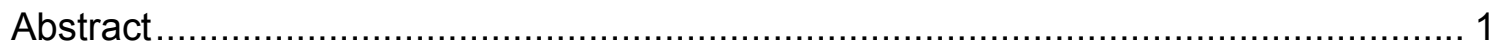

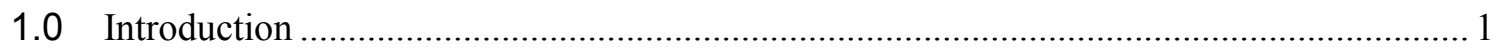

1.1 Storage Stability Problem ........................................................... 1

1.2 Combustion Problems Caused by Aging or Excessive Heat..................... 5

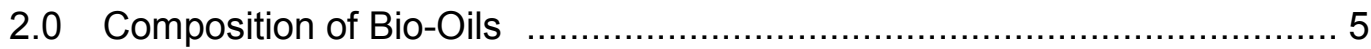

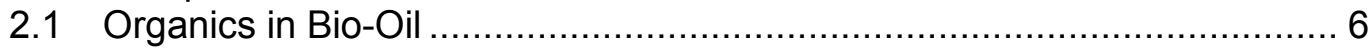

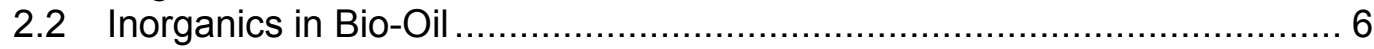

3.0 Probable Chemical Mechanisms of Storage Instability .................................... 11

3.1 Reactions of Organic Acids ........................................................ 12

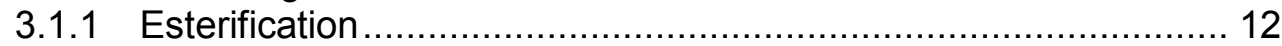

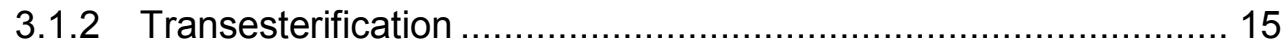

3.2 Reactions of Aldehydes................................................................... 15

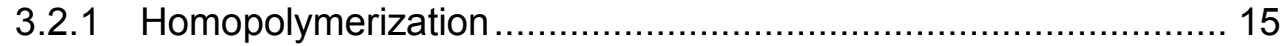

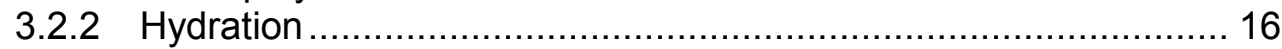

3.2.3 Hemiacetal Formation........................................................... 16

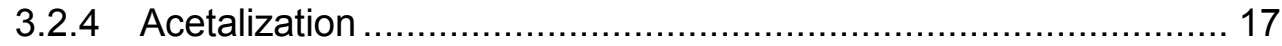

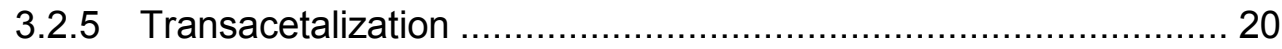

3.2.6 Phenol/Aldehyde Reactions and Resin .................................... 20

3.2.7 Polymerization of Furan Derivatives …………...................... 21

3.2.8 Dimerization of Organic Nitrogen Compounds ........................... 21

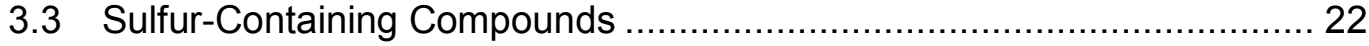

3.4 Unsaturated Organic Reactions …………………..................... 22

3.4.1 Alcohol Addition .............................................................. 22

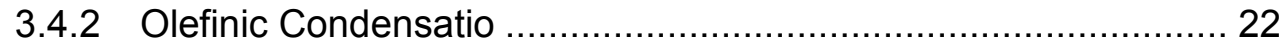

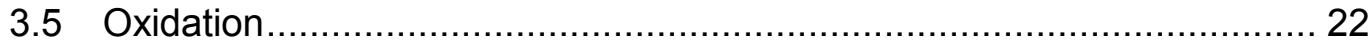

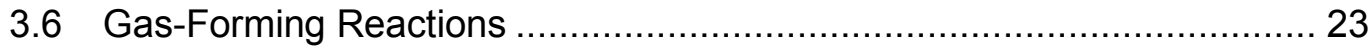

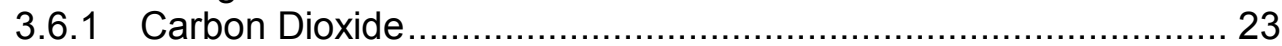

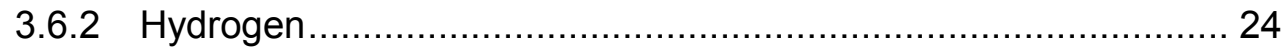

3.7 Insights to Be Gained from the Chemical Mechanisms of Aging............. 24

4.0 Observed Chemical Reactions in Wood Distillates, Wood Smoke, and

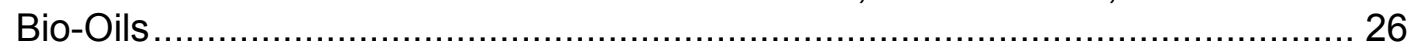

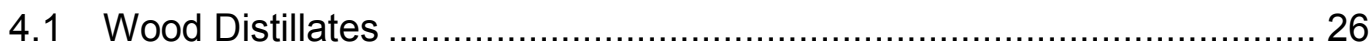

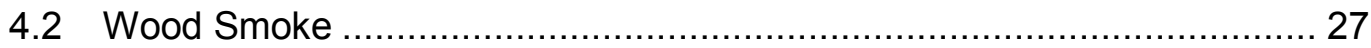

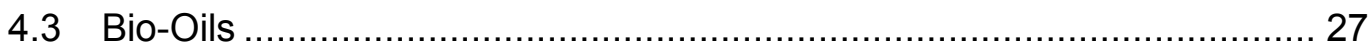

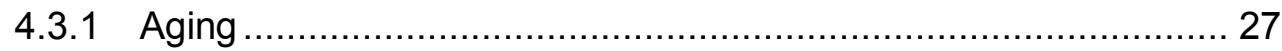

4.3.2 Esterification and Acetalization .............................................. 28

4.3.3 Hydrogenation ............................................................. 29

4.3.4 Polymerization with Formaldehyde ……………………….... 30

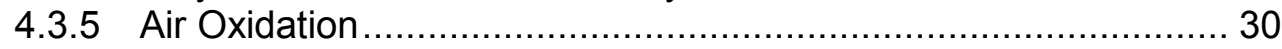




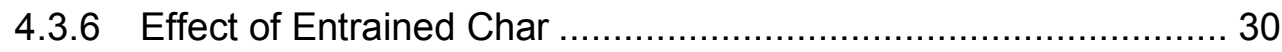

4.3.7 Off-Gassing during Storage ............................................... 31

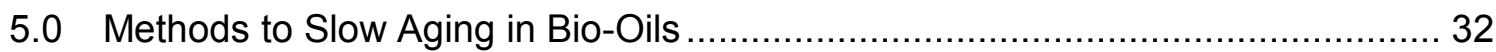

5.1 Solvent Addition to Reduce Viscosity and Aging Rates ......................... 32

5.2 Mild Hydrogenation .......................................................................... 34

5.3 Limiting Access to Air and Antioxidants ................................................ 35

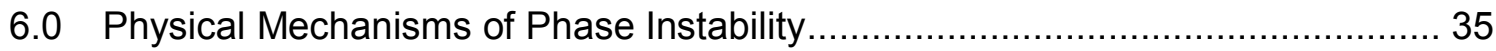

6.1 Co-Solvency of Bio-Oil Components ............................................ 35

6.2 Changes in Mutual Solubility with Aging .......................................... 38

6.3 Micelles, Suspensions, and Emulsions............................................. 38

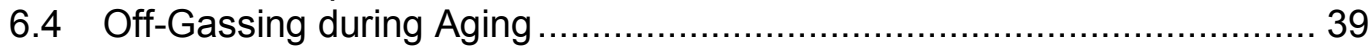

7.0 Comparisons of the Storage Instability Mechanisms of Bio-Oils and

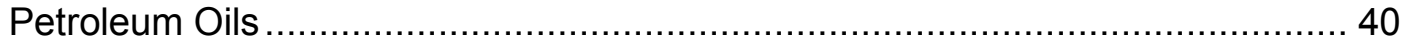

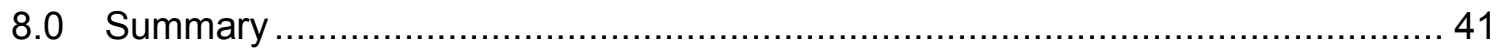

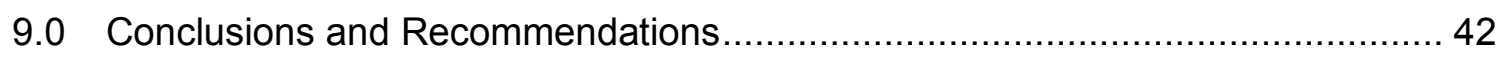

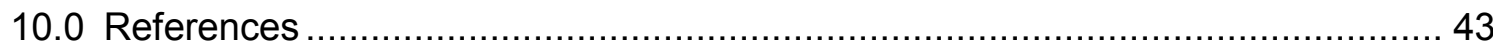

Figures

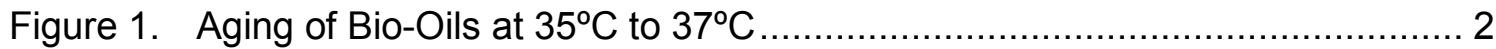

Figure 2. Effect of Measurement Temperature on Apparent Aging of Poplar Hot-Gas Filtered Bio-Oil ........................................................ 2

Figure 3. Rate of Viscosity Increase with Temperature during Storage of Bio-Oils...... 4

Figure 4. Viscosity and Molecular Weight after Aging of a Bio-Oil Made from Oak ...... 4

Figure 5. Hydrolysis Rate of Ethyl Acetate and pH........................................ 14

Figure 6. Calculated Equilibrium Composition of Pseudo Bio-Oil with Water Content at Start of Storage ............................................................. 25

Figure 7. Calculated Equilibrium Composition of Pseudo Bio-Oil with Added Methanol ............................................................................ 26

Figure 8. Noncatalytic Esterification in Whole Smoke Condensate at $25^{\circ} \mathrm{C} \ldots \ldots \ldots \ldots \ldots . . .28$

\section{Tables}

Table 1. Compounds Identified in Bio-Oils and Similar Pyrolysis Products .............. 7-8

Table 2. Inorganic Compositions of the Chars and Bio-Oils Made from Various Biomass Feeds at NREL with Char Removal by Cyclones or Filtration......... 10

Table 3. Normal Boiling Points of Probable Alcohols, Acids, and Esters in Bio-Oils, Liquid Phase, and Vapor Phase Equilibrium Constants for Ester Formation from Alcohol and Organic Acids at $25^{\circ} \mathrm{C}$.....

Table 4. Equilibrium Constants for Liquid Acetal Formation (at $25^{\circ} \mathrm{C}$ ) and Normal Boiling Point of Resulting Acetals 
Table 5. Effect of Adding Solvents on Aging Rates ........................................ 33

Table 6. Hansen Solubility Parameters for Solvents in Bio-Oil of Potential Interest to Bio-Oil Producers.................................................................. 37

Table 7. Hansen Solubility Parameters for Polymers Possibly Relevant

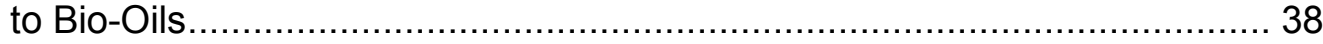




\title{
A REVIEW OF \\ THE CHEMICAL AND PHYSICAL MECHANISMS OF THE STORAGE STABILITY OF FAST PYROLYSIS BIO-OILS
}

\begin{abstract}
Understanding the fundamental chemical and physical aging mechanisms is necessary to learn how to produce a bio-oil that is more stable during shipping and storage. This review provides a basis for this understanding and identifies possible future research paths to produce bio-oils with better storage stability. Included are 108 references.

The literature contains insights into the chemical and physical mechanisms that affect the relative storage stability of bio-oil. Many chemical reactions that are normally thought to require catalysis, proceed quite nicely without them (or with catalysts indigenous to the bio-oil) during the long reaction times available in storage. The literature was searched for information about the equilibrium constants and reaction rates of selected aging mechanisms, to determine whether they apply to storage times. The chemical reactions reported to occur in pyrolytic liquids made from biomass are presented. As the bio-oil composition changes during aging, the mutual solubility of the components changes to make phase separation more likely. With these insights into the aging mechanisms, the use of additives to improve storage stability is examined. Comparisons are then made to the storage stability of petroleum fuels. The review is summarized, conclusions are drawn, and recommendations are made for future research to improve the storage stability of bio-oils.
\end{abstract}

\subsection{INTRODUCTION}

\subsection{Storage Stability Problem}

Pyrolysis of biomass under conditions of rapid heating and short reactor residence times can produce a low-viscosity, single-phase pyrolysis liquid (bio-oil) in yields reportedly higher than $70 \%$. Most projected uses of bio-oil require that it retain these initial physical properties during storage, shipment, and use. Unfortunately, some bio-oils rapidly become more viscous during storage. Figure 1 shows this increase for three bio-oils made from three hardwoods using different pyrolysis conditions, after aging 3 months at $35^{\circ} \mathrm{C}$ to $37^{\circ} \mathrm{C}$. These three bio-oils exhibit very different initial viscosities and rates of viscosity increase.

Figure 2 shows the effect of temperature on viscosity for three samples of a bio-oil made from poplar that had been aged at $90^{\circ} \mathrm{C}$ for 0,8 , and 20.5 hours. Aging effectively shifts the viscosity curve to the right on the temperature axis, resulting in higher viscosities. The effect of aging on viscosity is greater at lower measurement temperatures (Diebold and Czernik 1997). In this example, the change in viscosity appears to be about twice as high, if measured at $40^{\circ} \mathrm{C}$ rather than $50^{\circ} \mathrm{C}$. At the higher measurement temperature of $70^{\circ} \mathrm{C}$, the effects of aging amount to an increase of only a few centipoise (mPas). The measurement temperature is usually chosen to compare to petroleum fuel oil specifications (e.g., $40^{\circ} \mathrm{C}$ in the United States, $40^{\circ} \mathrm{C}$ and $50^{\circ} \mathrm{C}$ have been used in Finland). 


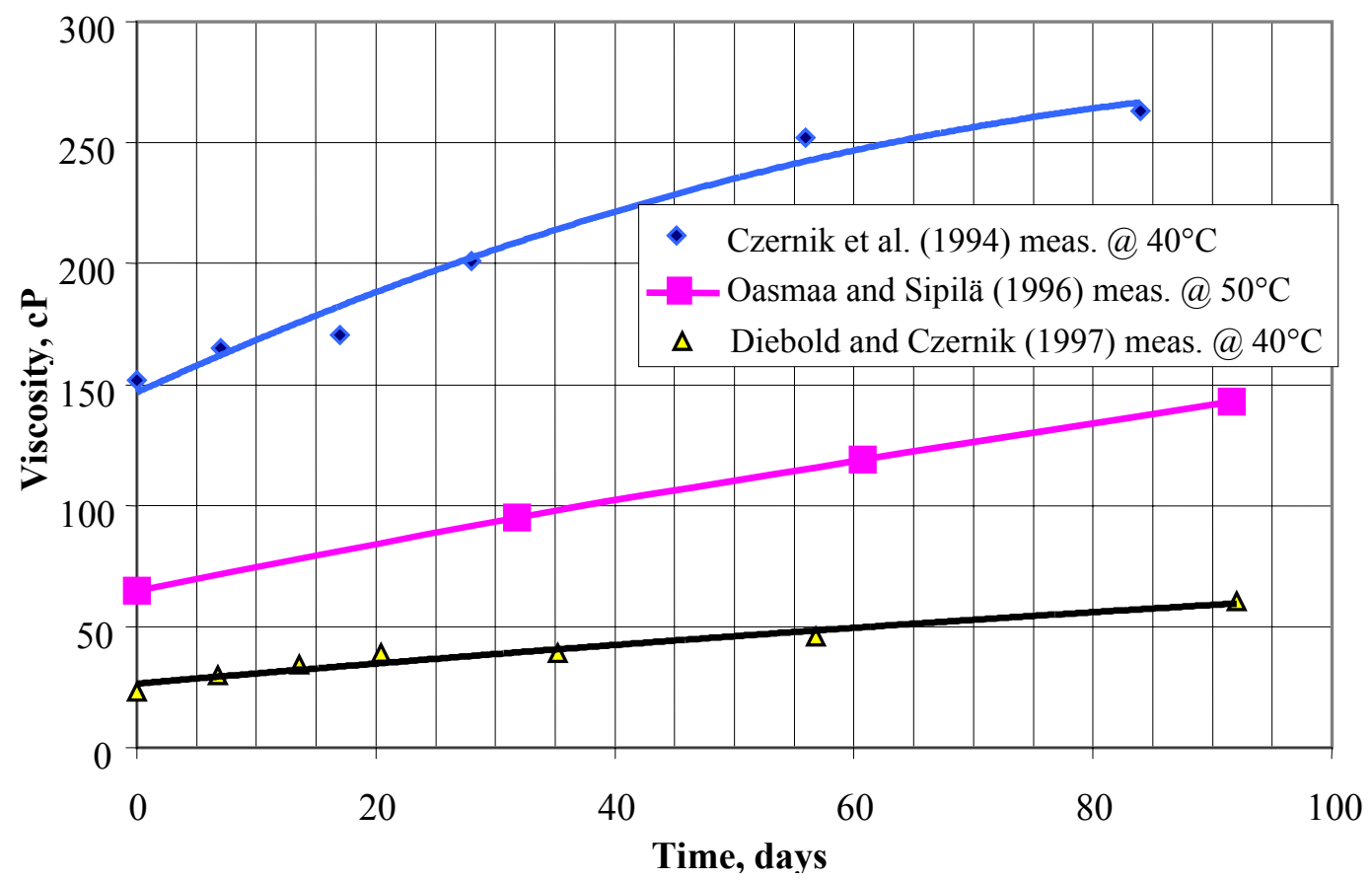

Figure 1. Aging of Bio-Oils at $35^{\circ} \mathrm{C}$ to $37^{\circ} \mathrm{C}(\mathrm{cP}=\mathrm{mPas})$

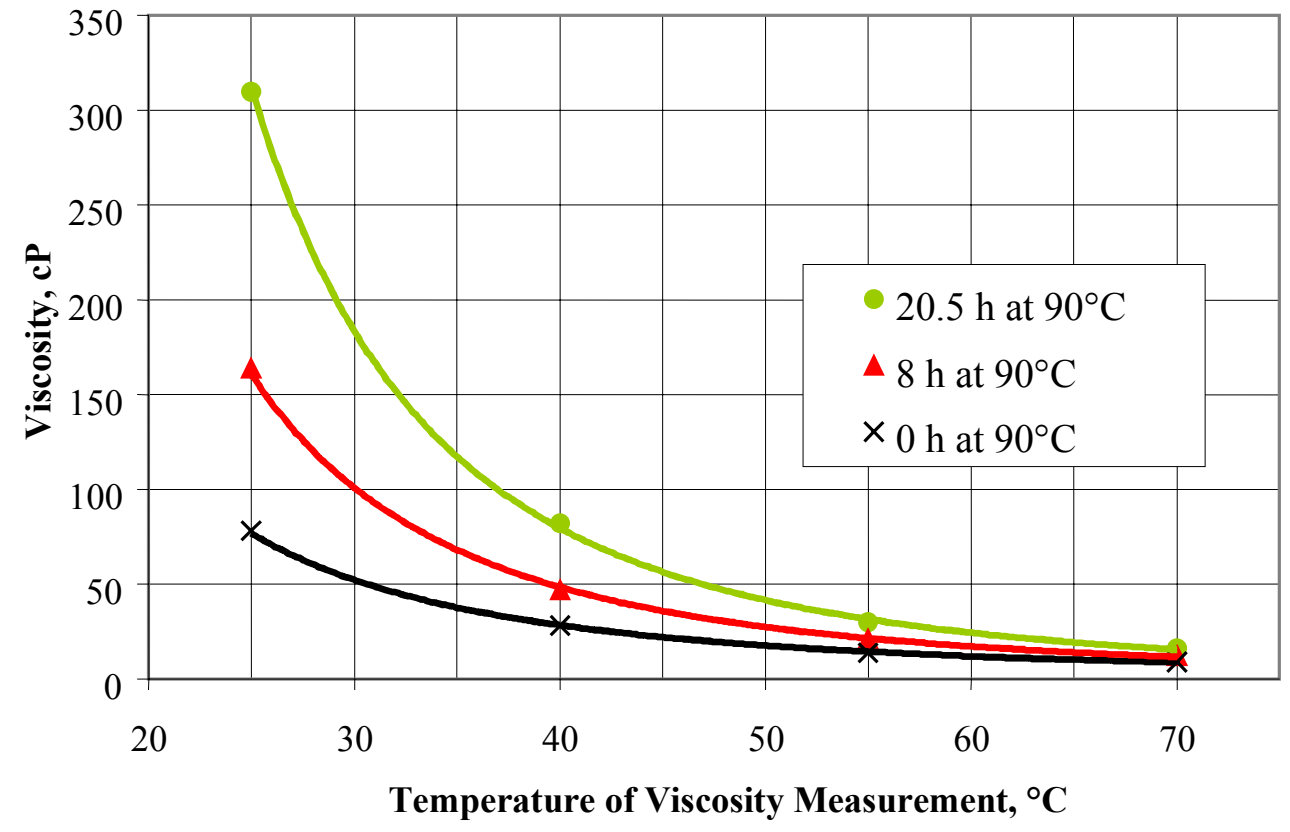

Figure 2. Effect of Measurement Temperature on Apparent Aging of Poplar Hot-Gas Filtered Bio-Oil (Diebold and Czernik 1997) 
The aging effects occur much faster at higher temperatures. Figure 3 shows that the viscosity increase rate of the hardwood bio-oils (shown in Figure 1) and for a softwood bio-oil varied more than four orders of magnitude, from $0.009 \mathrm{cP} /$ day at $-20^{\circ} \mathrm{C}$ to more than $300 \mathrm{cP} /$ day at $90^{\circ} \mathrm{C}$. This is approximately a doubling of the viscosity increase rate for each $7.3^{\circ} \mathrm{C}$ increase in storage temperature. The aging rate of softwood bio-oil is about the same as for hardwood bio-oils at $20^{\circ} \mathrm{C}$, with some possible differences at lower storage temperatures. However, the viscosity change during aging is very small (below $20^{\circ} \mathrm{C}$ ), making low-temperature aging rates subject to measurement errors.

Because the viscosity change rates may be represented as Arrhenius exponential functions of the inverse of absolute temperature, chemical reactions appear to be involved. Figure 3 shows that the bio-oils must be cooled quickly after being produced and then stored at low temperatures to maintain their low viscosity. The pyrolysis oils referred to in Figure 3 initially contained 10 to $21 \mathrm{wt} \%$ water.

A loss of volatiles will increase the viscosity of bio-oil, so the bio-oils shown in Figures 1-4 were carefully aged in sealed containers to prevent such losses. Using gel permeation chromatography with ultraviolet detection of the aromatic compounds, the weight-average molecular weights of the aromatic compounds in aged bio-oils made from oak were determined (Czernik et al. 1994). Figure 4 shows that molecular weight correlated very well with viscosity during aging, in this case with a linear-regression $\mathrm{R}^{2}$ value of 0.96 , for all aging data at $37^{\circ} \mathrm{C}, 60^{\circ} \mathrm{C}$, and $90^{\circ} \mathrm{C}$ treated as one data set. (The regression $\mathrm{R}^{2}$ values are slightly improved if the data set is divided into three sets, one for each aging temperature.)

Figure 4 strongly implies that if a pyrolysis process more thoroughly cracks the bio-oil to lower molecular weights, the initial viscosity is desirably lower. Thus, partially pyrolyzed particles and droplets must not be entrained prematurely from the reactor system, because if they are soluble in the bio-oil, they will cause the molecular weight and viscosity to increase.

During aging, chemical reactions, which apparently increase the average molecular weight, take place in bio-oil. Based on the good correlation for the aging data treated as one data set, relatively similar chemical reactions appear to occur over this temperature range. This is the basis for conducting accelerated aging research at elevated temperatures and then applying the results to predict storage of biooils at lower temperatures. The advantage of accelerated aging tests is the short time required to demonstrate the aging properties of a particular bio-oil.

Bio-oil is not a product of thermodynamic equilibrium during pyrolysis, but is produced with short reactor times and rapid cooling or quenching from the pyrolysis temperatures. This produces a condensate that is also not at thermodynamic equilibrium at storage temperatures. Bio-oil contains a large number of oxygenated organic compounds with a wide range of molecular weights, typically in small percentages. During storage, the chemical composition of the bio-oil changes toward thermodynamic equilibrium under storage conditions, resulting in changes in the viscosity, molecular weight, and co-solubility of its many compounds.

In addition to simple viscosity increases, the single-phase bio-oil can separate into various tarry, sludgy, waxy, and thin aqueous phases during aging. Tarry sludges and waxes still in suspension have caused rapid plugging of fuel filters. They can form during storage in previously filtered bio-oils and in aqueous phases. Bio-oils seem to be more unstable during storage than are petroleum-derived fuel oils, although there appear to be many similarities in their mechanisms. 


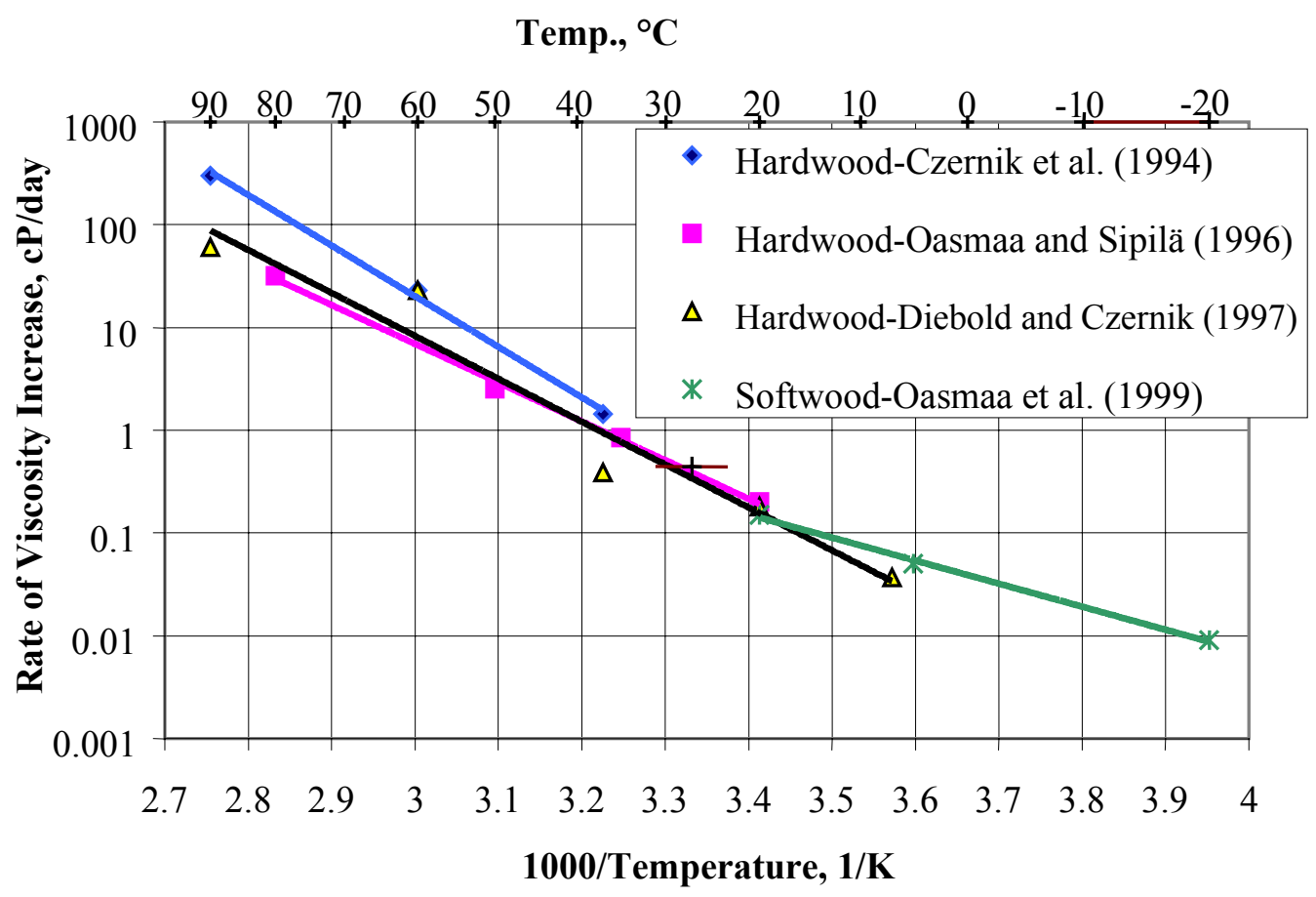

Figure 3. Rate of Viscosity Increase with Temperature during Storage of Bio-Oils

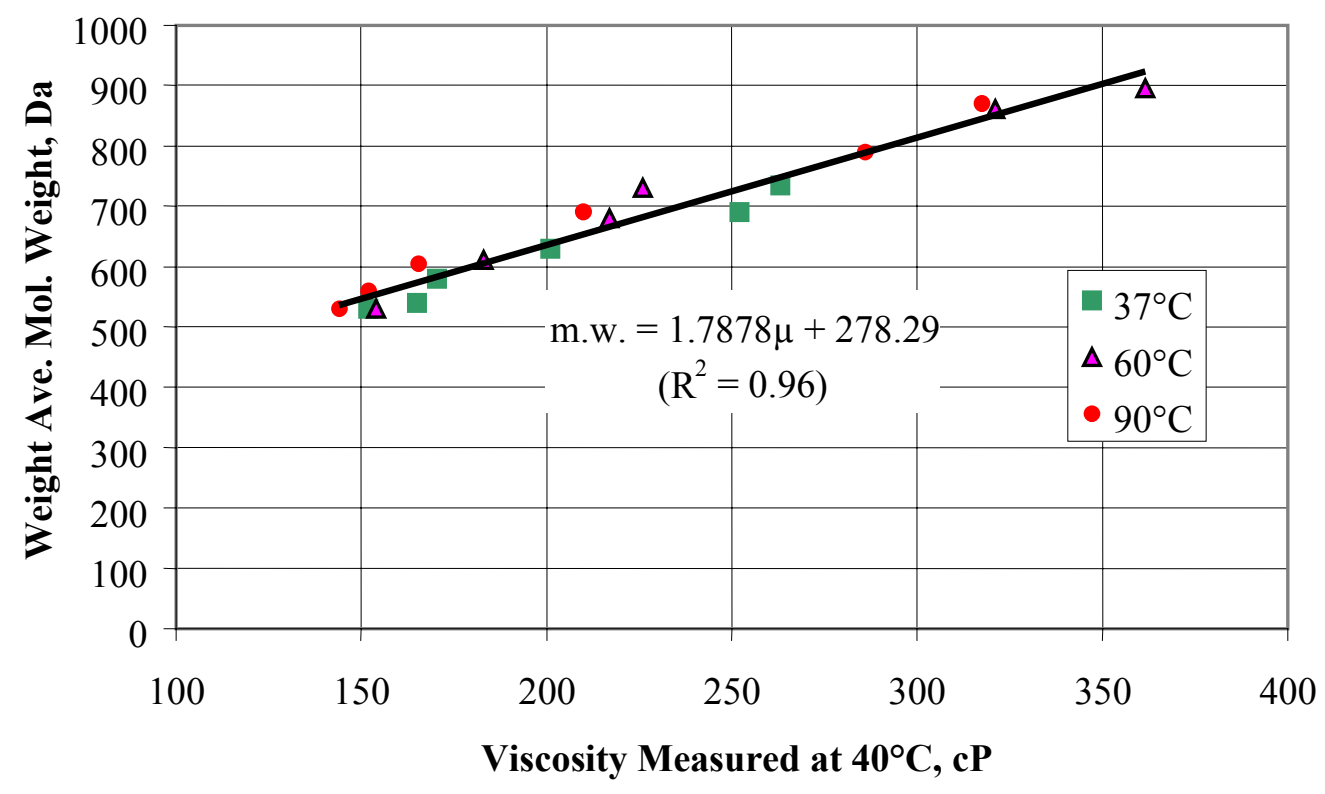

Figure 4. Viscosity and Molecular Weight after Aging of a Bio-Oil Made from Oak (data from Czernik et al. 1994)

(Molecular weight by GPC with UV detector) 


\subsection{Combustion Problems Caused By Aging or Excessive Heat}

Common practice is to preheat fuel oils before combustion to lower their viscosity for better atomization. With diesel engines, the fuel is pumped through a preheater to the injector, where only a small fraction of the fuel is injected into the engine. The remainder of the hot fuel is normally recirculated back to the pump. This was problematical with preheating bio-oils before they were injected into a diesel engine; particulates grew from smaller than $10 \mu \mathrm{m}$ to larger than $40 \mu \mathrm{m}$ in this recirculation loop. Although filters were used to remove these particulates from the recycled fuel, reliable operation was achieved only after the recirculation loop was removed and the excess hot bio-oil was dumped to a waste container (Shihadeh 1998). This particle growth is thought to be due to polymerization reactions occurring in the heated biooil, although physical agglomeration of micelles would also explain this phenomenon.

After preheating bio-oil to $90^{\circ} \mathrm{C}$ before atomization into a furnace, the $0.8-\mathrm{mm}$ diameter holes in the fuel injector were plugged with deposits (Rossi 1994). Deposits were formed in the hot injectors, if they were not rinsed out with alcohol before the furnace (Gust 1997a; Huffman and Freel 1997) or the diesel engine (Casanova 1994) was shut down. Sludge deposits in the bottom of the fuel tank and in the fuel lines were flushed out with methanol (Leech and Webster 1999). The need for this alcohol rinse was cited as an impediment to the use of bio-oil in small combustion systems (Gust 1997a).

Although the solubility of bio-oil in diesel fuel is relatively slight, operating the combustion system for a short time with diesel fuel after shutting off the bio-oil flow precluded the formation of tarry deposits in the injector nozzles (Andrews et al. 1997), but was not always effective (Gust 1997b). Although these deposits were often blamed on a loss of volatile components from the bio-oil during cooldown, polymerization probably occurred as well.

\subsection{COMPOSITION OF BIO-OILS}

The composition of bio-oils results form a complex interrelationship of:

- The biomass species used as feedstock (organic and inorganic compositions, including dirt and moisture).

- Organic nitrogen or protein content of the feedstock.

- The heat transfer rate and final char temperature during pyrolysis.

- The extent of vapor dilution in the reactor.

- The time and temperature history of the vapors in the reactor.

- The time and temperature history of the vapors in the heated transfer lines from the pyrolysis reactor through the char removal equipment to the quench zone.

- Whether the vapors pass through accumulated char (i.e., in hot-gas char filtration between backflushing operations).

- The efficiency of the char recovery system to separate the char from the bio-oil vapors before condensation.

- The efficiency of the condensation equipment to recover the volatile components from the noncondensable gas stream, e.g., water and low molecular weight esters, ethers, acetals, alcohols, and aldehydes.

- Whether the condensates have been filtered to remove suspended char fines.

- The water content of the bio-oil.

- The extent of contamination of the bio-oil during storage by corrosion or leaching of the containers.

- Exposure to air during storage.

- The length of storage time.

- The storage temperature. 
A thorough discussion of the effects of the reactor variables is outside the scope of this review. They have already been treated in considerable detail (e.g., Diebold and Bridgwater 1997). The other variables are discussed in this review.

\subsection{Organics in Bio-Oil}

Because fast pyrolysis involves only the partial decomposition of biomass, the chemical composition of the resulting bio-oil is feedstock dependent. Biomass feedstocks rich in proteins would be expected to have high organic nitrogen contents. For example, bark, alfalfa, or grass cut for hay would be expected to produce bio-oils with higher nitrogen contents than would materials having low protein contents, e.g., straw or debarked wood. The presence of nitrogen compounds in bio-oils will adversely affect the nitrogen oxide $\left(\mathrm{NO}_{\mathrm{x}}\right)$ content of the combustion products and the aging properties.

Other influences of the feedstock species are found in the lignin, from which the phenolics in bio-oils are primarily derived. A wood distillate made from hardwoods contained 55\% phenolics with methoxy groups attached at the number 2 and 6 positions of the phenolic molecule, i.e., syringols, and only $16 \%$ guaiacols with a methoxy at the number 2 position (Carraza et al. 1994). Lignins from softwood tend to have one or no methoxy group attached to the number 2 position of the phenolic molecule (Lewis and Lansky 1989). Bark tends to contain highly reactive tannins, as well as a high protein content.

As a consequence of the many variables in the pyrolysis of biomass and the storage of bio-oils, the reported compositions of bio-oil vary considerably. More than 400 organic compounds are reportedly in pyrolysis liquids or wood smoke. The wood smoke literature has a lot of detail on minor components that can affect the perceived flavors (Maga 1987). The literature on the composition of fast pyrolysis oils was summarized by Milne et al. (1997). Tables 1a and $1 \mathrm{~b}$ summarize these compilations, which show the similarities in the qualitative compositions of these pyrolysis-derived condensates (Diebold 1997). This implies similar chemical reactions in wood distillates, wood smoke, and bio-oil.

Of particular interest is the wide range reported for the composition of each organic component of bio-oil. For many compounds, this range exceeds a factor of 10:1. Bio-oil is apparently a poorly defined mixture of acids, alcohols, aldehydes, esters, ketones, sugars, phenols, guaiacols, syringols, furans, and multifunctional compounds, such as hydroxyacetic acid, hydroxyacetaldehyde, hyroxyacetone, and 3-hydroxy3-methoxy benzaldehyde. The organic acids cause bio-oil to be acidic, with a pH of about 2.3 to 3.0.

\subsection{Inorganics in Bio-Oil}

The inorganic or mineral content of biomass is found in many forms: in aqueous solution in association with various counter ions; bound to organic acids; as deposits; or related to various enzymatic compounds. The counter ions in solution include carbonates, oxalates, phosphates, silicates, chlorides, and sulfates (French and Milne 1994). The char and inorganic contents of bio-oil are important to its aging characteristics, as they appear to catalyze polymerization reactions during storage, leading to viscosity increases and growth in the apparent diameter of the suspended char (Agblevor et al. 1994, 1995).

The following discussion shows that some of these minerals are potential catalysts for reactions that are important in aging, e.g., chlorides of calcium, lithium, iron, magnesium, manganese, and zinc that catalyze acetal-forming reactions. 
Table 1a. Compounds Identified in Bio-Oils (Milne et al. 1997) and Similar Pyrolysis Products (Diebold 1997)

\begin{tabular}{|c|c|c|c|}
\hline Compound & $\mid \begin{array}{c}\text { Wood } \\
\text { Distillate }\end{array}$ & \begin{tabular}{|c} 
Smoke \\
Flavors
\end{tabular} & \begin{tabular}{|c} 
Bio-Oils \\
wt\%
\end{tabular} \\
\hline \multicolumn{4}{|l|}{$\underline{\text { Acids }}$} \\
\hline Formic (methanoic) & $\mathrm{f}, \mathrm{g}, \mathrm{h}, \mathrm{k}, \mathrm{s}, \mathrm{v}$ & $G I, \mathrm{~m}, \mathrm{t}$ & $0.3-9.1$ \\
\hline \begin{tabular}{|l|} 
Acetic (ethanoic) \\
\end{tabular} & $\mathrm{f,g,h,k,s,v}$ & $G I, \mathrm{~m}, \mathrm{t}$ & $0.5-12$ \\
\hline Propanoic & $\mathrm{f}, \mathrm{g}, \mathrm{h}, \mathrm{k}, \mathrm{s}, \mathrm{v}$ & $G I, \mathrm{~m}$ & $0.1-1.8$ \\
\hline Hydroxyacetic & $\mathrm{f},,, \mathrm{s}, \mathrm{v}$ & $\mathrm{M}$ & $0.1-0.9$ \\
\hline 2-Butenic(crotonic) & $\mathrm{f}, \mathrm{g}, \mathrm{h}, \mathrm{k}, \mathrm{s}, \mathrm{v}$ & $\mathrm{M}$ & --- \\
\hline Butanoic & $\mathrm{f}, \mathrm{g}, \mathrm{h}, \mathrm{k}, \mathrm{s}, \mathrm{v}$ & $\mathrm{T}$ & $0.1-0.5$ \\
\hline Pentanoic (valeric) & $\mathrm{f}, \mathrm{h}, \mathrm{k}, \mathrm{s}, \mathrm{v}$ & $G I, \mathrm{~m}, \mathrm{t}$ & $0.1-0.8$ \\
\hline 2-Me butenoic & $\mathrm{f}, \mathrm{h}, \mathrm{k}, \mathrm{s}$ & $\mathrm{M}$ & --- \\
\hline 4-Oxypentanioc & $,,, \mathrm{s}, \mathrm{V}$ & $G I, \mathrm{~m}$ & $0.1-0.4$ \\
\hline 4-Hydroxypentanoic &,,,,, $\mathrm{V}$ & & --- \\
\hline Hexanoic (caproic) & $\mathrm{f}, \mathrm{h}, \mathrm{s}, \mathrm{s}$ & $\mathrm{M}$ & $0.1-0.3$ \\
\hline Benzoic & & $\mathrm{m}, \mathrm{t}$ & $0.2-0.3$ \\
\hline Heptanoic & --- & $\mathrm{M}$ & 0.3 \\
\hline
\end{tabular}

Esters
\begin{tabular}{|l|c|c|c|}
\hline Methyl formate & $\mathrm{f}, \mathrm{,h}, \mathrm{,s}$, & $\mathrm{m}, \mathrm{t}$ & $0.1-0.9$ \\
\hline Methyl acetate & $\mathrm{f}, \mathrm{h}, \mathrm{k}, \mathrm{s}, \mathrm{v}$ & $\mathrm{m}, \mathrm{t}$ & --- \\
\hline Methyl propionate & $\mathrm{f}, \mathrm{h}, \mathrm{h}, \mathrm{,v}$ & $\mathrm{M}$ & --- \\
\hline Butyrolactone & ,g, , ,s, $\mathrm{v}$ & $\mathrm{m}, \mathrm{t}$ & $0.1-0.9$ \\
\hline Methyl Crotonate & --- & $\mathrm{M}$ & --- \\
\hline Methyl n-butyrate & $\mathrm{f}, \mathrm{h}, \mathrm{h}, \mathrm{,}$, & $\mathrm{m}, \mathrm{t}$ & --- \\
\hline Valerolactone & $\mathrm{f}, \mathrm{h}, \mathrm{h}, \mathrm{s}, \mathrm{v}$ & --- & 0.2 \\
\hline Angelicalactone & ---- & $\mathrm{M}$ & $0.1-1.2$ \\
\hline Methyl valerate & $\mathrm{f}, \mathrm{h}, \mathrm{h}$, & $G I, \mathrm{~m}, \mathrm{t}$ & --- \\
\hline
\end{tabular}

\begin{tabular}{|c|c|c|c|}
\hline Compound & $\begin{array}{c}\text { Wood } \\
\text { Distillate }\end{array}$ & $\begin{array}{c}\text { Smoke } \\
\text { Flavors }\end{array}$ & $\begin{array}{c}\text { Bio-Oils } \\
\text { wt } \%\end{array}$ \\
\hline \multicolumn{4}{|l|}{ Alcohols } \\
\hline Methanol & $\mathrm{f}, \mathrm{g}, \mathrm{h}, \mathrm{k}, \mathrm{s}, \mathrm{v}$ & $\mathrm{m}, \mathrm{t}$ & $0.4-2.4$ \\
\hline Ethanol & $\mathrm{g},,,,, \mathrm{V}$ & $\mathrm{m}, \mathrm{t}$ & $0.6-1.4$ \\
\hline 2-Propene-1-ol & $\mathrm{f}, \mathrm{h}, \mathrm{k}, \mathrm{s}$ & $\mathrm{m}, \mathrm{t}$ & --- \\
\hline Isobutanol & $\mathrm{f}, \mathrm{h}, \mathrm{k}, \mathrm{,v}$ & $\mathrm{m}$ & --- \\
\hline 3-Methyl-1-butanol &,,,, $\mathrm{s}$, & --- & --- \\
\hline Ethylene glycol & --- & $\mathrm{m}$ & $0.7-2.0$ \\
\hline
\end{tabular}

\begin{tabular}{|c|c|c|c|}
\hline \multicolumn{4}{|l|}{ Ketones } \\
\hline Acetone & $\mathrm{f}, \mathrm{h}, \mathrm{k}, \mathrm{s}, \mathrm{V}$ & $\mathrm{m}, \mathrm{t}$ & 2.8 \\
\hline 2-Butenone & & $\mathrm{d}$ & --- \\
\hline 2-Butanone (MEK) & $\mathrm{f}, \mathrm{g}, \mathrm{h}, \mathrm{k}, \mathrm{s}, \mathrm{v}$ & $\mathrm{m}$ & $0.3-0.9$ \\
\hline 2,3 Butandione &,,,,, $\mathrm{V}$ & --- & --- \\
\hline Cyclo pentanone & $\mathrm{f}, \mathrm{h}, \mathrm{s}, \mathrm{v}$ & $\mathrm{m,t}$ & --- \\
\hline 2-Pentanone & $\mathrm{f},,,,, \mathrm{v}$ & $\mathrm{m}$ & --- \\
\hline 3-Pentanone & $\mathrm{h}, \mathrm{,}$, & $\overline{\mathrm{m}}$ & --- \\
\hline 2-Cyclopentenone &, $\mathrm{V}$ & $G I, \mathrm{~m}$ & --- \\
\hline 2,3 Pentenedione &,,,, $\mathrm{V}$ & $\mathrm{m}, \mathrm{t}$ & $0.2-0.4$ \\
\hline 3Me2cyclopenten2ollone & $\mathrm{f}$, & $\mathrm{m}$ & $0.1-0.6$ \\
\hline Me-cyclopentanone & $\mathrm{f}, \mathrm{h}, \mathrm{s}, \mathrm{v}$ & $\mathrm{m}$ & --- \\
\hline 2-Hexanone & --- & $\mathrm{m}$ & --- \\
\hline Cyclo hexanone & --- & $\mathrm{m}$ & trace \\
\hline Methylcyclohexanone & $\mathrm{f},,,$, , & --- & --- \\
\hline 2-Et-cyclopentanone & --- & $\mathrm{t}$ & $0.2-0.3$ \\
\hline Dimethylcyclopentanone & --- & $\mathrm{m}$ & 0.3 \\
\hline Trimethylcyclopentenone & --- & $G I$ & $0.1-0.5$ \\
\hline Trimethylcyclopentanone & --- & $\mathrm{m}$ & $0.2-0.4$ \\
\hline
\end{tabular}

\begin{tabular}{|c|c|c|c|}
\hline Compound & $\begin{array}{c}\text { Wood } \\
\text { Distillate }\end{array}$ & $\begin{array}{r}\text { Smoke } \\
\text { Flavors }\end{array}$ & $\begin{array}{c}\text { Bio-Oils } \\
\text { wt } \%\end{array}$ \\
\hline \multicolumn{4}{|l|}{ Aldehydes } \\
\hline Formaldehyde & ,h, & $\mathrm{m}, \mathrm{t}$ & $0.1-3.3$ \\
\hline Acetaldehyde & $\mathrm{f}, \mathrm{g}, \mathrm{h}, \mathrm{k}, \mathrm{s}, \mathrm{V}$ & $G I, \mathrm{~m}, \mathrm{t}$ & $0.1-8.5$ \\
\hline 2-Propenal (acrolein) & --- & $\mathrm{m}$ & $0.6-0.9$ \\
\hline 2-Butenal &,,,,, $\mathrm{V}$ & $\mathrm{m}$ & trace \\
\hline 2-Methyl-2-butenal & --- & $G I, \mathrm{~m}$ & $0.1-0.5$ \\
\hline Pentanal & $\mathrm{f}, \mathrm{h}, \mathrm{h}, \mathrm{v}$ & $\mathrm{m}$ & 0.5 \\
\hline Ethanedial & --- & --- & $0.9-4.6$ \\
\hline
\end{tabular}

\begin{tabular}{|c|c|c|c|}
\hline \multicolumn{4}{|l|}{ Phenols } \\
\hline Phenol & $\mathrm{f}, \mathrm{h}, \mathrm{s}, \mathrm{s}$ & $\mathrm{G}, G I, \mathrm{~m}, \mathrm{t}$ & $0.1-3.8$ \\
\hline 2-Methyl phenol & $\mathrm{f}, \mathrm{h}, \mathrm{s}, \mathrm{s}$ & $\mathrm{G}, G I, \mathrm{~m}, \mathrm{t}$ & $0.1-0.6$ \\
\hline 3-Methyl phenol & $\mathrm{f}, \mathrm{h}, \mathrm{h}, \mathrm{s}, \mathrm{V}$ & $\mathrm{G}, G I, \mathrm{~m}, \mathrm{t}$ & $0.1-0.4$ \\
\hline 4-Methyl phenol & $\mathrm{f}, \mathrm{h}, \mathrm{h}, \mathrm{,v}$ & $\mathrm{G}, G I, \mathrm{~m}, \mathrm{t}$ & $0.1-0.5$ \\
\hline 2,3 Dimethyl phenol & $, \mathrm{s}, \mathrm{V}$ & $\mathrm{G}, G I, \mathrm{~m}, \mathrm{t}$ & $0.1-0.5$ \\
\hline 2,4 Dimethyl phenol & $\mathrm{f}, \mathrm{h}, \mathrm{s}, \mathrm{s}$ & $\mathrm{G}, G I, \mathrm{~m}, \mathrm{t}$ & $0.1-0.3$ \\
\hline 2,5 Dimethyl phenol & $,,,, \mathrm{s}, \mathrm{V}$ & $\mathrm{G}, G I, \mathrm{~m}, \mathrm{t}$ & $0.2-0.4$ \\
\hline 2,6 Dimethyl phenol & $,,,, \mathrm{s}, \mathrm{V}$ & $\mathrm{G}, G I, \mathrm{~m}, \mathrm{t}$ & $0.1-0.4$ \\
\hline 3,5 Dimethyl phenol & $\mathrm{f}, \mathrm{h}, \mathrm{s}, \mathrm{s}$ & $\mathrm{m}, \mathrm{t}$ & $\begin{array}{ll}-- \\
\end{array}$ \\
\hline 2-Ethylphenol & $\mathrm{f},,,,,$, & $\mathrm{G}, G I, \mathrm{~m}, \mathrm{t}$ & $0.1-1.3$ \\
\hline 2,4,6 TriMe phenol & --- & $\mathrm{m}$ & 0.3 \\
\hline 1,2 DiOH benzene & $\mathrm{f}, \mathrm{h}, \mathrm{h}, \mathrm{s}, \mathrm{v}$ & $\mathrm{G}, G I, \mathrm{~m}, \mathrm{t}$ & $0.1-0.7$ \\
\hline 1,3 DiOH benzene & --- & $\mathrm{m}$ & $0.1-0.3$ \\
\hline 1,4 DiOH benzene & --- & --- & $0.1-1.9$ \\
\hline 4-Methoxy catechol & --- & $\mathrm{G}, G I, \mathrm{~m}, \mathrm{t}$ & 0.6 \\
\hline $1,2,3$ Tri-OH-benzene & $, \mathrm{h}, \mathrm{s}$, & $\mathrm{t}$ & 0.6 \\
\hline
\end{tabular}

h---Hawley (1923)

k---Klar (1925)

s---Stamm and Harris (1953)

v---Vergnet and Villeneuve (1988)

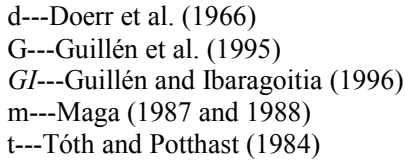

t---Tóth and Potthast (1984) 
Table 1b. Compounds Identified in Bio-Oils (Milne et al. 1997) and Similar Pyrolysis Products (Diebold 1997)

\begin{tabular}{|c|c|c|c|}
\hline Compound & $\begin{array}{c}\text { Wood } \\
\text { Distillate }\end{array}$ & $\begin{array}{r}\text { Smoke } \\
\text { Flavors } \\
\end{array}$ & \begin{tabular}{|c} 
Bio-Oils \\
wt $\%$
\end{tabular} \\
\hline \multicolumn{4}{|l|}{ Guaiacols } \\
\hline 2-Methoxy phenol & $\mathrm{f}, \mathrm{g}, \mathrm{h}, \mathrm{s}, \mathrm{V}$ & $\mathrm{G}, G I, \mathrm{~m}, \mathrm{t}$ & $0.1-1.1$ \\
\hline 4-Methyl guaiacol & $, \mathrm{,}, \mathrm{V}$ & $\mathrm{G}, G I, \mathrm{~m}, \mathrm{t}$ & $0.1-1.9$ \\
\hline Ethyl guaiacol & $\mathrm{f}, \mathrm{g}, \mathrm{h}, \mathrm{,}, \mathrm{v}$ & $\mathrm{G}, G I, \mathrm{~m}, \mathrm{t}$ & $0.1-0.6$ \\
\hline Eugenol &,,,,, $\mathrm{V}$ & $G I, \mathrm{~m}, \mathrm{t}$ & $0.1-2.3$ \\
\hline Isoeugenol & & $G I, \mathrm{~m}, \mathrm{t}$ & $0.1-7.2$ \\
\hline 4-Propylguaiacol & $\mathrm{f}, \mathrm{h},,, \mathrm{v}$ & $\mathrm{G}, G I, \mathrm{~m}, \mathrm{t}$ & $0.1-0.4$ \\
\hline Acetoguiacone & --- & --- & 0.8 \\
\hline Propioguiacone & --- & --- & 0.8 \\
\hline
\end{tabular}

Syringols
\begin{tabular}{|l|c|c|c|}
\hline 2,6-DiOMe phenol & $\mathrm{f}, \mathrm{g}, \mathrm{h}, \mathrm{,} \mathrm{,} \mathrm{v}$ & $\mathrm{G}, G I, \mathrm{~m}, \mathrm{t}$ & $0.7-4.8$ \\
\hline Methyl syringol & $\mathrm{f}$, ,h, , ,v & $\mathrm{G}, G I, \mathrm{~m}, \mathrm{t}$ & $0.1-0.3$ \\
\hline 4-Ethyl syringol &,,,,,, $\mathrm{v}$ & $\mathrm{G}, G I, \mathrm{~m}, \mathrm{t}$ & 0.2 \\
\hline Propyl syringol & $\mathrm{f}, \mathrm{h}, \mathrm{,} \mathrm{,} \mathrm{,v}$ & $\mathrm{G}, G I, \mathrm{~m}, \mathrm{t}$ & $0.1-1.5$ \\
\hline Syringaldehyde &,,,,,,, $\mathrm{v}$ & $\mathrm{G}, G I, \mathrm{~m}, \mathrm{t}$ & $0.1-1.5$ \\
\hline 4-Propenylsyringol &,,,,,, $\mathrm{v}$ & $\mathrm{G}, G I, \mathrm{~m} . \mathrm{t}$ & $0.1-0.3$ \\
\hline 4-OH-3,5-diOMe phenyl ethanone & $\mathrm{G}, G I$ & $0.1-0.3$ \\
\hline
\end{tabular}

\section{Sugars}

Sugars
\begin{tabular}{|l|c|c|c|}
\hline Levoglucosan &,,,, ,, & --- & $0.4-1.4$ \\
\hline Glucose & --- & --- & $0.4-1.3$ \\
\hline Fructose & --- & --- & $0.7-2.9$ \\
\hline D-xylose & --- & --- & $0.1-1.4$ \\
\hline D-Arabinose & --- & --- & 0.1 \\
\hline Cellobiosan & --- & --- & $0.6-3.2$ \\
\hline 1,6 Anhydroglucofuranose & --- & 3.1 \\
\hline
\end{tabular}

\begin{tabular}{|c|c|c|c|}
\hline Compound & $\begin{array}{c}\text { Wood } \\
\text { Distillate }\end{array}$ & $\begin{array}{r}\text { Smoke } \\
\text { Flavors }\end{array}$ & \begin{tabular}{|c|} 
Bio-Oils \\
wt\%
\end{tabular} \\
\hline \multicolumn{4}{|l|}{ Furans } \\
\hline Furan &,, $\mathrm{V}$ & $\mathrm{M}, \mathrm{t}$ & $0.1-0.3$ \\
\hline 2-Methyl furan & $\mathrm{f}, \mathrm{h}, \mathrm{,}, \mathrm{,}$ & m.t & $0.1-0.2$ \\
\hline 2-Furanone & & $G I$ & $0.1-1.1$ \\
\hline Furfural & $\mathrm{f}, \mathrm{h}, \mathrm{k}, \mathrm{s}, \mathrm{v}$ & $\mathrm{G}, G I, \mathrm{~m}, \mathrm{t}$ & $0.1-1.1$ \\
\hline 3-Methyl-2(3h)furanone & -- & $\mathrm{G}, G I$ & 0.1 \\
\hline Furfural alcohol & $, \mathrm{S}, \mathrm{V}$ & $G I, \mathrm{~m}, \mathrm{t}$ & $0.1-5.2$ \\
\hline Furoic acid & $\mathrm{h}, \mathrm{k}, \mathrm{s}$ & $\mathrm{m}$ & 0.4 \\
\hline Methyl furoate & $\mathrm{g},,,, \mathrm{v}$ & $\mathrm{m}, \mathrm{t}$ & --- \\
\hline 5-Methylfurfural & $\mathrm{f}, \mathrm{h}, \mathrm{k}, \mathrm{s}, \mathrm{v}$ & $\mathrm{G}, \mathrm{m}, \mathrm{t}$ & $0.1-0.6$ \\
\hline 5-OH-methyl-2-furfural &,,,, $\mathrm{s}$ & $\mathrm{m}$ & $0.3-2.2$ \\
\hline Dimethyl furan & $\mathrm{f}, \mathrm{h}, \mathrm{,}, \mathrm{,}$ & $\mathrm{m}$ & --- \\
\hline
\end{tabular}

\section{Misc. Oxvgenates}

\begin{tabular}{|l|c|c|c|}
\hline \hline Hydroxyacetaldehyde & --- & $\mathrm{m}, \mathrm{t}$ & $0.9-13$ \\
\hline Acetol (hydroxyacetone) & $,,,, \mathrm{s}, \mathrm{v}$ & $\mathrm{m}, \mathrm{t}$ & $0.7-7.4$ \\
\hline Methylal & $\mathrm{f},$, , ,, $\mathrm{s}$, & $\mathrm{m}$ & --- \\
\hline Dimethyl acetal & $,, \mathrm{h}, \mathrm{k}, \mathrm{s}$, & $\mathrm{m}$ & --- \\
\hline Acetal & --- & --- & $0.1-0.2$ \\
\hline Acetyloxy-2-propanone & --- & $\mathrm{m}$ & 0.8 \\
\hline $\begin{array}{l}\text { 2-OH-3-Me-2-cyclopentene-1- } \\
\text { one }\end{array}$ & --- & $\mathrm{m}$ & $0.1-0.5$ \\
\hline Methyl cyclopentenolone & ---- & $\mathrm{m}$ & $0.1-1.9$ \\
\hline 1-Acetyloxy-2-propanone & --- & $\mathrm{G}, G I$ & 0.1 \\
\hline 2-Methyl-3-hydroxy-2-pyrone & --- & --- & $0.2-0.4$ \\
\hline 2-Methoxy-4-methylanisole & --- & --- & $0.1-0.4$ \\
\hline 4-OH-3-methoxybenzaldehyde & --- & $\mathrm{G}, G I, \mathrm{~m}$ & $0.1-1.1$ \\
\hline Maltol & $, \mathrm{g},,, \mathrm{s}$, & $\mathrm{G}, G I, \mathrm{~m}, \mathrm{t}$ & --- \\
\hline
\end{tabular}

\begin{tabular}{|c|c|c|c|}
\hline Compound & $\begin{array}{c}\text { Wood } \\
\text { Distillate }\end{array}$ & $\begin{array}{r}\text { Smoke } \\
\text { Flavors }\end{array}$ & \begin{tabular}{|c} 
Bio-Oils \\
wt $\%$
\end{tabular} \\
\hline \multicolumn{4}{|l|}{ Alkenes } \\
\hline 2-Methyl propene & --- & --- & --- \\
\hline Dimethylcyclopentene & --- & --- & 0.7 \\
\hline Alpha-pinene &,, $\mathrm{s}$, & --- & --- \\
\hline
\end{tabular}

Aromatics
\begin{tabular}{|l|c|c|c|}
\hline Benzene & $,,, \mathrm{k}, \mathrm{,}, \mathrm{v}$ & $\mathrm{m}$ & --- \\
\hline Toluene & $\mathrm{f}, \mathrm{h}, \mathrm{h}, \mathrm{s}, \mathrm{v}$ & $\mathrm{G}, \mathrm{m}$ & --- \\
\hline Xylenes & $\mathrm{f}, \mathrm{h}, \mathrm{h}, \mathrm{s}$ & --- & --- \\
\hline Naphthalene & $,,,,, \mathrm{s}, \mathrm{v}$ & $\mathrm{t}$ & --- \\
\hline Phenanthrene & ---- & $\mathrm{t}$ & --- \\
\hline Fluoranthene & --- & $\mathrm{t}$ & --- \\
\hline Chrysene & $,,, \mathrm{k},, \mathrm{r}$ & $\mathrm{t}$ & --- \\
\hline
\end{tabular}

\section{Nitrogen Compounds}

\begin{tabular}{|l|c|c|c|}
\hline \hline Ammonia &, ,h,k,s, & --- & --- \\
\hline Methyl amine & $\mathrm{f}, \mathrm{h}, \mathrm{h}, \mathrm{s}$, & $\mathrm{m}$ & --- \\
\hline Pyridine & $,, \mathrm{h}, \mathrm{s}, \mathrm{m}$, & $\mathrm{m}$ & --- \\
\hline Methyl pyridine & $,, \mathrm{h}, \mathrm{,s}$, & --- & --- \\
\hline
\end{tabular}

\section{f---Fraps (1901)}

g---Goos and Reiter (1946)

h---Hawley (1923)

k---Klar (1925)

s---Stamm and Harris (1953)

G---Guillén et al. (1995)

GI---Guillén and Ibaragoitia (1996)

m---Maga (1987 and 1988)

t---Tóth and Potthast (1984) 
The inorganic content of biomass forms ash during combustion, which can have a negative impact on its combustion applications (Miles et al. 1996), but this report is primarily concerned with the inorganic constituents in bio-oil.

Fortunately, the minerals in biomass remain largely in the condensed phase during fast pyrolysis, which concentrates the minerals in the char. During the production of bio-oil, char is entrained with organic vapors and separated from the vapors using equipment with varying efficiencies. Cyclonic separation is the easiest way to remove char, but even the best cyclones begin to lose their efficiency with char particles smaller than about $10 \mu \mathrm{m}$ in diameter. Hot-gas filtration removes smaller char particles more efficiently, but a small amount of char fines passes through these filters as well. Filtration after the bio-oil has condensed can also remove char fines, but results in a high-ash sludge as a by-product and does not remove nano-sized char particles or minerals already solubilized by the acidic solution of bio-oil.

Table 2 shows representative inorganic elemental analyses made of wood and grass, char filtered from condensed bio-oil, and bio-oils made with char separated by cyclones or by hot-gas filtration. A comparison of the inorganic content of the bio-oil and the char recovered by filtration from the condensed bio-oil verifies that the inorganics were concentrated in the char. However, filtering the bio-oil (after dilution with methanol through a $2.5-\mu \mathrm{m}$ filter after condensation) removed only $20 \%$ to $50 \%$ of the total inorganic content of the oil. This implies that the remaining inorganic elements are in suspended char particles smaller than $2.5 \mu \mathrm{m}$ in diameter, or they are in solution. Adding water to separate the bio-oil into aqueous and tar phases resulted in a disproportion of the inorganics, but not in a clean separation. In fact, the potassium content of the aqueous phase was higher than for the tar phase (Elliott 1994).

Filtering liquid bio-oil derived from switchgrass through a series of five progressively finer filters showed that most of the calcium and about half the potassium were present in suspended char or sludge particles larger than $10 \mu \mathrm{m}$. However, the remaining potassium was not removed with $0.7-$ $\mu \mathrm{m}$ filters (Agblevor et al. 1994). Similarly, the calcium level was reduced only from $540 \mathrm{ppm}$ to $311 \mathrm{ppm}$ using $0.1-\mu \mathrm{m}$ filters to filter an oak bio-oil. The potassium level was reduced even less, from $440 \mathrm{ppm}$ to $402 \mathrm{ppm}$ (Oasmaa et al. 1997). A significant amount of the inorganic material was either associated with particles smaller than $0.1 \mu \mathrm{m}$, or was dissolved by the acidic bio-oil and in solution.

Table 2 also shows the much lower inorganic content of bio-oil produced by filtering the hot vapors before condensation, compared to removing char with cyclones. The best job of hot-gas filtering to date at the National Renewable Energy Laboratory (NREL) resulted in less than 2 ppm alkali and 2 ppm alkaline earth metals (Scahill et al. 1997). To obtain very low levels of inorganics, the char particles apparently must be removed before the pyrolysis vapors are condensed.

At these low sodium levels, significant sodium contamination can be leached from common laboratory glassware by the acidic bio-oil, as the sodium ion appears to be mobile in the sodium borosilicate glass. The sodium content increased steadily from $8 \mathrm{ppm}$ to $17 \mathrm{ppm}$ as the bio-oil from switchgrass was filtered through progressively finer filters; the potassium and calcium contents decreased to constant values below $10 \mu \mathrm{m}$ (Agblevor et al. 1994). This anomalous increase in sodium content with increased processing could be explained by the leaching of sodium from laboratory glassware. In addition, the alkali contamination from dust in 
Table 2. Inorganic Compositions of the Chars and Bio-Oils Made from Various Biomass Feeds at NREL with Char Removal by Cyclones or Filtration

\begin{tabular}{|c|c|c|c|c|c|c|c|c|c|c|}
\hline \multirow{3}{*}{$\begin{array}{l}\text { Reference } \\
\text { Feedstock } \\
\text { Material }\end{array}$} & \multicolumn{4}{|c|}{ Elliott 1994} & \multicolumn{3}{|c|}{ Agblevor et al. 1994} & \multicolumn{3}{|c|}{ 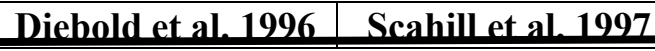 } \\
\hline & \multicolumn{2}{|c|}{ Oak } & \multicolumn{2}{|c|}{ Southern Pine } & \multicolumn{3}{|c|}{ Switchgrass } & \multicolumn{3}{|c|}{ Hybrid Poplar } \\
\hline & Bio-Oil & $\begin{array}{l}+2-\mu \mathrm{m} \\
\text { Char in } \\
\text { Bio-Oil }\end{array}$ & Bio-Oil & $\begin{array}{l}+2-\mu \mathrm{m} \\
\text { Char in } \\
\text { Bio-Oil }\end{array}$ & Feed & $\begin{array}{l}+10-\mu \mathrm{m} \\
\text { Char in } \\
\text { Bio-Oil }\end{array}$ & $\begin{array}{l}\text { Bio-Oil } \\
-0.7 \mu \mathrm{m}\end{array}$ & Feed & $\begin{array}{c}\text { Bio-Oil } \\
\text { (Run 175) }\end{array}$ & $\begin{array}{c}\text { Bio-Oil } \\
\text { (Run M2-10) }\end{array}$ \\
\hline $\begin{array}{l}\text { Char Removal } \\
\text { Method }\end{array}$ & Cyclones & $\begin{array}{l}\text { Cyclones } \\
+ \text { Oil Filtr. }\end{array}$ & Cyclones & $\begin{array}{l}\text { Cyclones+ } \\
\text { Oil Filtr. }\end{array}$ & --- & $\begin{array}{l}\text { Cyclones } \\
+ \text { Oil Filtr. }\end{array}$ & $\begin{array}{l}\text { Cyclones } \\
+ \text { Oil Filtr. }\end{array}$ & --- & $\begin{array}{c}\text { Hot-Gas } \\
\text { Filter }\end{array}$ & $\begin{array}{l}\text { Hot-Gas } \\
\text { Filter }\end{array}$ \\
\hline Char, \% & 0.74 & --- & 0.13 & --- & --- & --- & --- & --- & --- & --- \\
\hline Ash, $\%$ & 0.09 & --- & 0.03 & --- & 4.92 & 15.3 & $<0.05$ & 0.77 & 0.01 & 0.007 \\
\hline Calcium, ppm & 160 & 4580 & 160 & 8100 & 2400 & 7100 & 2.2 & 1550 & 2.2 & 1 \\
\hline Silicon & 112 & --- & 93 & 3452 & --- & --- & 1.4 & --- & --- & --- \\
\hline Potassium & 55 & 1300 & 10 & 667 & 8500 & 8500 & 175 & 1200 & 2.7 & 1 \\
\hline Iron & 86 & --- & 47 & 1772 & --- & --- & --- & --- & --- & --- \\
\hline Aluminum & 55 & --- & 41 & --- & --- & --- & --- & --- & 2.6 & 0.3 \\
\hline Sodium & 2 & 60 & $<0.1$ & 372 & 31 & 690 & 17 & 27 & 7.2 & 0.9 \\
\hline Sulfur & $<60$ & --- & $<50$ & 349 & --- & --- & --- & --- & --- & --- \\
\hline Phosphorus & $<50$ & --- & $<50$ & 550 & --- & 3600 & 0.6 & --- & --- & --- \\
\hline Magnesium & $<55$ & --- & $<45$ & 903 & --- & --- & --- & --- & --- & 0.7 \\
\hline Nickel & $<22$ & --- & $<20$ & 288 & --- & --- & --- & --- & --- & --- \\
\hline Chromium & $<17$ & --- & $<17$ & 524 & --- & --- & --- & --- & --- & --- \\
\hline Zinc & 28 & --- & 14 & 258 & --- & --- & --- & --- & --- & --- \\
\hline Lithium & 25 & --- & 7 & 110 & --- & --- & --- & --- & --- & --- \\
\hline Titanium & 17 & --- & 5 & 130 & --- & --- & --- & --- & $<0.2$ & --- \\
\hline Manganese & 15 & --- & 6 & 353 & --- & --- & --- & --- & 0.063 & 0.04 \\
\hline Copper & --- & --- & --- & 39 & --- & --- & --- & --- & --- & --- \\
\hline Barium & $<3$ & --- & $<2$ & 170 & --- & --- & --- & --- & --- & --- \\
\hline Vanadium & --- & --- & & --- & --- & --- & --- & --- & 0.002 & $<0.01$ \\
\hline Chlorine & --- & --- & --- & --- & 6800 & 10600 & 1600 & --- & 7.9 & 11 \\
\hline $\begin{array}{l}\text { equiv. } \mathrm{Cl} \text { per } \\
\text { equiv. } \mathrm{K}+\mathrm{Na}+\mathrm{Ca}\end{array}$ & & --- & --- & --- & 0.57 & 0.50 & 8.5 & --- & 0.3 & 2 \\
\hline
\end{tabular}


the air and residual alkali contents of purified water can be significant at these low levels. These considerations require special reagents and handling of the samples in clean, inert containers.

Other inorganic contaminants in acidic bio-oil appear to be from processing or storage equipment made of iron or galvanized steel, or from the attrition of heat-transfer sands. For example, extraneous contamination levels of $2270 \mathrm{ppm}$ iron, $1950 \mathrm{ppm}$ zinc, and $80 \mathrm{ppm}$ lead were reported by Elliott (1986) to be in an early SERI (NREL) bio-oil, which had been produced using a galvanized scrubbing tower for condensate recovery. (This scrubber was taken out of service shortly after the analyses were made.) The silicon level in a bio-oil made in an entrained sand reactor was $330 \mathrm{ppm}$ (Oasmaa et al. 1997), compared to $112 \mathrm{ppm}$ for a bio-oil made in an entrained flow reactor without sand (Elliott 1994).

Very few analyses have been performed on pyrolysis bio-oil and char for chlorine. Table 2 shows that the chlorine content of the hot-gas-filtered hardwood bio-oils varied considerably, from 0.3 to 2 equivalents of chlorine per equivalent of potassium, sodium, and calcium (Diebold et al. 1996; Scahill et al. 1997). The chlorine content of switchgrass oils did not change significantly during filtration of the bio-oil and was in the range of $1200 \mathrm{ppm}$ to $1600 \mathrm{ppm}$; the metal ion content decreased (Agblevor et al. 1994). The equivalents of chlorine per equivalent of alkali or alkaline earth metals increased from 3.4 to 8.5 during this filtration. This suggests that the residual inorganics may be present as chlorides and that much of the chlorine may be in solution. Chloride ions in solution will have an adverse effect on corrosion of many metals, including stainless steels such as SS304.

Compared to coal and many crude oils, biomass has a low sulfur content. Table 2 reveals that the small amount of sulfur in the biomass feed becomes concentrated in the char, rather than in the bio-oil.

\subsection{PROBABLE CHEMICAL MECHANISMS OF STORAGE INSTABILITY}

A discussion of all possible reactions taking place in a mixture of as many as 400 organic compounds is beyond the scope of any review. However, reviewing several of the generic chemical reactions thought to play an important part in the aging reactions of bio-oil is instructive. According to organic chemistry textbooks, many require catalysis, but during the long times available in storage, additional catalysis may not be needed or the catalysts may already be present in the bio-oil. Referring to the original literature is often necessary to find information on reactions that take place too slowly to generate commercial interest. Industry already controls some of these chemical reactions during the commercial shipping and storage of chemicals, which could be relevant to the aging of bio-oil.

Most important reactions that occur within bio-oil probably involve:

- Organic acids with alcohols to form esters and water.

- Organic acids with olefins to form esters.

- Aldehydes and water to form hydrates.

- Aldehydes and alcohols to form hemiacetals, or acetals and water.

- Aldehydes to form oligomers and resins.

- Aldehydes and phenolics to form resins and water.

- Aldehydes and proteins to form oligomers.

- Organic sulfur to form oligomers.

- Unsaturated compounds to form polyolefins. 
- Air oxidation to form more acids and reactive peroxides that catalyze the polymerization of unsaturated compounds.

Reactions 1 through 5 can form products in thermodynamic equilibrium with the reactants, which means that a change in temperature or relative amounts of water and other reactive compounds will upset the equilibrium and initiate compositional changes. Reactions 4 through 10 can form resins or polyolefins and may be irreversible under likely bio-oil storage conditions.

\subsection{Reactions of Organic Acids}

\subsubsection{Esterification}

The reaction of alcohols with organic acids forms esters and water:<smiles>[R]O[R](=O)C=CC(=O)O</smiles>

where R and R' are alkyl groups. Esters are well known for their aromas. In wines and liquors, these reversible ester-forming reactions can take place over the course of several years. They are catalyzed by acids, which are of interest in bio-oil with its naturally low $\mathrm{pH}$ of 2.3 to 3.0.

Table 3 shows the volatility expressed as the normal boiling point for esters and solvents likely to be present in bio-oils. Esters are relatively volatile compounds. For comparison, the boiling point of acetone at $56.5^{\circ} \mathrm{C}$ lies between that of ethyl formate and methyl acetate. The boiling point of methyl formate at $32^{\circ} \mathrm{C}$ is similar to that of diethyl ether. The vapor pressure at $0^{\circ} \mathrm{C}$ of methyl formate is $27 \mathrm{kPa}(200 \mathrm{~mm} \mathrm{Hg})$ and that of methyl acetate is $8.8 \mathrm{kPa}(66 \mathrm{~mm} \mathrm{Hg})$. If methyl formate were present in the pyrolysis products, its volatility would prevent it from being recovered from the pyrolysis gases in most condensation trains.

The formation of esters from organic acids and alcohols is thermodynamically favored (i.e., an equilibrium constant greater than 1). Table 3 also shows that the equilibrium constants reported for the liquid phase vary from 4 to 5.2 for the lower molecular weight esters from primary alcohols and about half that for those from secondary alcohols. The heat of esterification is relatively low, so the equilibrium constants are nearly independent of temperature (Simons 1983). With equal initial molar concentrations of the alcohol and the acid, an equilibrium constant of 2 corresponds to a conversion of $59 \mathrm{~mol} \%$ of the reactants; an equilibrium constant of 4 corresponds to a conversion of $67 \mathrm{~mol} \%$.

The vapor-phase equilibrium constants are quite different from the liquid-phase equilibrium constants. Using values for the standard free energy at $25^{\circ} \mathrm{C}$ from the literature (DIPPR 1998) for the reactants and the products in the gas phase for the esterification reactions, the free energy for esterification in the gas phase was calculated. The thermodynamic equilibrium constants were then calculated from:

$$
\ln \mathrm{K}_{\mathrm{e}}=-\Delta \mathrm{F} / \mathrm{RT}
$$

Values for these calculated vapor-phase equilibrium constants are given in Table 3. The equilibrium constant of 367 for ethyl acetate in the vapor state corresponds to a conversion of $95 \%$ of the reactants. The calculated equilibrium constant for the formation of ethyl acetate from ethanol and acetic acid in the vapor phase is nearly two orders of magnitude higher than for the same reaction in the liquid phase. 
Table 3. Normal Boiling Points of Probable Alcohols, Acids, and Esters in Bio-Oils, Liquid Phase (Simons 1983), and Vapor Phase Equilibrium Constants for Ester Formation from Alcohol and Organic Acids at $25^{\circ} \mathrm{C}$ (calculated from Gibbs free energy in DIPPR 1998)

\begin{tabular}{|l|c|c|c|}
\hline & & \multicolumn{2}{|c|}{ Thermodynamic Equilibrium Constant } \\
\hline Compound & $\mathbf{n b p} \boldsymbol{~}^{\mathbf{0}} \mathbf{C}$ & Liquid & Vapor \\
\hline Methyl formate & 32.0 & --- & 60 \\
\hline Ethyl formate & 54.3 & --- & 174 \\
\hline Methyl acetate & 57.8 & 5.2 & 243 \\
\hline Methanol & 64.7 & --- & --- \\
\hline Ethyl acetate & 77.1 & 4 & 367 \\
\hline Ethyl alcohol & 78.4 & --- & --- \\
\hline Methyl propionate & 79.8 & --- & 68 \\
\hline Iso-propanol & 82.5 & --- & 400 \\
\hline Iso-propyl acetate & 88.4 & 2.4 & --- \\
\hline Propanol & 97.8 & --- & 213 \\
\hline Ethyl propionate & 99.1 & --- & --- \\
\hline Formic acid & 100.6 & --- & 200 \\
\hline Propyl acetate & 101.6 & 4.1 & --- \\
\hline Acetic acid & 118.1 & --- & 31 \\
\hline Propyl propionate & 122.5 & --- & --- \\
\hline Propionic acid & 141.1 & --- & \\
\hline
\end{tabular}

Esterification studies by Berthelot and Péan de Saint-Gilles during the 1800 s used sealed tubes with various relative vapor headspaces. They found that the equilibrium shifted to higher ester yields with more headspace. During the 1920s, vapor-phase esterification reactions were reexamined. Three equilibrium mixtures of acetic acid, ethanol, water, and ethyl acetate (in the absence of known catalysts) were refluxed for about 1 hour. Reactions occurred during the vapor phase at temperatures as low as $53^{\circ} \mathrm{C}$ to form about the same vapor composition from the three initially very different equilibrium compositions. The vapor composition shifted to more heavily favor ester formation. Equilibrium constants higher than 400 were calculated, taking into account the dimerization of acetic acid during the vapor phase (Edgar and Schuyler 1924).

The temperature and liquid residence time used by Edgar and Schuyler (1924) are commonly encountered during the scrubbing of hot fast-pyrolysis vapors and gases downstream of the pyrolysis reactor with recirculated condensates. Under these conditions, this suggests the probable formation and subsequent loss of the volatile esters in the noncondensable gases. These losses could cause problems with a lack of mass closure in fast pyrolysis systems using this type of scrubbing, because the off-gases are not usually analyzed for esters or other oxygenated volatiles. These volatile losses would increase with the use of large amounts of carrier gases for fluidization or entrainment in the pyrolysis reactor. Larger amounts of carrier gases reduce the partial pressure of the volatiles, requiring a lower temperature for their condensation.

With no added catalysts, the reaction of acetic acid in an excess of methanol in the liquid phase appears to be a second-order reaction with respect to acetic acid. At $70^{\circ} \mathrm{C}$, a mixture of $1 \mathrm{~N}$ acetic acid in purified methanol was $50 \%$ complete after about 27 hours. Sodium acetate or ammonium acetate buffers reduced the reaction rate; after 27 hours the reaction was only $10 \%$ complete at $70^{\circ} \mathrm{C}$. With methanol and acetic acid at $0.125 \mathrm{~N}$ to $1.0 \mathrm{~N}$ in anisol as the solvent, the esterification 
rate appeared to be proportional to the concentration of methanol times the concentration of acetic acid raised to the 1.5 power (Rolfe and Hinshelwood 1934).

At $25^{\circ} \mathrm{C}$ with no added catalysts, the bimolecular reaction rates of acetic acid and methanol were extrapolated to be twice those of acetic acid and benzyl alcohol; 88 times faster than for methyl alcohol and benzoic acid; and 173 times faster than for benzyl alcohol and benzoic acid. This reflects the slower reaction rate of the larger molecules (Hinshelwood and Legard 1935).

With $0.005 \mathrm{~N}$ hydrochloric acid $(\mathrm{HCl})(182 \mathrm{ppm}$ or a $\mathrm{pH}$ of 2.3$)$ as the catalyst at $30^{\circ} \mathrm{C}$, the esterification of a stoichiometric mixture of methyl alcohol with formic acid was $50 \%$ complete in about 3 minutes. The reaction rate of the mixture then slowed considerably and approached equilibrium after about 40 minutes. The catalyzed reaction rate for methanol with formic acid was 14 times higher than with acetic acid; 18 times higher than with propionic acid, and 28 times higher than with butyric and higher acids (Smith 1939).

Experimentally the rate of ester hydrolysis is a function of $\mathrm{pH}$. Figure 5 shows that the hydrolysis rate of ethyl acetate varied continuously over five orders of magnitude, when the $\mathrm{pH}$ was changed from -0.9 to 3.7 (Euranto 1969). The esterification rate (forward reaction) can be calculated from the hydrolysis rate (reverse reaction) multiplied by the thermodynamic equilibrium constant.

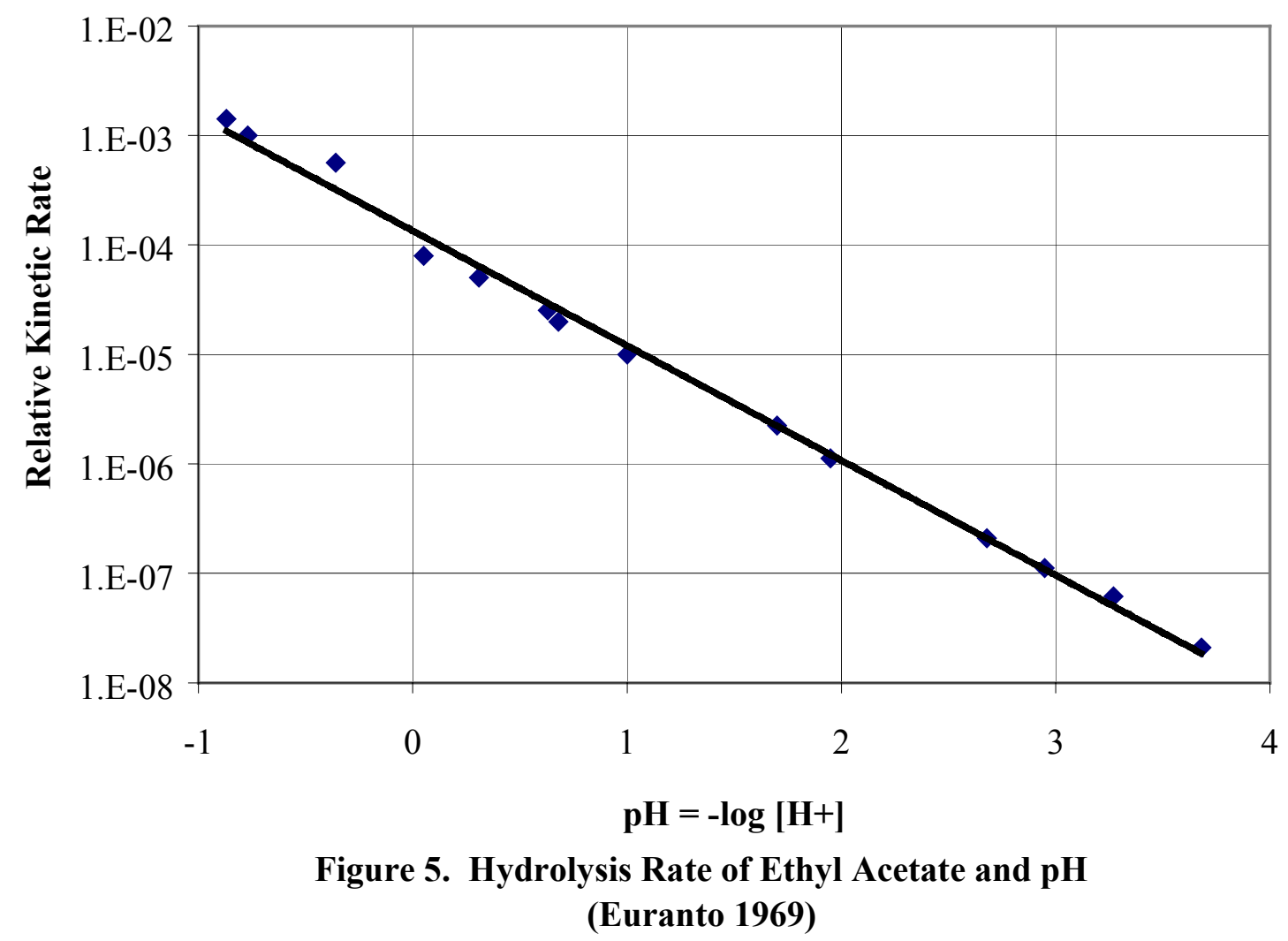


Organic acids react with olefins to form iso-esters, but do not form water as a by-product. This reaction is normally catalyzed with a strong acid, e.g., sulfuric or zeolites (Sato 1984), to achieve reaction rates of commercial interest. However, without added catalysts, olefins (except ethylene) react slowly with dilute acetic acid at elevated temperatures to form iso-esters. Thus, the reaction of propene with acetic acid yields isopropyl acetate. Hydrolysis of the iso-ester causes the isoalcohol to form (Suida 1931).

Relatively anhydrous formic acid under reflux conditions without added catalysts reacted with unsaturated, long-chain fatty acids to form the expected iso-ester. These iso-esters were then hydrolyzed to form the iso-alcohol (Knight et al. 1954).

\subsubsection{Transesterification}

The transesterification reaction is the exchange of alcohol and acid groups in a mixture of two or more esters:

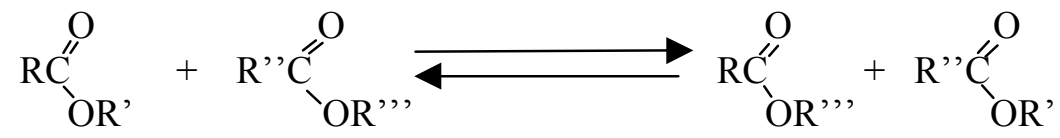

This reaction is catalyzed similarly to esterification. In a mixture of esters, transesterification is thought to occur. Because esterification is reversible, acids and alcohols can also be reacted with esters to form new esters, acids, and alcohols.

\subsection{Reactions of Aldehydes}

\subsubsection{Homopolymerization}

Aldehydes can react with each other to form polyacetal oligomers and polymers:<smiles>[R]C(=O)[R]([H])=O</smiles>

The poly(oxymethylene) polymer has limited solubility in water. Methanol in aqueous formaldehyde solution decreases the value of $n$, which is used advantageously to stabilize formaldehyde commercially. The methanol content of commercial formaldehyde solutions is usually $6 \%$ to $15 \%$, although contents of $1 \%$ or less are available. These solutions develop measurable amounts of methylal during prolonged aging. Ethanol, propanol, isopropanol, glycols, and glycerol are used to stabilize formaldehyde solutions (Walker 1953).

Additives to stabilize formaldehyde solutions include hydroxypropyl methyl cellulose, methyl and ethyl cellulose, and isophthalobisguanamine at levels as high as $100 \mathrm{ppm}$. Conversely, if the formaldehyde polymer is stabilized with the proper end groups (e.g., esterification of the hydroxyl end group with acetic anhydride), it can be a useful polymer such as DuPont's Delrin. Without special polymerization techniques, the value of $\mathrm{n}$ is limited to about 100 (Gerberich et al. 1980).

The addition reaction of aldehydes to form hydroxy aldehyde dimers is known as the aldol reaction, which proceeds nicely under basic conditions and very slowly under acidic conditions (Cason 1956). Formaldehyde condenses to form hydroxyacetaldehyde, glyceraldehyde, dihydroxy acetone, ketotetrose, and various aldotetroses in the presence of a small amount of 
organic acid and the oxides, hydroxides, carbonates, and organic salts of lead, magnesium, zinc, and the alkaline earth metals. Formaldehyde was dissolved in an essentially anhydrous solvent and acidified with the equivalent of 0.08 to $0.19 \mathrm{wt} \%$ of acetic acid (after the catalyst was neutralized). Organic acids useful to catalyze this reaction were said to be formic, acetic, propionic, glycolic, benzoic, oxalic, etc. Solvents used included methanol, ethanol, dioxan, $n-$ butanol, and ethylene glycol. Yields of syrups or precipitates were $55 \%$ to $93 \%$ of the formaldehyde charged, after heating to $100^{\circ} \mathrm{C}$ to $138^{\circ} \mathrm{C}$ for 20 to 100 minutes. No examples were given for an aqueous reaction medium or for an uncatalyzed reaction. Also, no quantitative analyses were given for the products (Lorand 1942).

Furfural forms a resinous tar under acidic conditions at rates proportional to the concentration of the acid times that of furfural. Temperatures studied were $50^{\circ} \mathrm{C}$ to $300^{\circ} \mathrm{C}$. Acids used included $\mathrm{HCl}$ at $1800 \mathrm{ppm}$ (Williams and Dunlop 1948).

\subsubsection{Hydration}

Aldehydes or ketones mixed with water react to form hydrates, also referred to as glycols:

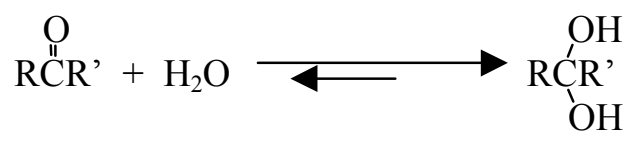

where R and R' are hydrogen or alkyl groups. The rate of formation of aldehyde hydrates was said to be quite rapid (Adkins and Broderick 1928a). The reaction of formaldehyde in an excess of water had a half-life of only $70 \mathrm{~ms}$ at $22^{\circ} \mathrm{C}$. The ratio of the hydrate to formaldehyde was 2200 at $22^{\circ} \mathrm{C}$ (Sutton and Downes 1972).

The equilibrium constants (molar basis) for water and aldehyde reacting to form the hydrate are 41 for formaldehyde, 0.018 for acetaldehyde, and 0.000025 for acetone (Carey 1996). For a biooil containing $25 \mathrm{wt} \%$ water and $3 \mathrm{wt} \%$ formaldehyde in equilibrium, $99.9 \mathrm{~mol} \%$ of the formaldehyde would be in the hydrate form. For a similar bio-oil with $3 \mathrm{wt} \%$ acetaldehyde, $24 \mathrm{wt} \%$ of the acetaldehyde would be in the hydrate form. Only a trace of the hydrate of acetone $(0.04 \%$ of the acetone weight) would be present as the hydrate in a bio-oil with $3 \mathrm{wt} \%$ acetone and $25 \mathrm{wt} \%$ water.

\subsubsection{Hemiacetal Formation}

When an alcohol is mixed with an aldehyde, a significant amount of heat is liberated and the hemiacetal is formed by the following reaction:<smiles>[R]O[R]([H])=O</smiles>

This reaction takes place relatively quickly and without catalysis. Hemiacetals were studied that were made from ethyl alcohol and acetaldehyde; isopropyl alcohol and acetaldehyde; ethyl alcohol and benzaldehyde; and ethyl alcohol and methoxy benzaldehyde. Refractive index and density measurements were used to confirm the rapid formation of hemiacetals. In cases where the refractive index of the hemiacetal varied considerably from idealized mixtures of the reactants, equilibrium compositions apparently favored the hemiacetals (Adkins and Broderick 1928a, 1928b). 
In the absence of catalyst, phenol reacts with formaldehyde to form the phenyl hemiformal, although to a much lesser degree than the methyl hemiformal. Formaldehyde reacts in the absence of catalysts with the hydroxyl groups of sugars, starches, and cellulose to form loosely bound hemiformals (Walker 1953).

Commercially available formaldehyde is mixed with water and methanol to chemically stabilize it. In aqueous solutions, the amount of free, monomeric formaldehyde is less than $100 \mathrm{pp}$. This forms "...a complex equilibrium mixture of methylene glycol $\left(\mathrm{CH}_{2}(\mathrm{OH})_{2}\right)$, poly $($ oxymethylene glycols) and hemiformals of these glycols." The water and methanol stabilize the formaldehyde and prevent the formation of polyformaldehyde resins (Gerberich et al. 1980).

\subsubsection{Acetalization}

Aldehydes and alcohols react to form acetals as shown by the following reaction:<smiles>[R][R](=C=C)[R]([R20])([R2])[R]</smiles>

A modification to this acetal formation is with a diol such as ethylene glycol $\left(\mathrm{HOCH}_{2} \mathrm{CH}_{2} \mathrm{OH}\right)$, in which one mole rather than two moles of glycol react with the aldehyde to form a cyclic diether (Street and Adkins 1928).<smiles></smiles>

In the presence of acid catalysts, stable formals are formed by the reaction of aldehydes and the hydroxyl groups of sugars, starches, and cellulose. Cellulose reacted with formaldeyde and an acid catalyst creates a crosslinked polymer that resists swelling in water and dyes. Cotton cloth treated with formaldehyde and an acid catalyst will hold creases better and is less likely to shrink (Walker 1953).

In the vapor phase at $25^{\circ} \mathrm{C}$, the equilibrium constant for the formation of 1,1 dimethoxy methane (methylal) is 3402 and for 1,1 diethoxy ethane (acetal) is 36, based on aldehyde and alcohol reactants and the Gibbs free energy of formation (DIPPR 1998). Without catalysts high temperature vapor phase reactions of methanol with saturated aldehydes through heptaldehyde and of formaldehyde with saturated primary or secondary alcohols are very rapid. These reactions were explored in a plug flow reactor at stoichiometric ratios of alcohols to aldehydes, temperature histories of 1.3 to 6 seconds at $350^{\circ} \mathrm{C}$ or 1.4 to 2.5 seconds at $460^{\circ} \mathrm{C}$. The reported yields of acetals were $15 \mathrm{wt} \%$ to $69 \mathrm{wt} \%$, based on the weight of starting materials. There was apparently very little, if any, cracking of the materials to noncondensable gases under these reaction conditions. The mass balances of just the liquids closed more than $98 \%$, except when nitrogen carrier gas was used, resulting in a 93\% mass balance (Frevel and Hedelund 1954). The actual average temperature of the reactants may have been lower than stated, as no details were given on how and where it was measured.

Conditions the vapor phase formation of acetals are very close to those used to produce bio-oil. This implies that freshly made bio-oil should contain a large amount of acetals, especially with a long residence time at just below the pyrolysis temperature, e.g., in cyclonic separators, hot-gas filters, or in the free-board volume above a fluidized bed. Because the normal boiling temperature 
of methylal is only $42^{\circ} \mathrm{C}$ and its vapor pressure at $0^{\circ} \mathrm{C}$ is $17.2 \mathrm{kPa}(129 \mathrm{~mm} \mathrm{Hg})$, most of the volatile methylal formed will probably not be collected in a typical condensation system.

Catalysts for acetal formation at lower temperatures condensed phase reactions include many salts potentially present in biomass as ash, e.g., chloride salts of aluminum, calcium, iron (ferric), lithium, magnesium, manganese, and zinc; copper sulfate, sodium bisulfite; and monosodium phosphate. Successful acetalization catalysts also form alcoholates. Noncatalytic salts for this reaction include carbonates and chlorides of sodium and potassium; calcium and sodium sulfates; and calcium and sodium acetates (Adams and Adkins 1925; Adkins and Nissen 1922). Catalysts for formal formation include formates of iron, zinc, and aluminum (Walker 1953).

Calcium chloride was an effective acetal catalyst at concentrations as low as $0.2 \mathrm{wt} \%$, although higher concentrations were more effective. Part of its function was to remove water from the reaction mixture to achieve a higher conversion, but other dehydration salts, e.g., sodium chloride or zinc chloride, reduced its catalytic effect (Adams and Adkins 1925).

Trace amounts of strong mineral acids also catalyze the acetalization reaction, e.g., $\mathrm{HCl}$, phosphoric acid, and nitric acid. In the presence of $5 \mathrm{mg} \mathrm{HCl}$ per mole of aldehyde (114 ppm), the times required to achieve equilibrium at $25^{\circ} \mathrm{C}$ with alcohols were 1 to 2 hours with furfural and unsaturated aldehydes; and 2 days for saturated aldehydes (Minné and Adkins 1933). The formation rate of acetal increased with the acid concentration; the reactions were complete within an hour or so with $\mathrm{HCl}$ at concentrations as low as $900 \mathrm{ppm}$ or within 5 to 10 minutes with 9000 ppm $\mathrm{HCl}$ (Adams and Adkins 1925).

Later studies showed that with only $13 \mathrm{ppm} \mathrm{HCl}$ as catalyst, the acetal formation with acetaldehyde was $50 \%$ complete after 50 minutes with methanol, 60 minutes for ethanol and isopropanol, and 120 to 180 minutes for butanol (Adkins and Broderick 1928b). With only 3 ppm $\mathrm{HCl}$, a mixture of ethanol and furfural achieved about $75 \%$ of the equilibrium amount of acetal within 1 day. Nonequilibrium mixtures of furfural acetal, water, and ethanol with only $0.5 \mathrm{ppm}$ $\mathrm{HCl}$ formed essentially equilibrium compositions after an unspecified time (Adkins et al. 1931). Assuming $100 \%$ ionization of dilute $\mathrm{HCl}, 3 \mathrm{ppm} \mathrm{HCl}$ and $0.5 \mathrm{ppm} \mathrm{HCl}$ correspond to a $\mathrm{pH}$ of 4.0 and 4.9 , respectively. Clearly, only trace amounts of $\mathrm{HCl}$ are necessary to catalyze the formation of acetals.

Strong organic acids such as oxalic acid $\left(\mathrm{pK}_{\mathrm{a}}=1.3\right)$ and tartaric acid $\left(\mathrm{pK}_{\mathrm{a}}=3.0\right)$ also catalyze acetalization, but acetic acid $\left(\mathrm{pK}_{\mathrm{a}}=4.7\right)$ does not catalyze this reaction (Adams and Adkins 1925). Oxalic and tartaric acids are not among the acids listed by Maga (1987) or by Milne et al. (1997), but 2-hydroxy benzoic acid, which has a $\mathrm{pK}_{\mathrm{a}}$ equal to that of tartaric acid, was listed by Maga (1987). So some of the stronger organic acids in bio-oil, along with chloride ions in solution and some chloride salts, may catalyze acetal reactions.

Table 4 shows that the structure of the alcohol and the aldehyde affect the equilibrium constant $\left(\mathrm{K}_{\mathrm{e}}\right)$ of acetal formation. In general, the acetals from primary alcohols and saturated primary aldehydes are favored. Primary alcohols have $\mathrm{K}_{\mathrm{e}} \mathrm{s}$ about 10 times higher than secondary alcohols. Secondary alcohols have $\mathrm{K}_{\mathrm{e}} \mathrm{s}$ about 10 times higher than tertiary alcohols. Likewise, if the aldehyde group was attached to a primary carbon ( $n$-butanal), the $\mathrm{K}_{\mathrm{e}}$ was about 100 times higher than if the aldehyde group was attached to a secondary carbon (iso-butanal). Using the reaction of ethanol with aldehydes containing four carbon atoms as an example, saturated aldehydes had a $\mathrm{K}_{\mathrm{e}}$ about 100 times higher than unsaturated aldehydes and 30 times higher than cyclic unsaturated aldehydes (furfural) (Minné and Adkins 1933). With a mixture of various alcohols and aldehydes, the number of possible acetals is quite high, as different alcohols could react with the same aldehyde. 
The rate of acetal formation has no relationship to the relative value of the equilibrium constant. In fact, methanol and butanol, which have high equilibrium constants with acetaldehyde, react relatively slowly to form the acetals. In the presence of $13 \mathrm{ppm} \mathrm{HCl}$, the reaction rates of secondary alcohols were about twice as fast as with primary alcohols. Tertiary alcohols were about twice as fast as secondary alcohols. Acetaldehyde reacted up to twice as fast as butyr aldehyde. The reaction rates of furfural, benzaldehyde, cinnamic aldehyde, and heptaldehyde with alcohols were extremely fast and could not be accurately measured (Adkins and Adams 1925).

Table 4. Equilibrium Constants for Liquid Acetal Formation (at $25^{\circ} \mathrm{C}$ ) (Minné and Adkins 1933) and Normal Boiling Point of Resulting Acetals ( $\mathrm{K}_{\mathrm{e}}$ based on concentrations expressed on a mole fraction)

\begin{tabular}{|c|c|c|c|}
\hline Alcohol & Aldehyde & $\mathbf{K}_{\mathbf{e}}$ & $\begin{array}{c}\text { nbp of } \\
\text { Acetal, }{ }^{\circ} \mathrm{C} \\
\end{array}$ \\
\hline Methanol & Formaldehyde & $\begin{array}{ll}--- \\
\end{array}$ & 42 \\
\hline “ & Ethanal (Acetaldehyde) & 1.95 & 64 \\
\hline “" & Propanal & --- & 83 \\
\hline “6 & Propenal (Acrolein) & --- & 89 \\
\hline “6 & $n$-Butanal & 4.22 & --- \\
\hline “" & Furfural & 0.100 & --- \\
\hline Ethanol & Formaldehyde & --- & 87 \\
\hline “ & Ethanal (Acetaldehyde) & 1.21 & 102.2 \\
\hline “" & Hydroxyacetaldehyde (Glycolic) & 0.28 & 167 \\
\hline “" & Propanal & 1.21 & 123 \\
\hline “" & Propenal (Acrolein) & 0.176 & 125 \\
\hline “" & 2-Butenal (Crotonaldehyde) & 0.011 & --- \\
\hline “" & $n$-Butanal & 1.21 & --- \\
\hline “" & Furfural & 0.041 & --- \\
\hline “" & Benzaldehyde & 0.083 & --- \\
\hline “" & 3-Phenyl Propenal (Cinnamaldehyde) & 0.013 & --- \\
\hline$n$-Propanol & Ethanal (Acetaldehyde) & 1.06 & --- \\
\hline “" & $n$-Butanal & 1.95 & --- \\
\hline 2-Propen-1-ol & Ethanal (Acetaldehyde) & 0.84 & --- \\
\hline iso-Propanol & Ethanal (Acetaldehyde) & 0.107 & --- \\
\hline “" & Propanal & 0.057 & --- \\
\hline “6 & $n$-Butanal & 0.069 & --- \\
\hline “6 & iso-Butanal & 0.018 & --- \\
\hline "“ & Furfural & 0.009 & --- \\
\hline & Benzaldehyde & 0.005 & --- \\
\hline & 3-Phenyl Propenal (Cinnamaldehyde) & 0.005 & ---- \\
\hline$n$-Butanol & Ethanal (Acetaldehyde) & 3.08 & --- \\
\hline 2-Butanol & “" & 0.128 & --- \\
\hline$t$-Butanol & "“ & 0.019 & --- \\
\hline Benzyl Alcohol & "“ & 0.94 & --- \\
\hline$\beta$-Methoxyethanol & " & 0.94 & --- \\
\hline$\beta$-Ethoxyethanol & "“ & 0.94 & --- \\
\hline
\end{tabular}




\subsubsection{Transacetalization}

Because the formation of acetals is reversible, alcohols can be reacted with acetals or different acetals with each other to generate new acetals. If a low molecular weight alcohol or aldehyde were added to acetals formed from high molecular weight alcohols and acids, the average molecular weight of the original mixture would be expected to decrease.

\subsubsection{Phenol/Aldehyde Reactions and Resins}

In the absence of catalysts, phenol reacts as an alcohol with formaldehyde to form the hemiformal, although it is less favored than the methyl formal from methanol. The phenyl hemiformal is an intermediate in the formation of ortho-methylol phenol:

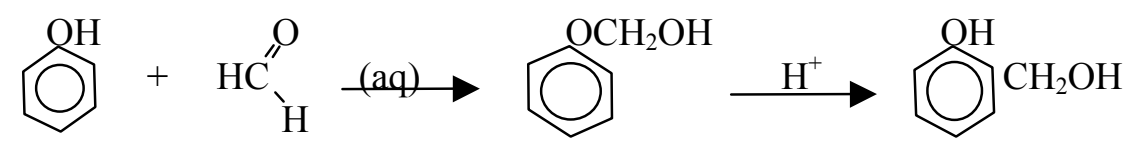

In the presence of acid catalysts, the ortho-methylol phenol is very reactive with other phenols to attach to the ortho or para position with the elimination of water. In the presence of added acid catalysts and methanol, methyl phenyl formal can be made from the phenyl hemiformal (Walker 1953).

In the presence of acid catalysts, phenols and substituted phenols react with aldehyde hydrates to form novolak resins and water.<smiles>CCC(C)(Cc1cccc(CCc2cccc([18OH])c2)c1)c1cccc(O)c1</smiles>

Use of strong acids such as oxalic or mineral acids results in thermoplastic novolak resins with molecular weights of 500 to 5000; the methylene linkages constitute a mixture of ortho and para. The reaction rate is inversely proportional to the water content and proportional to the concentration of the reactants and catalyst. Other aldehydes react similarly to formaldehyde, although typically at much lower rates (Kopf 1996).

In contrast to reactions under alkaline conditions, the reaction rates of various phenolic compounds with formaldehyde are relatively the same under acidic conditions. The condensation reaction of the methylol phenol in the presence of acid catalysts is much faster than the formation rate of the methylol phenol. Because the reaction rate of formaldehyde with the polymer is much slower than with monomeric phenolics, novolaks have very little three-dimensional crosslinking between the chains. The relatively non-crosslinked novolak chains maintain their solubility in solvents such as acetone (Granger 1937).

At higher $\mathrm{pH}$ (4 to 7), phenol and formaldehyde react in the presence of catalysts to form "high ortho" novolaks. Catalysts for this reaction are some aluminum salts and divalent metals such as calcium, zinc, magnesium, manganese, lead, copper, and nickel. These metals are solubilized as the acetate salts. Under these conditions, about $10 \%$ of the product was dibenzyl ether (Kopf 1996). 
With no catalysts present, the dimethylol cresols reacted slowly to form resins, achieving $50 \%$ of theoretical reaction within 24 hours at $100^{\circ} \mathrm{C}$. These resins readily precipitated from aqueous solutions and appeared to be novolaks (Granger 1937).

The active sites for reacting formaldehyde with phenol are at the 2, 4, and 6 positions, i.e., the ortho and para positions. For catechol (1,2 dihydroxy benzene), all remaining sites are available to react with formaldehyde (Kelley et al. 1997). The 2,6-dimethoxy phenols (syringols) in bio-oils derived from hardwoods have only the para site remaining for reaction with aldehydes, which will result in chain-termination of the resultant phenol/aldehyde oligomer. If the phenol/ formaldehyde reaction is important during the storage of bio-oils, then hardwood bio-oils should store better than softwood bio-oils, because of this chain-termination ability of the syringols.

Furfural has the reactivity of its aldehyde functional group to form polymers with phenol. The initial reaction products are analogous to those from phenol and formaldehyde (Dunlop and Peters 1953).

\subsubsection{Polymerization of Furan Derivatives}

Fufural alcohol undergoes condensation reactions with the evolution of water, analogous to the condensation of ortho-methylol phenol, i.e., with linkages at the 2 and 5 ring positions (adjacent to the oxygen of the furan ring). This reaction is catalyzed by lactic acid, hydroxy acetic acid, formic acid, calcium chloride, and strong acids. The polymerization takes place in 1 to $1 \frac{1 / 2}{2}$ hours at $100^{\circ} \mathrm{C}$ to produce an acetone-soluble resin. This resin can be crosslinked with added formaldehyde using the same catalysts to form an insoluble resin (Harvey 1944a). Furfural alcohol, in the presence of water and an acid catalyst, also opens the furan ring to form levulinic acid (Dunlop and Peters 1953).

Thermosetting resins can also be made by reacting furfural alcohol and formaldehyde in a onestep process to produce the intermediate acetone-soluble resin, which crosslinks when heated further. The reaction takes place at a $\mathrm{pH}$ of 1.5 to 3.5, using the same acid catalysts as for the twostep process (Harvey 1944b).

\subsubsection{Dimerization of Organic Nitrogen Compounds}

The chemical reaction of aldehydes with proteins is used advantageously in liquid smoke applications to give meat a desirable brown color. Aldehydes that are very reactive for this purpose include hydroxyacetaldehyde (glycoaldehyde), ethanedial (glyoxal), and methyl glyoxal (Riha and Wendorff 1993). These reactions can lead to crosslinking of the proteins (Acharya and Manning 1983):

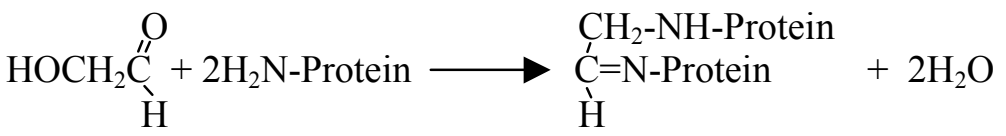

Pyrolysis operators who have had bio-oil on their skin are well aware of the brown stains rapidly left by this reaction. In bio-oil, these reactions lead to an effective dimerization of the proteins to increase the average molecular weight. 


\subsection{Sulfur-Containing Compounds}

Although bio-oil normally contains very low levels of sulfur, organic sulfur counteracts the formation of peroxides. Especially effective for this are nonyl sulfide and thiophenol (phenyl mercaptan). In the reaction of mercaptans (RSH) with peroxides, the hydrogen is abstracted and the disulfide is formed, which nearly doubles the molecular weight of the sulfur compounds. Alternatively, the RS* free-radical can attach to unsaturated bonds to form larger molecules. The benefit is the termination of the free-radical to prevent further chain reactions (Mushrush and Speight 1995).

\subsection{Unsaturated Organic Reactions}

\subsubsection{Alcohol Addition}

Unsaturated aldehydes such as acrolein are very reactive because the vinyl group conjugates with the carbonyl group. In addition to forming acetals with alcohols, acrolein can react with alcohol in a reaction that is catalyzed by acids or bases to form the alkoxy aldehyde, unsaturated acetal, or alkoxy acetal (Etzkorn et al. 1991):

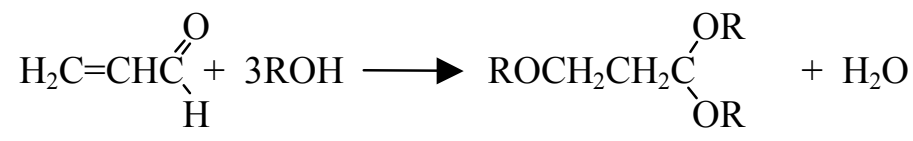

where $\mathrm{R}$ is an alkyl group.

\subsubsection{Olefinic Condensation}

Unsaturated compounds can react with each other to form polyolefins. Examples of unsaturated compounds in bio-oil (listed in Table 1) include acrolein, 2-butenone, propenyl substituted phenolics, and 2-propene-1-ol. Acrolein homo-polymerizes in the presence of anionic, cationic, or free-radical agents to form an insoluble, highly crosslinked resin in the absence of inhibitors. Acrolein is commercially stabilized with acetic acid and $0.10 \mathrm{wt} \%$ to $0.25 \mathrm{wt} \%$ hydroquinone (Etzkorn et al. 1991).

In strongly acidic $(3 \mathrm{~N} \mathrm{HCl})$ solutions overnight, 2-methoxy-4-propenylphenol turned into a solid precipitate, 2-methoxy-4-allylphenol formed a brown viscous gel, and 4-allyl anisole and 4-propenyl anisole formed brown oils (Polk and Phingbodhippakkiya 1981).

Carboxylic acids catalyze olefinic condensation reactions, but hydroperoxides that form freeradicals are the most deleterious oxygenated species in petroleum liquids (Mushrush and Speight 1995). The free-radicals catalyze olefin condensation reactions. Sources of free-radicals in the bio-oil include organic hydroperoxides, organic peroxides, and nitrogen compounds. Nitrogen compounds in the bio-oil would be derived from proteins in the original feedstock.

\subsection{Oxidation}

The exposure of bio-oil to air can oxidize the alcohols and aldehydes to carboxylic acids. An example of this reaction is the autooxidation of ethanol in wine to vinegar (acetic acid) after exposure to air, which is perceived as a sour taste after exposure overnight at room temperature or after storage with a defective cork. 
However, a more important reaction that affects the storage of pyrolysis oils is that of forming hydroperoxides and alkylperoxides by autoxidation with air. For example, the formation of $\alpha$ hydroperoxy ether from diethyl ether is a hazard after the ether container has been opened. These peroxides are not very stable and spontaneously decompose to form free-radicals. In concentrated form, many organic peroxides are explosive.

Organic peroxides or hydroperoxides can be formed by reacting air with olefins, ethers, ketones, nitrogen compounds, aldehydes, and organic acids. Peroxides are sources of free-radicals, which can catalyze olefinic polymerization. The ease of forming hydroperoxides is related to the ease of breaking the $\mathrm{C}-\mathrm{H}$ bonds involved. Thus, for hydrocarbons the relative ease of forming hydro peroxides increases: $n$-alkanes $<$ branched alkanes $<$ aralkanes $\cong$ alkenes $<$ alkynes (Hiatt 1971). The "drying" of linseed oil when it is exposed to air is an example of air oxidation that catalyzes the unsaturated oil to polymerize it to a solid varnish.

The importance of forming free-radicals from peroxides is that they can catalyze the polymerization of olefins. Thus, exposure to air would be expected to increase formation of polyolefins during bio-oil storage.

\subsection{Gas-Forming Reactions}

\subsubsection{Carbon Dioxide}

The reactions considered thus far have increased the molecular weight of the organic material and possibly coproduced water. Most carboxylic acids are stable relative to decarboxylation, but some di-carboxylic acids are relatively unstable and decarboxylate to form the mono-acid and $\mathrm{CO}_{2}$ at moderate temperatures:

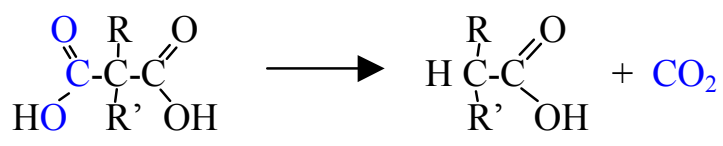

Where $\mathrm{R}$ and $\mathrm{R}$ ' are $\mathrm{H}$ or alkyl groups. If $\mathrm{R}$ and $\mathrm{R}$ ' are both hydrogen (malonic acid), the decarboxylation proceeds readily at $150^{\circ} \mathrm{C}$ (Carey 1996). Although this easy decarboxylation is widely believed to occur only when two carboxyl groups are attached to the same carbon atom (Cason 1956), a brief examination of the physical properties of organic compounds reveals that many di-carboxylic compounds decompose at low temperatures, e.g., 1,2 di-carboxyl ethylene (maleic acid) decomposes readily at $135^{\circ} \mathrm{C}, 1,2$ di-carboxyl-2-hydroxy ethane (malic acid) decomposes at $140^{\circ} \mathrm{C}$, and 2-hydroxy acetic acid (glycolic acid) decomposes before boiling (Perry et al. 1997).

Similarly, $\beta$-keto acids also decompose at low temperatures to form ketone and $\mathrm{CO}_{2}$ :

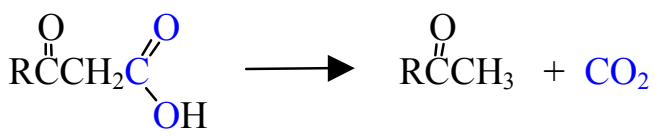

where $\mathrm{R}$ is $\mathrm{H}$ or an alkyl group. If $\mathrm{R}$ is $-\mathrm{CH}_{3}$, the decarboxylation proceeds readily at $25^{\circ} \mathrm{C}$ (Carey 1996).

An alternative route to forming $\mathrm{CO}_{2}$ in bio-oil is from ferulic acid, which was said to be a primary pyrolysis product of lignin. With thermogravimetric analysis at $6^{\circ} \mathrm{C} / \mathrm{min}$, recrystallized ferulic acid started to decompose noticeably at $200^{\circ} \mathrm{C}$ to 4 -vinylguiacol and $\mathrm{CO}_{2}$ : 


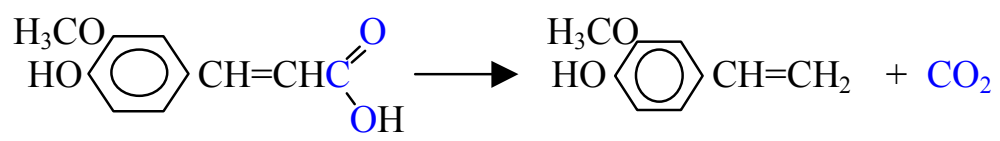

The activation energy was much lower than for normal carbon-carbon bond breakage and the decomposition rate was faster in the presence of oxygen; Fiddler et al. (1967) therefore postulated that free-radical reactions were involved. Free-radicals in aqueous solutions of bio-oil may catalyze this reaction at much lower temperatures during the long times available in aging.

These three possible routes for $\mathrm{CO}_{2}$ formation during storage involve relatively unstable organic compounds. Their low temperature instability would seem to preclude their survival through the high temperatures of pyrolysis. This suggests that they would have to be formed during the aging process, but their presence in bio-oil has not been reported in reviews of bio-oil composition (Milne et al. 1997) or of liquid smoke flavors (Maga 1987).

\subsubsection{Hydrogen}

If metals such as iron, zinc, and aluminum are present with the bio-oils, they would presumably react to form organic acid salt and free hydrogen. This hydrogen might not react with unsaturated organic compounds in the absence of hydrogenation catalysts, and could escape as a gas to the headspace of the storage container.

\subsection{Insights to Be Gained from the Chemical Mechanisms of Aging}

In bio-oil, the various equilibrium chemical reactions constantly adjust to changes in temperature, water content, volatile content, etc. Using the thermodynamic equilibrium constants for the liquid phase of 0.018 for acetaldehyde hydrate formation, 5.2 from Table 3 for methyl acetate and 1.95 from Table 4 for 1,1 dimethoxyethane, the equilibrium composition was calculated for a pseudo bio-oil. The base-case pseudo bio-oil initially contained $25 \mathrm{wt} \%$ water, $3 \%$ acetaldehyde, $2 \%$ methanol, and $8 \%$ acetic acid. The volumes of the water and bio-oil were assumed to be additive and the density change during aging of the bio-oil solutions to be negligible. The linear mass balances for the four initial compounds and the three nonlinear equilibrium expressions involving the products were simultaneously solved by trial-and-error, using a simple computer spreadsheet.

Figure 6 shows the effect of changing the initial water content on the final equilibrium composition, by removing water from or adding it to the original base-case pseudo bio-oil. As predicted by equilibrium concepts, increasing the water initially in the pseudo bio-oil from $5 \mathrm{wt} \%$ to $30 \mathrm{wt} \%$ decreased the methyl acetate content (from $2.8 \mathrm{wt} \%$ to $0.98 \mathrm{wt} \%$ of the basecase initial bio-oil, respectively). As the equilibrium amount of methyl acetate decreased with more initial water, the acetic acid content increased from $5.7 \mathrm{wt} \%$ to $7.2 \mathrm{wt} \%$, respectively. The content of acetaldehyde hydrate increased from $0.3 \mathrm{wt} \%$ to $1.21 \mathrm{wt} \%$ with this same increase in initial water content, which caused the net yield of water to decrease from $0.6 \mathrm{wt} \%$ to $-0.09 \%$.

In a complex, real bio-oil, the number of possible chemical reactions is very high, especially considering the large number of complex oligomers. However, the trends calculated to occur with representative low molecular weight compounds are instructive for speculation on reactions with the complex oligomers. The reactions between the oligomers are responsible for nearly all the viscosity increases observed during aging of bio-oil. 


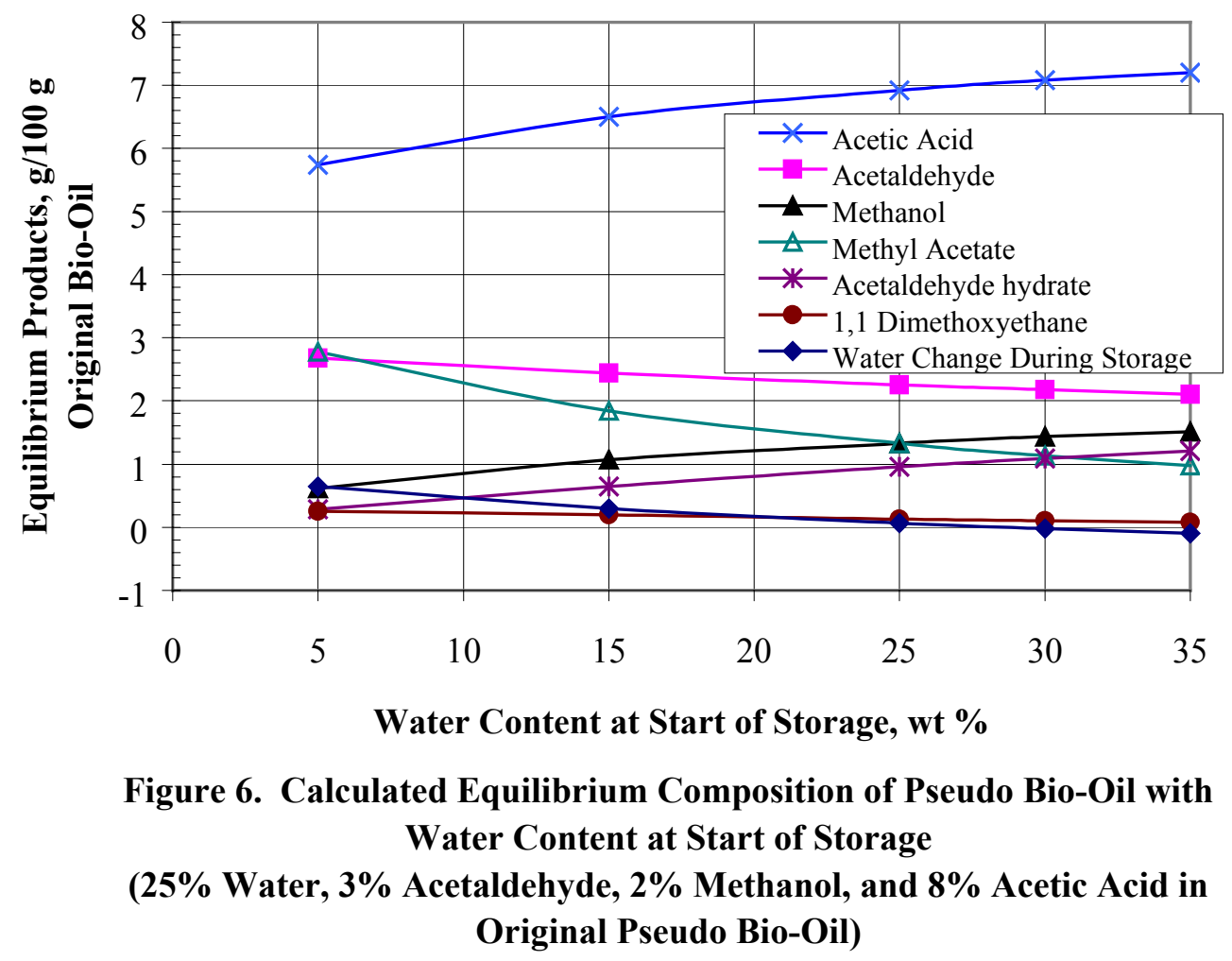

For example, an increase in formation of aldehyde hydrates with higher water contents leaves fewer free aldehydes available to react with hydroxy-containing oligomers to form acetal linked polymers. Increased water content encourages the hydrolysis of ester-linked polymers to form lower molecular weight acidic and hydroxy compounds. Recalling the relationship of viscosity and molecular weight shown in Figure 4, reducing polymerization reactions will reduce the viscosity increase during aging.

Adding methanol to bio-oil shifts the equilibrium toward more esters, acetals, and water. Figure 7 shows the effect of adding methanol to the same base-case psuedo bio-oil used for Figure 6 . By adding $20 \mathrm{~g}$ methanol per $100 \mathrm{~g}$ base-case pseudo bio-oil, $57 \%$ of the acetic acid present at thermodynamic equilibrium was calculated to be converted to methyl acetate, and $68 \%$ of the acetaldehyde was converted to 1,1 dimethoxyethane. The yield of methyl acetate was calculated to be $6.2 \mathrm{wt} \%$ of the pseudo bio-oil and that of 1,1 dimethoxyethane was $4.3 \mathrm{wt} \%$.

The increases in molecular weights of these methyl esters and acetals are relatively low compared to the possible doubling or tripling of molecular weights that occurs in a real bio-oil with oligomeric hydroxy compounds reacting with oligomeric acids and aldehydes. This suggests the addition of low molecular weight reactants to react with oligomeric bio-oil components to form medium molecular weight oligomers, rather than high molecular weight polymers. 


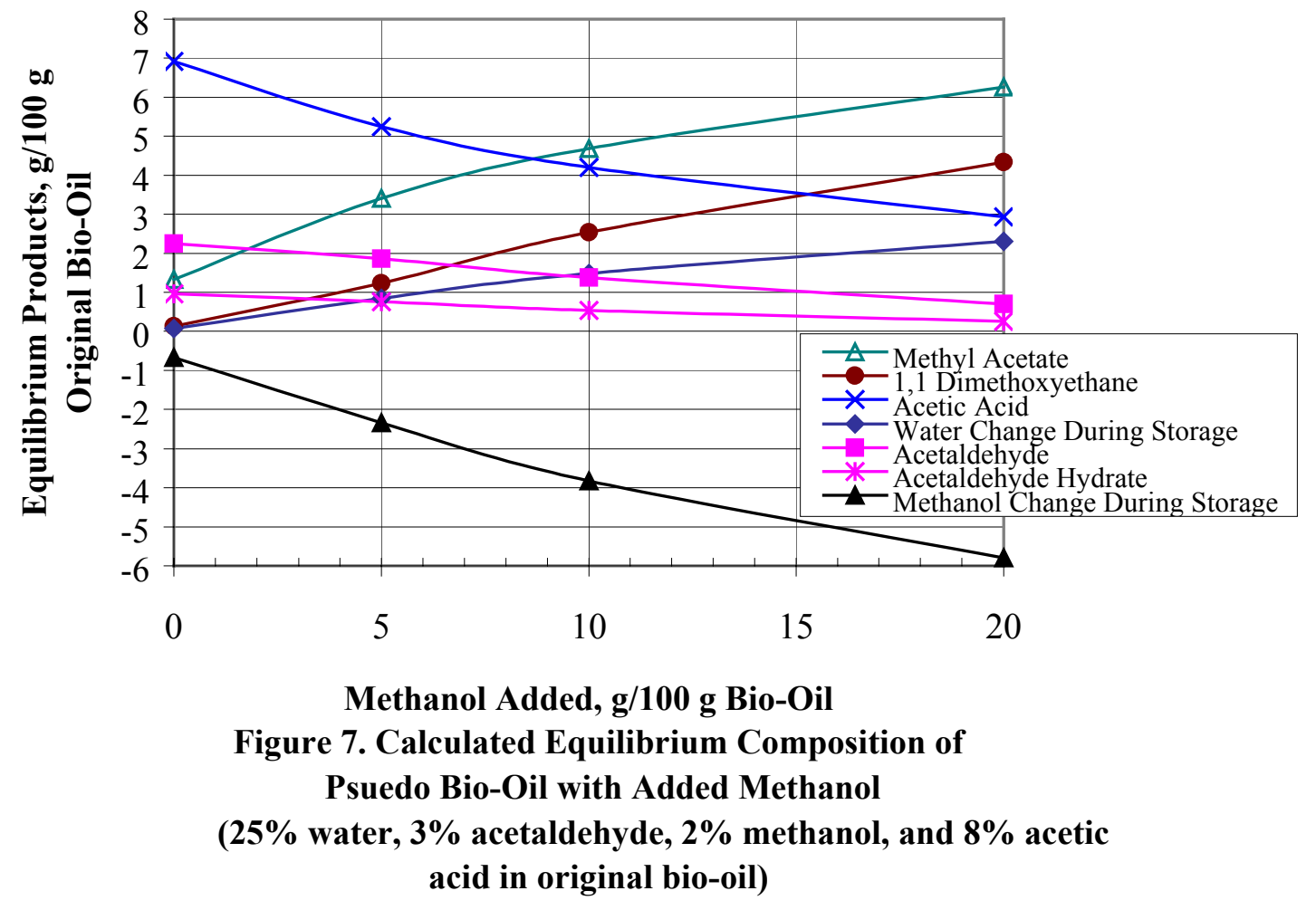

\subsection{OBSERVED CHEMICAL REACTIONS IN WOOD DISTILLATES, WOOD SMOKE, AND BIO-OILS}

\subsection{Wood Distillates}

Making esters from pyrolysis condensates goes back to the days of wood distillation, using slow pyrolysis in a large updraft retort. The condensates were allowed to settle into aqueous and tar phases. The tar phase was distilled to recover the volatiles, including acids, before the oils were distilled at higher temperatures to recover creosote oil and pitch. The tar-distilled volatiles were returned to the aqueous phase to recover acids as bottoms and crude methanol spirits as overheads in another distillation step. Methanol, methyl acetate, and 2-butanone (methyl ethyl ketone) were recovered from the crude methanol spirits. The acidic bottoms were mixed with either lime to make a brown calcium-acetate precipitate or with ethanol (with sulfuric acid as catalyst) to make ethyl acetate and ethyl formate esters commercially (Nelson 1930).

Using Georgia Tech's updraft gasifier with pine as a feedstock, a condenser oil and a draft-fan oil were recovered. The draft fan was located downstream of the condenser. Some very curious results were reported for the aging of these two oils. The viscosity of the condenser oil at $25^{\circ} \mathrm{C}$ decreased after aging for 8 months at ambient temperatures, but increased after storage at $0^{\circ} \mathrm{C}$. With the draft fan oil, the viscosity at $25^{\circ} \mathrm{C}$ was lower after 8 months at $0^{\circ} \mathrm{C}$ than initially, but higher after storage at ambient temperatures. These conflicting results on the effect of temperature are not the trends others have experienced with the aging of bio-oils at moderately low temperatures, which suggests that perhaps phase separations were involved. Data were presented for the accelerated aging of the condenser oil at $110^{\circ} \mathrm{C}$, from which aging rates 
(measured at $40^{\circ} \mathrm{C}$ ) of 100 to $235 \mathrm{cP} /$ day were derived, which is in agreement with the magnitude of extrapolations of the aging rates shown in Figure 3 (Knight et al. 1977).

Again using Georgia Tech's updraft gasifier with pine, a condenser oil and a draft-fan oil were recovered. The condenser oil was vacuum distilled at $22^{\circ} \mathrm{C} / 6.6 \mathrm{~mm} \mathrm{Hg}$ to $128^{\circ} \mathrm{C} / 15 \mathrm{~mm} \mathrm{Hg}$. Gas chromatography (GC) of the fresh distillate, and again after $5 \frac{1}{2}$ months of aging at room temperature, showed a drop in the contents of acids, alcohols, aldehydes, and phenolics with unsaturated-alkyl groups. Water content increased. Esters, acetals, and polyolefinic phenolic polymers were thus formed during the aging process (Polk and Phingbodhippakkiya 1981).

Also using an updraft gasifier, the condensates were gravity separated into oil and aqueous phases. The aqueous phase was distilled to drive off much of the water (and volatiles), resulting in a water-insoluble oil phase forming in the bottom of the still. The two oil phases were then mixed together and esterified with methanol. Heating and catalysis were recommended to increase the reaction rates. The reaction mixture was optionally distilled to reduce the water content of the esterified oils (this would also drive the esterification reaction to completion). Alternatively, the methanol was just added to the oil phase to reduce the viscosity; esterification was thought to occur during storage (Capener and Low 1982). During distillation of the aqueous phase, the formic acid and much of the acetic acid apparently distilled over with the water phase. The remaining organic acids with low volatility in the oil phase would then have formed esters with the added methanol. No examples were given in this patent, so the efficiency of the esterification cannot be judged.

\subsection{Wood Smoke}

The formation of esters and transesterification in whole smoke condensates (made from hickory sawdust) during aging occurs without catalysts. Figure 8 shows that methyl acetate formed over a period of 25 days, whereas methyl formate was at equilibrium after $3 \frac{1}{2}$ days. Also, 2-butenone disappeared after 72 hours, but no conjecture was made as to the products (Doerr et al. 1966). Figure 8 shows the effect of transesterification: the equilibrium amount of the first-formed methyl formate decreased slightly; the amount of methyl acetate increased. This reflects the decrease in the amount of methanol after significant amounts of methyl acetate were formed and the equilibrium quantity of methyl formate shifted.

\subsection{Bio-Oils}

\subsubsection{Aging}

Using a bio-oil made from oak at NREL, the viscosity and weight average molecular weight increased with time. Gel permeation chromatography (detecting only the aromatic compounds) showed that aging decreased the amount of lower molecular weight (100 to 300) material and increased the higher molecular weight $(300$ to 10,000$)$ material. The weight-average molecular weight of the aromatic fraction increased from 530 to 990 . Figure 4 shows that the viscosity of the bio-oil could be used to predict the weight-average molecular weight during aging, after calibration for a specific bio-oil. Analysis for water content using Karl Fischer titration with Hydra-Point Comp 5 showed an increase in water content of $1.6 \%$, from $16.1 \%$ to $17.7 \%$ during aging at $60^{\circ} \mathrm{C}$ and $90^{\circ} \mathrm{C}$. Analysis of the bio-oils by FTIR revealed an increase in water, carbonyls, and ethers and/or esters after aging. The carbonyls may have been products of oxidation (or possibly from the hydrolysis of acetals to form aldehydes and alcohols). Esterification or etherification was a probable mechanism of condensation during storage (Czernik et al. 1994; Czernik 1994). The formation of additional aldehyde hydrates or an 
equilibrium shift from acetals to hemiacetals may have kept the water content from increasing more.

Analysis by gas chromatography with mass-spectrometric detection of bio-oil made from poplar at NREL revealed that the levels of hydroxyacetaldehyde, propenal (acrolein), 2-methoxy-4propenylphenol, and 5-methylfurfural quickly decreased during aging in neat bio-oil samples and methanol/oil samples. Adding methanol to bio-oil before aging showed a decrease in acetic acid and an increase in methyl acetate after aging at $90^{\circ} \mathrm{C}$, verifying that the esterification reaction is active in bio-oils. Analysis by nuclear magnetic resonance showed the increase in ether and ester bonds during aging (Diebold and Czernik 1997).

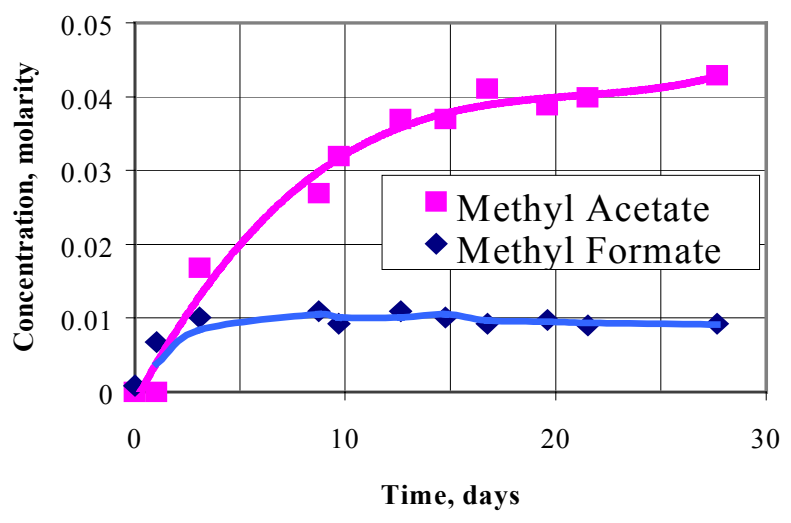

Figure 8. Noncatalytic Esterification in Whole Smoke Condensate at $25^{\circ} \mathrm{C}$ (Doerr et al. 1966)

Room temperature aging data for an oil made from mixed hardwoods for a 12-month period were presented, but with no speculation on chemical mechanism. The viscosity reached an unusual asymptote after 10 months of aging (Bakhshi and Adjaye 1994). It may have leveled off because thermodynamic equilibrium was achieved or because micelles were formed and phase separation occurred.

\subsubsection{Esterification and Acetalization}

Adding alcohol (methanol, ethanol, and propanol) and a mineral acid catalyst to pyrolysis tars and bio-oils caused esters, hemiacetals, and acetals, to form after reaction at room temperature for 2 to 5 hours. By using molecular sieves to selectively dehydrate the reaction mixture, the thermodynamic equilibrium shifted to heavily favor the esters and acetals. Because the water was removed from the reaction mixture, the heating value of the remaining oil product increased. With an aged sample of hardwood bio-oil, $0.16 \mathrm{~kg}$ ethanol was chemically bound per $\mathrm{kg}$ of organics in the bio-oil (Radlein et al. 1996). No viscosity information was given and no comparisons were made of the reaction rate with mineral acid catalyst to the noncatalyzed rate.

Some bio-oil researchers have reported very carefully made mass balances in which the condensing equipment was washed with methanol or acetone to recover all the bio-oils. The biooils were then heated under vacuum to distill off the solvent, resulting in very high recovered biooil yields. The solvent presumably did not react with the bio-oil (Palm et al. 1993; Scott and Piskorz 1984). Based on the earlier discussion of bio-oil composition and chemistry, these solvents may have reacted with the bio-oil to form ketals or acetals and esters, with a probable loss of the volatile products and an increase in yield of the less volatile products. 


\subsubsection{Hydrogenation}

A low-temperature, mild catalytic hydrogenation was performed on bio-oil from Georgia Tech's entrained flow pyrolysis reactor. The bio-oil originally contained $29 \mathrm{wt} \%$ moisture, $38 \%$ oxygen (dry basis), and had a viscosity of $10 \mathrm{cP}$ at $60^{\circ} \mathrm{C}$. The intent was to merely stabilize the oil before it was more extensively hydrogenated. The oil was hydrogenated at $274^{\circ} \mathrm{C}$ and $14 \mathrm{Mpa}(2025$ psia) over a CoMo catalyst. A total of $60 \mathrm{~L}$ of hydrogen were consumed per liter of bio-oil, resulting in a $69 \%$ by volume conversion to a tar having a viscosity of $14,200 \mathrm{cP}$ measured at $60^{\circ} \mathrm{C}$. Although a small amount of hydrogen was consumed, a significant amount of $\mathrm{CO}_{2}$ formed (a $7 \%$ conversion of the carbon to gas) and $34 \%$ by volume yield of an aqueous phase containing $8.2 \%$ of the carbon. The oxygen content of the bio-oil was reduced from $38 \%$ to $15 \%$ in the hydrotreated product, on a dry basis, with a $31 \%$ loss in volume; viscosity increased by a factor of 1420 (Baker and Elliott 1988).

Later, a more extensive experiment was performed with mild hydrogenation at $150^{\circ} \mathrm{C}$ to $450^{\circ} \mathrm{C}$ in a two-stage reactor with sulfided NiMo and CoMo catalysts at pressures lower than $21 \mathrm{Mpa}$ (3000 psi). This hydrogenation removed about $50 \%$ of the oxygen in bio-oil, but resulted in a viscosity increase of about three orders of magnitude to make a tar-like product. In addition, an aqueous phase after hydrogenation contained significant amounts of organic compounds. Only after more extensive hydrogenation in the second-stage reactor, which reduced the oxygen content to less than $10 \%$, was the viscosity of the product oil lower than that of the original biooil (Elliott and Neuenschwander 1997). Much of the initial oxygen reduction in the tar-like product was apparently due to the extraction of the polar oxygenated organic compounds by the aqueous phase from the tar phase, removing their viscosity-reducing (solvent) properties from the organic phase.

A bio-oil with $40.7 \%$ oxygen (dry basis) was hydrogenated at $15 \mathrm{Mpa}$ ( 2200 psi pressure), $275^{\circ} \mathrm{C}$, with a sulfided NiMo catalyst. Aging the hydrogenated bio-oil, having $23 \%$ residual oxygen and a nearly neutral $\mathrm{pH}$ of 6.5 , showed good viscosity stability after 24 hours at $100^{\circ} \mathrm{C}$. However, the viscosity of the hydrogenated bio-oil was about 1000 times higher than that of the aged, nonhydrogenated bio-oil (Conti et al. 1996, 1997).

These high-pressure studies were not promising that a very mild hydrogenation of bio-oil to just saturate reactive unsaturated olefinic molecules can be easily done, without drastically increasing the viscosity.

Hydrotreating a vacuum-pyrolysis oil under mild conditions, the molecular weight of the oil increased by thermal polymerization and decreased by hydrogenolysis by varying degrees, depending on the reaction conditions. The thermal polymerization was speculated to be due to reaction of aldehydes with carbohydrates, catalyzed by carboxylic acids. The best conditions for stabilizing the bio-oil for subsequent hydrodeoxygenation were at the lowest temperature and pressure investigated, $80^{\circ} \mathrm{C}$ and 600 psig for 120 minutes with a ruthenium catalyst. Under these conditions the average molecular weight decreased from $1775 \mathrm{Da}$ to $1040 \mathrm{Da}$, with very little loss of oxygen and a $10 \%$ increase in hydrogen content. Reactive aldehyde groups in sugars were likely being reduced to their corresponding alcohols (Gagnon and Kaliaguine 1988). No speculation was made concerning possible hydrogenation of olefinic compounds. Viscosity and aging characteristics were not reported.

Milder hydrogenation conditions have also been investigated at pressures from a few mbar to 100 bar, temperatures of $20^{\circ} \mathrm{C}$ to $200^{\circ} \mathrm{C}$, and with various catalysts: ruthenium, copper, copperchromite, palladium, platinum, cobalt-molybdenum, nickel, and nickel oxide. The best conditions for hydrotreating were with fresh bio-oils, dry Raney nickel catalyst, 200 to $300 \mathrm{kPa}$ (2-3 bar) 
hydrogen pressure, and $80^{\circ} \mathrm{C}$. Most of the ketones and aldehydes were reduced to alcohols, but acetic acid was unchanged under these mild conditions. No mention was made of the fate of the unsaturates in the bio-oil, e.g., propenyl phenolics (Meier et al. 1997). The viscosity of these mildly hydrogenated bio-oils was said to be very high (Meier 1999).

Mild hydrogenation to saturate the olefins and to convert acids and esters to the corresponding alcohols is being developed. A catalyst based on CoMo on a carbon support gave some conversion of ethyl decanoate to ethanol and decanol (Maggi et al. 1996). No results were given for the hydrogenation of bio-oils.

\subsubsection{Polymerization with Formaldehyde}

Starting with bio-oils made from redwood (or preferably pine), a series of extractions recovered a fraction very high in phenolics and "neutrals" $(\mathrm{P} / \mathrm{N})$. The bio-oil was first extracted with ethyl acetate, and the extract treated with an aqueous solution of sodium bicarbonate to extract the organic acids into the aqueous phase. The solvent remaining in the organic solution was evaporated to recover the $\mathrm{P} / \mathrm{N}$ material, which used as an inexpensive replacement for phenol in acid-catalyzed phenol/formaldehyde novolak resins. With a mixture of $50 \%$ phenol and $50 \% \mathrm{P} / \mathrm{N}$, the amount of formaldehyde required to make a good novolak resin was reduced by one-third, reflecting the oligomeric nature of $\mathrm{P} / \mathrm{N}$ and its aldehyde content. In the presence of about $2 \%$ $\mathrm{HCl}$, the novolak reaction was completed in about 1 hour at $90^{\circ}$ to $95^{\circ} \mathrm{C}$ (Chum and Kriebich 1991).

The use of as much as $20 \%$ of a pine bio-oil in a urea-formaldehyde resin has been reported for use in making particle board, with no loss in strength (Meier et al. 1998). No mention was made of any partitioning of the bio-oil into different fractions before being used in the formulation.

\subsubsection{Air Oxidation}

The effect of the small amount of air in the headspace above a hardwood bio-oil while aging has been investigated. Eight glass containers were $90 \%$ filled with a bio-oil, leaving a headspace equal to $10 \%$ of the volume. If all the headspace were filled with air, the maximum initial amount of oxygen in the headspace would have been $0.025 \mathrm{wt} \%(250 \mathrm{ppm})$ of the bio-oil. This represents the upper limit of air, because some of this headspace would be filled by volatiles from the biooil. In half the containers, no attempt was made to remove the air above the bio-oil. In the other half, the headspace was purged with nitrogen. The tightly closed samples were then exposed to accelerated aging at $80^{\circ} \mathrm{C}$ for 25 hours. No significant differences were observed in the viscosity increase or in the water content for the two sets of bio-oils (Oasmaa et al. 1997). Further testing with and without stirring of closed containers showed no significant differences (Oasmaa 1999). These data indicate that purging the air from the headspace of a nearly full, closed container during storage is not necessary.

\subsubsection{Effect of Entrained Char}

Many of the reaction mechanisms in the preceeding discussion were catalyzed by the inorganic contents of the char, e.g., calcium, magnesium, aluminum, and zinc. Adding char to bio-oil greatly increased its viscosity rate (Agblevor et al. 1994, 1995). Also, previously filtered and aged bio-oil needed to be refiltered after aging because of the apparent growth or agglomeration of tar particles (Shihadeh 1998), possibly using char particles as catalytic condensation sites. 


\subsubsection{Off-Gassing during Storage}

Aging pyrolysis oils causes permanent gases to evolve. During severe accelerated aging tests of bio-oil at $90^{\circ} \mathrm{C}$, gas pressure built up in the closed containers. The gases saturated the bio-oil at the autogenous pressure. After removing the bio-oil samples from the storage oven, cooling, and weighing, the sample vials were opened very slowly to prevent the bio-oil from foaming over. This was analogous to opening a bottle of a warm, shaken carbonated beverage. The gases were not analyzed (Diebold and Czernik 1997).

The headspace of a barrel of pyrolysis oil was sampled after 6 months of closed storage under ambient conditions in shipping and customs. A positive pressure had built up. Analysis by GC revealed that the gas contained 29 vol $\% \mathrm{CO}_{2}, 1 \% \mathrm{CO}, 1 \% \mathrm{CH}_{4}, 61 \% \mathrm{~N}_{2}$, and $6 \% \mathrm{O}_{2}$ for a $2 \%$ lack of closure (Peacocke et al. 1994). (The 2\% missing material puts an upper limit on the possible amount of the unreported organic vapors.) Assuming that all the nitrogen was originally air in the headspace, 10 percentage points of oxygen were missing from the headspace gas. This missing oxygen could have been responsible for only a fraction (10 percentage points) of the 29 percentage points of $\mathrm{CO}_{2}$ present. This small weight of oxygen actually missing could easily have been absorbed by the relatively large weight of bio-oil in the barrel.

During the repeated operation of a viscometer, which used a timed, falling gold-plated ball, anomalies were observed after an induction period with a pine bio-oil at $40^{\circ} \mathrm{C}$ and higher temperatures. These anomalies were caused by gas or vapor bubbles adhering to the ball, which gave the ball an increased buoyancy and longer falling times. By periodically degassing the sample, the minimum time for the ball to fall was ascertained and assumed to relate to the true viscosity of the bio-oil. The bubbles appeared to form even after $2 \frac{1}{2}$ hours, which was interpreted as being indicative of chemical reactions. No analyses were made of the bubbles, but after 6 weeks of storing one of the bio-oils at ambient temperatures, the gases in the headspace were found to have equimolar amounts of $\mathrm{CO}_{2}$ and $\mathrm{CO}$ (Radovanovic et al. 1997). The normal boiling point of methyl formate is $32^{\circ} \mathrm{C}$ and methylal is $42^{\circ} \mathrm{C}$, so they could have been significant parts of the vapors in the bubbles forming at $40^{\circ} \mathrm{C}$ and higher.

Gas or vapor bubbles were also observed while using capillary tubes to determine viscosity. However, these bubbles were easily removed by preheating the fluid at temperatures above ambient. Viscosity measurements were successfully made with hardwood bio-oil at temperatures as high as $80^{\circ} \mathrm{C}$ (Oasmaa et al. 1997).

Chemical reactions that would have produced $\mathrm{CO}$ or $\mathrm{CH}_{4}$ in the headspace are not listed in the model reactions considered previously. The chemical reactions that could produce $\mathrm{CO}_{2}$ produce compounds with molecular weights lower than the reactants, i.e., they are not polymerization reactions. This consideration appears to decouple gas-forming reactions from those identified as molecule-building or polymerization reactions. However, the decarboxylation of ferulic acid appears to involve free-radicals, so olefinic polymerization may be a by-product.

If bio-oil produces gases during storage, as indicated in the aging tests, these gases will need to be properly vented and disposed. According to Peacocke et al. (1994), they have a molecular weight higher than 33, making them $13 \%$ denser than air. This means they would not disperse readily after venting and would tend to collect in low-lying areas. They could cause asphyxiation and contain enough $\mathrm{CO}_{2}$ to be deadly even after some dilution, but their heating value is too low for them to be considered a fuel. One disposal method would be to oxidize the off-gases using automotive catalytic muffler technology. Depending on the amount of organic vapors in the offgases and relative heat losses, supplemental fuel might have to be added for catalytic oxidation, because their adiabatic combustion temperature would be only about $320^{\circ} \mathrm{C}$. 


\subsection{METHODS TO SLOW AGING IN BIO-OILS}

\subsection{Solvent Addition to Reduce Viscosity and Aging Rates}

Polk and Phingbodhippakkiya (1981) recommended adding low-viscosity water, methanol, or acetone to combat increases in viscosity after aging of updraft gasifier oils. This was apparently to dilute the polymers being formed. No mention of chemical reactions with the solvents was made, nor were any data presented to demonstrate the effectiveness of these solvent additions. Other early work with updraft gasifier oils used methanol to reduce viscosity; esterification was thought to be involved during storage (Capener and Low 1982). Adding 10\% furfural to a very thick pyrolysis oil reduced its viscosity from 7000 cSt to 767 cSt (Salvi and Salvi, Jr. 1991).

Water and methanol added to a hardwood bio-oil were systematically investigated for their impact on viscosity. Water contents as high as $30 \mathrm{wt} \%$ and methanol contents as high as $10 \mathrm{wt} \%$ were investigated and found to reduce the viscosity of the mixtures (methanol was slightly more effective). The viscosity at $25^{\circ} \mathrm{C}$ was lowered from $76 \mathrm{cP}$ with $20 \mathrm{wt} \%$ water and to $12 \mathrm{cP}$ with $30 \%$ water and 10\% methanol (Diebold et al. 1996).

Similarly, the viscosity at $25^{\circ} \mathrm{C}$ of a hardwood bio-oil was reduced from $1127 \mathrm{cP}$ to $199 \mathrm{cP}$ as the moisture content increased from $17.4 \mathrm{wt} \%$ to $30 \mathrm{wt} \%$. More importantly, the viscosity rate increase after aging 4 months at room temperature decreased from $3.3 \mathrm{cP} /$ day with $20 \mathrm{wt} \%$ water, to $0.9 \mathrm{cP} /$ day with $25 \%$ water, to about $0.05 \mathrm{cP} /$ day at $30 \%$ water. Thus, water at $25 \mathrm{wt} \%$ to $30 \mathrm{wt} \%$ apparently stabilized the bio-oil from aging effects (Tiplady et al. 1996).

Oasmaa et al. (1997) investigated adding $2 \mathrm{wt} \%, 5 \%, 10 \%$, and $20 \%$ ethanol to a hardwood biooil. The initial viscosity of the bio-oil at $50^{\circ} \mathrm{C}$ was decreased from $50 \mathrm{cSt}$ with no ethanol to 10 $\mathrm{cSt}$ with $20 \%$ ethanol ( $\mathrm{cSt}=$ the viscosity in $\mathrm{cP}$ divided by the density in $\mathrm{g} / \mathrm{cc}$ ). After aging at $20^{\circ} \mathrm{C}$ for as long as 4 months the aging rate decreased an order of magnitude from $0.12 \mathrm{cSt} / \mathrm{day}$ with no ethanol to a barely perceptible value of about $0.01 \mathrm{cSt} /$ day with $20 \%$ ethanol (Table 5). After aging at $50^{\circ} \mathrm{C}$ for as long as 7 days, the viscosity increase of the neat bio-oil was $3.5 \mathrm{cSt} /$ day compared to $0.4 \mathrm{cSt} /$ day for a mixture of $5 \mathrm{wt} \%$ ethanol in bio-oil, for a reduction in the aging rate by a factor of 8.5 .

Diebold and Czernik (1997) investigated stabilizing a hardwood bio-oil by adding as much as $10 \mathrm{wt} \%$ methanol, ethanol, acetone, ethyl acetate, a 1/1 mixture of acetone and methanol, or a 1/1 mixture of methanol and methyl iso-butyl ketone. The initial viscosities at $40^{\circ} \mathrm{C}$ decreased from $30 \mathrm{cP}$ for the neat bio-oil to about $15 \mathrm{cP}$ for the bio-oil/solvent mixtures. These experiments used accelerated aging at $90^{\circ} \mathrm{C}$ to demonstrate the ability to preheat the stabilized bio-oil before combustion and to reduce the amount of time required for aging studies. The viscosities for the aged neat bio-oil and the bio-oil/solvent mixtures varied quite linearly with time. Table 5 shows the dramatic impact these solvents had on slowing the aging rate and viscosity increase. Methanol was the cheapest and most effective organic solvent on a weight basis to reduce the rate of viscosity increase at $90^{\circ} \mathrm{C}$; the aging rate was reduced by a factor of 17 with $10 \%$ methanol, compared to the neat bio-oil aged at the same temperature.

Table 5 shows that the beneficial effect on aging of adding solvents to bio-oil to decrease the aging rate is progressively more effective at higher storage temperatures. Bio-oils from hardwoods and softwoods benefit by reducing the aging rates with solvents. 
Table 5. Effect of Adding Solvents on Aging Rates

\begin{tabular}{|c|c|c|c|c|}
\hline Reference & Bio-Oil Sample & $\begin{array}{c}\text { Aging } \\
\text { Temp. } \\
{ }^{\circ} \mathrm{C} \\
\end{array}$ & $\begin{array}{c}\text { Aging } \\
\text { Rate }\end{array}$ & $\begin{array}{l}\text { Aging Rate } \\
\text { Relative to } \\
\text { Neat Bio-Oil } \\
\end{array}$ \\
\hline Oasmaa et al. 1997 & VTT Batch 10/95 (Oak+Maple) & 20 & $0.12 \dagger$ & 1.0 \\
\hline "“ & Batch $10 / 95+5 \%$ Ethanol & 20 & $0.04 \dagger$ & 0.3 \\
\hline “" & Batch 10/95 + 20\% Ethanol & 20 & $0.008 \dagger$ & 0.07 \\
\hline Oasmaa 1999 & AFBP10/2 (Hot Gas Filtered Pine) & 20 & $0.15 \dagger$ & 1.0 \\
\hline “ & AFBP $10 / 2+10 \% \mathrm{MeOH}$ & 20 & $0.029 \dagger$ & 0.19 \\
\hline “" & PDU8 (Pine) & 20 & $0.19^{*}$ & 1.0 \\
\hline “ & PDU $8+2 \% \mathrm{MeOH}$ & 20 & $0.065^{*}$ & 0.34 \\
\hline “" & PDU8 + 5\% MeOH & 20 & $0.062 *$ & 0.33 \\
\hline “" & PDU $8+10 \% \mathrm{MeOH}$ & 20 & $0.016^{*}$ & 0.083 \\
\hline Oasmaa et al. 1997 & VTT batch $10 / 95$ & 50 & $3.6 \dagger$ & 1.0 \\
\hline " & Batch $10 / 95+5 \%$ Ethanol & 50 & $0.43 \dagger$ & 0.12 \\
\hline \multirow{2}{*}{$\begin{array}{l}\text { Diebold and Czernik } \\
1997\end{array}$} & NREL Run 175 (Poplar) & 90 & $60^{*}$ & 1.0 \\
\hline & Run $175+5 \% \mathrm{MeOH}$ & 90 & $12^{*}$ & 0.20 \\
\hline "6 & Run $175+10 \%$ Ethyl Acetate & 90 & $8.6^{*}$ & 0.14 \\
\hline “ & Run $175+5 \% \mathrm{MiBK}+5 \% \mathrm{MeOH}$ & 90 & $6.0^{*}$ & 0.10 \\
\hline “ & Run $175+10 \%$ Ethanol & 90 & $5.3^{*}$ & 0.091 \\
\hline “6 & Run $175+5 \% \mathrm{MeOH}+5 \%$ Acetone & 90 & $4.8^{*}$ & 0.080 \\
\hline “6 & Run $175+10 \%$ Acetone & 90 & $4.6^{*}$ & 0.077 \\
\hline “6 & Run $175+10 \% \mathrm{MeOH}$ & 90 & $3.4^{*}$ & 0.057 \\
\hline
\end{tabular}

$\mathrm{MeOH}$ is methanol; MiBK is methyl iso-butyl ketone

$\dagger \mathrm{cSt} /$ day measured at $50^{\circ} \mathrm{C}$

$* \mathrm{cP} /$ day measured at $40^{\circ} \mathrm{C}$

With $0 \%$ and 5 wt $\%$ methanol in the bio-oil, the viscosity increase decreased slightly by increasing the water content from $20 \%$ to $30 \%$. With $10 \%$ methanol, the aging rate was independent of water content over this same range. The effect of the solvents was thus greater than would be expected from a physical dilution (Diebold and Czernik 1997).

Adding methanol shortly after producing a hardwood bio-oil was significantly better than after aging at $90^{\circ} \mathrm{C}$ for 20.5 hours. Some aging reactions are apparently not in thermodynamic equilibrium and some reactions cannot be reversed by adding low molecular weight reactants. However, viscosity decreased dramatically by adding methanol to previously aged oil (Diebold and Czernik 1997).

Similarly, adding 5\% methanol to a fresh softwood bio-oil, which was then aged at room temperature for 3 months, increased viscosity by only $15 \%$. Adding the same amount of methanol after the same aging increased viscosity by $28 \%$ (Oasmaa 1999).

From a molar perspective, ethyl acetate and acetone were twice as effective as methanol in lowering the aging rate of a hardwood bio-oil. The solvents were probably reacting to form low molecular weight products at the expense of polymerization reactions. For example, ethyl acetate 
can hydrolyze to form ethyl alcohol and acetic acid; acetone can react under acidic conditions to form cyclic ketals with two adjacent hydroxyl groups on a polyhydroxyl organic molecule. The cost of adding methanol to the bio-oil is at least partially compensated by the increased energy content of the mixture (Diebold and Czernik 1997).

The phase stability of bio-oils during storage is increased by adding the proper solvents. Between $2 \%$ and $10 \%$ methanol was added to bio-oils that had previously phase separated to result in homogenous liquids (Oasmaa 1999).

The efficient collection of volatile components during the production of the bio-oil will result in a bio-oil with more low molecular weight components having lower viscosity, better solvency properties, and possibly better storage properties. Because the volatiles will not condense until their vapor pressure equals their partial pressure, these volatiles are collected more efficiently with less carrier gas present to dilute them.

Hemiacetal, acetal, and ester linkages could be important in the aging process of bio-oils. Because they react toward thermodynamic equilibrium, adding a low molecular weight alcohol to a mixture of high molecular weight hemiacetals, acetals, and esters would shift the equilibrium composition to a mixture with a lower molecular weight and viscosity. This could be important in stabilizing bio-oil by four mechanisms: (1) reducing the concentration of reactive aldehydes, by converting more of them to less reactive, relatively low to moderate molecular-weight hemiacetals and acetals; (2) transacetalizing large hemiacetals and acetals to form lower molecular weight hemiacetals and acetals; (3) converting organic acids to low molecular weight esters; and (4) transesterifying large esters to form lower molecular weight esters. The second and fourth mechanisms could be considered depolymerizing the original high molecular weight hemiacetals, acetals, and esters. An example of the fourth mechanism is reacting canola oil (a high molecular weight triglyceride) with methanol to form lower molecular weight mono methyl esters (biodiesel) and glycerol.

\subsection{Mild Hydrogenation}

From a cost perspective, mildly hydrogenating the bio-oil to saturate only the reactive aliphatic unsaturated compounds, e.g., the propenyl group of 2-methoxy-4-propenyl phenol (eugenol) would be ideal. However, hydrogenating unsaturated vegetable oils creates a viscous greasy semisolid material used for imitation lard and butter. Thus, saturating the olefins in bio-oil might increase the viscosity of the product oil.

Wood distillates from an updraft gasifier were hydrogenated with a catalyst of $\mathrm{Pd}$ on carbon at hydrogen pressures lower than $405 \mathrm{kPa}$ (four atmospheres). This mild hydrogenation eliminated 4-hydroxy-3-methoxy styrene, and reduced the content of 2-methoxy-4-allyl phenol (isoeugenol) and 2-methoxy-4-propenyl phenol (eugenol). The actual viscosity of the hydrotreated oil was not given. The hydrogenated oil was apparently quite viscous, as it was diluted with $\mathrm{m}$-cresol and then aged at room temperature. After 8 months of aging, the viscosity of a dilute solution of $20 \%$ of the as-produced oil in m-cresol increased $72 \%$, whereas the viscosity of $20 \%$ hydrogenated oil in m-cresol increased by a factor of only $21 \%$. Thus, the viscosity increase was reduced by a factor of 3.3 by the hydrogenation, strongly implying that olefin condensation was one of several mechanisms involved with aging (Polk and Phingbodhippakkiya 1981). 
Researchers speculate that a very mild hydrogenation of bio-oil could eliminate olefinic condensation as one of several aging mechanisms. However, if this causes a large increase in viscosity, as it apparently has thus far, this processing step would not be advantageous. Future hydrogenation experimentation in this area needs to be directed toward minimizing this viscosity increase during very mild hydrogenation.

\subsection{Limiting Access to Air and Antioxidants}

Although the small amount of air in the headspace of a sample did not appear to catalyze aging reactions, the result could have been different with more air available to the bio-oil. For example, vigorously mixing the bio-oil in an open container before sampling could entrain air into the biooil and saturate it with air, even if allowed to sit until the entrained bubbles rise to the surface. This increased level of oxygen in the bio-oil could produce enough peroxides to catalyze the polymerization of the olefins. Limiting the access of air to the bio-oil to minimize the possibility of forming peroxides that catalyze olefinic polymerization would be prudent.

Many phenolics are good free-radical traps and are used to protect olefins from the polymerizing effect of free-radicals. However, based on the reported disappearance of olefinic compounds in bio-oils and wood smoke, bio-oils apparently do not contain enough free-radical trap molecules for stabilization.

The phenolics deliberately used as free-radical traps can form free-radicals that are stabilized by resonance, thus stopping the chain reaction of polymerization. Commercially, hydroquinone is used as a free-radical trap to stabilize acrolein during storage and shipping. Very small quantities of hydroquinone at 0.10 to $0.25 \mathrm{wt} \%$ are used for this purpose in the presence of acetic acid at a $\mathrm{pH}$ of 6 (Etzkorn et al. 1991). Adding a small quantity of an antioxidant such as hydroquinone to stabilize the olefins in bio-oil, rather than using mild hydrogenation to saturate the olefins, may be more cost effective.

\subsection{PHYSICAL MECHANISMS OF PHASE INSTABILITY}

\subsection{Co-Solvency of Bio-Oil Components}

The mutual solubility of a mixture of compounds is related to their chemical structures and their relative amounts. In general, compounds with lower molecular weights are more soluble than those with higher molecular weights. Compounds with similar polarities or similar molecular structures tend to be mutally soluble. Examples of highly polar materials are water, alcohols, and organic acids. Less polar materials include esters, ethers, and phenolics. Nonpolar materials include hexane and other hydrocarbons. Compounds that favor mutual solubility between compounds with different polarities have both a polar and a nonpolar aspect, e.g., a long hydrocarbon chain (low polarity) with an alcohol group (high polarity), such as $n$-butanol at the end. In general, bio-oils containing more oxygen on a dry basis can keep more water in solution than bio-oils with lower oxygen contents. Some of that water appears to be in the form of aldehyde hydrates, but much of it is probably just hydrogen bonded to polar organic functionalities, e.g., carboxylic acids and alcohols. 
Because a higher amount of hydrogen bonding of a compound increases its heat of vaporization, this property is used to define the solubility parameter, $\delta$ :

$$
\delta=\left[\left(\Delta \mathrm{H}_{\mathrm{v}}-\mathrm{RT}\right) / \mathrm{V}\right]^{0.5}
$$

where $\Delta \mathrm{H}_{\mathrm{v}}$ is the molar heat of vaporization in $\mathrm{J} / \mathrm{kmol}, \mathrm{R}$ is the gas constant $(8314 \mathrm{~J} / \mathrm{kmol} / \mathrm{K}), \mathrm{T}$ is the temperature in Kelvin, and $\mathrm{V}$ the molar volume $\left(\mathrm{m}^{3} / \mathrm{kmol}\right)$. This solubility parameter is also called the Hildebrand parameter and was developed for use with nonpolar materials. Materials with similar solubility parameters tend to be mutally soluble (Barton 1983).

For multifunctional component mixtures, expanding the solubility parameter to include a better description of the organic compounds involved is useful. The solubility is presumbaly a combination of contributions from the nonpolar or dispersion interactions, the polar interactions, and the hydrogen bonding interactions of the molecules:

$$
\delta_{\mathrm{t}}^{2}=\delta_{\mathrm{d}}^{2}+\delta_{\mathrm{p}}^{2}+\delta_{\mathrm{h}}^{2}
$$

where $\delta_{\mathrm{t}}$ is the total solubility parameter, $\delta_{\mathrm{d}}$ is the dispersive solubility parameter, $\delta_{\mathrm{p}}$ is the polar solubility parameter, and $\delta_{\mathrm{h}}$ is the hydrogen bonding solubility parameter. These are called Hansen solubility parameters. The Hansen total solubility parameter is qualitatively similar to the Hildebrand parameter (Barton 1983).

The Hansen parameters are used to predict the solubility of solutes (j) and solvents (i). If the Hansen parameters for the solvent fall within the "spherical volume" of the solute, solubility is predicted. This is satisfied if the distance from the center of the solvent sphere to the center of the solute sphere $\left(R_{i j}\right)$ is smaller than the radius of the solute sphere $(R j)$ :

$$
\begin{gathered}
\mathrm{R}_{\mathrm{ij}}=\left[4\left(\delta_{\mathrm{di}}-\delta_{\mathrm{dj}}\right)^{2}+\left(\delta_{\mathrm{pi}}-\delta_{\mathrm{pj}}\right)^{2}+\left(\delta_{\mathrm{hi}}-\delta_{\mathrm{hj}}\right)^{2}\right]^{0.5} \\
\mathrm{R}_{\mathrm{ij}}<\mathrm{R}_{\mathrm{j}}
\end{gathered}
$$

Tables 6 and 7 show the Hansen solubility parameters for 37 solvents and 11 polymeric materials (Barton 1983) commonly reported to be in bio-oils or thought to be similar to some compounds in bio-oils. Water (when mixed with organic compounds) has the highest $\delta_{\mathrm{p}}$ at $17.8 \mathrm{MPa}^{0.5}$, which contributes along with a high $\delta_{\mathrm{h}}$ of $17.6 \mathrm{MPa}^{0.5}$ and a high $\delta_{\mathrm{d}}$ of $19.5 \mathrm{MPa}^{0.5}$ to the highest $\delta_{\mathrm{t}}$ shown on the table of $31.7 \mathrm{MPa}^{0.5}$. In contrast, $n$-hexane with a $\delta_{\mathrm{p}}$ and a $\delta_{\mathrm{h}}$ of zero results in a low $\delta_{\mathrm{t}}$ of $14.9 \mathrm{MPa}$. Between these two extremes are the organic compounds reportedly in bio-oil. The polymer solubility radius, $\mathrm{R}_{\mathrm{j}}$, is based the observed solubility of $0.5 \mathrm{~g}$ of polymer in $5 \mathrm{~cm}^{3}$ of solvent (Barton 1983).

To predict the solubility of a polymer in a mixture of various solvents, each solubility parameter $\left(\delta_{\mathrm{d}}, \delta_{\mathrm{p}}\right.$, and $\left.\delta_{\mathrm{h}}\right)$ for each solvent is multiplied by its volume fraction (vol.fr. $\left.{ }_{i}\right)$ and added, e.g.,

$$
\delta_{\mathrm{dm}}=\Sigma_{i}\left(\delta_{\mathrm{d} i} * \text { vol.fr. }_{i}\right)
$$

where $\delta_{\mathrm{dm}}$ is the dispersive solubility parameter for the solvent mixture, and $\delta_{\mathrm{d} i}$ is the dispersive solubility parameter for the $i$ th solvent (Barton 1983). 
Table 6. Hansen Solubility Parameters (Barton 1983) for Solvents in Bio-Oil of Potential Interest to Bio-Oil Producers

\begin{tabular}{|c|c|c|c|c|}
\hline Compound & $\delta_{\mathrm{di}}, \mathrm{MPa}^{-0.5}$ & $\delta_{\mathrm{pi}}, \mathrm{MPa}^{-0.5}$ & $\delta_{\mathrm{hi}}, \mathrm{MPa}^{-0.5}$ & $\delta_{\mathrm{ti}}, \mathrm{MPa}^{-0.5}$ \\
\hline \multicolumn{5}{|l|}{ Alcohols } \\
\hline Methanol & 15.1 & 12.3 & 22.3 & 29.6 \\
\hline Ethanol & 15.8 & 8.8 & 19.4 & 26.5 \\
\hline 1,2-ethanediol (ethylene glycol) & 17.0 & 11.0 & 26.0 & 32.9 \\
\hline 2-Propen-1-ol (allyl alcohol) & 16.2 & 10.8 & 16.8 & 25.7 \\
\hline 1-Propanol & 16.0 & 6.8 & 17.4 & 24.5 \\
\hline 2-Propanol & 15.8 & 6.1 & 16.4 & 23.5 \\
\hline Propanediol & 16.8 & 9.4 & 23.3 & 30.2 \\
\hline 1,2,3 propanetriol (glycerol) & 17.4 & 12.1 & 29.3 & 36.1 \\
\hline 1-Butanol & 16.0 & 5.7 & 15.8 & 23.1 \\
\hline Furfuryl alcohol & 17.4 & 7.6 & 15.1 & 24.3 \\
\hline \multicolumn{5}{|l|}{ Aldehydes } \\
\hline Acetaldehyde & 14.7 & 8.0 & 11.3 & 20.3 \\
\hline Butanal & 14.7 & 5.3 & 7.0 & 17.1 \\
\hline Furfural & 18.6 & 14.9 & 5.12 & 24.4 \\
\hline Benzaldehyde & 19.4 & 7.4 & 5.3 & 21.5 \\
\hline \multicolumn{5}{|l|}{ Acids } \\
\hline Formic & 14.3 & 11.9 & 16.6 & 24.9 \\
\hline Acetic & 14.5 & 8.0 & 13.5 & 21.4 \\
\hline 1-Butanoic & 14.9 & 4.1 & 10.6 & 18.8 \\
\hline Benzoic & 18.2 & 7.0 & 9.8 & 21.8 \\
\hline \multicolumn{5}{|l|}{ Esters } \\
\hline Methyl acetate & 15.5 & 7.2 & 7.6 & 18.7 \\
\hline Ethyl formate & 15.5 & 7.2 & 7.6 & 18.7 \\
\hline Ethyl acetate & 15.8 & 5.3 & 7.2 & 18.1 \\
\hline Ethyl lactate & 16.0 & 7.6 & 12.5 & 21.6 \\
\hline$n$-Butyl acetate & 15.8 & 3.7 & 6.3 & 17.4 \\
\hline$\gamma$-Butyrolactone & 19.0 & 16.6 & 7.4 & 26.3 \\
\hline Ethyl cinnamate & 18.4 & 8.2 & 4.1 & 20.6 \\
\hline \multicolumn{5}{|l|}{ Ethers } \\
\hline Dimethoxy methane (Methylal) & 15.1 & 1.8 & 8.6 & 17.5 \\
\hline Furan & 17.8 & 1.8 & 5.3 & 18.6 \\
\hline Methoxy benzene (anisol) & 17.8 & 4.1 & 6.8 & 19.5 \\
\hline Dibenzel ether & 17.4 & 3.7 & 7.4 & 19.3 \\
\hline \multicolumn{5}{|l|}{ Ketones } \\
\hline Acetone & 15.5 & 10.4 & 7.0 & 20.0 \\
\hline Methyl ethyl ketone & 16.0 & 9.0 & 5.1 & 19.0 \\
\hline Methyl isobutyl ketone & 15.3 & 6.1 & 4.1 & 17.0 \\
\hline \multicolumn{5}{|l|}{ Phenolics } \\
\hline Phenol & 18.0 & 5.9 & 14.9 & 24.1 \\
\hline 1,3 Benzendiol (resorcinol) & 18.0 & 8.4 & 21.1 & 29.0 \\
\hline 3-methyl phenol (m-cresol) & 18.0 & 5.1 & 12.9 & 22.7 \\
\hline$o$-Methoxy phenol & 18.0 & 8.2 & 13.3 & 23.8 \\
\hline \multicolumn{5}{|l|}{ Hydrocarbons } \\
\hline$n$-Hexane & 14.9 & 0.0 & 0.0 & 14.9 \\
\hline Benzene & 18.4 & 0.0 & 2.0 & 18.6 \\
\hline Toluene & 18.0 & 1.4 & 2.0 & 18.2 \\
\hline Styrene & 18.6 & 1.0 & 4.1 & 19.0 \\
\hline Turpentine & 16.4 & 1.4 & 0.4 & 16.5 \\
\hline Naphthalene & 19.2 & 2.0 & 5.9 & 20.3 \\
\hline Water (with organic liquids) & 19.5 & 17.8 & 17.6 & 31.7 \\
\hline
\end{tabular}


Table 7. Hansen Solubility Parameters for Polymers (Barton 1983) Possibly Relevant to Bio-Oils

\begin{tabular}{|l|c|c|c|c|}
\hline \multicolumn{1}{|c|}{ Polymer } & $\begin{array}{c}\boldsymbol{\delta}_{\mathbf{d j}} \\
\mathbf{M P a}^{-\mathbf{0 . 5}}\end{array}$ & $\begin{array}{c}\boldsymbol{\delta}_{\mathbf{p j}} \\
\mathbf{M P a}^{-\mathbf{0 . 5}}\end{array}$ & $\begin{array}{c}\boldsymbol{\delta}_{\mathbf{h j}} \\
\mathbf{M P a}^{-\mathbf{0 . 5}}\end{array}$ & $\begin{array}{c}\mathbf{R}_{\mathbf{j}} \\
\mathbf{M P a}^{-\mathbf{0 . 5}}\end{array}$ \\
\hline Cellulose acetate (Cellidore A. Bayer) & 18.6 & 12.7 & 11.0 & 7.6 \\
\hline Coumarone-indene resin (Parlon P-10, Hercules) & 19.4 & 5.5 & 5.8 & 9.6 \\
\hline Epoxy (Epikote 1001, Shell) & 20.4 & 12.0 & 11.5 & 12.7 \\
\hline Ester gum (Ester gum BL, Hercules) & 19.6 & 4.7 & 7.8 & 10.6 \\
\hline Furfuryl alcohol resin (Durez 14383, Hooker Chem.) & 21.2 & 13.6 & 12.8 & 13.7 \\
\hline Isoprene elasomer (Ceriflex IR305, Shell) & 16.6 & 1.4 & -0.8 & 9.6 \\
\hline $\begin{array}{l}\text { Phenolic resin (resole, Phenodur 373U, } \\
\text { Chemische Werke Albert) }\end{array}$ & 19.7 & 11.6 & 14.6 & 12.7 \\
\hline $\begin{array}{l}\text { Phenolic resin, pure (Super Beckacite 1001, } \\
\text { Reichhold) }\end{array}$ & 23.3 & 6.6 & 8.3 & 19.8 \\
\hline Poly(ethyl methacrylate) (Lucite 2042, Du Pont) & 17.6 & 9.7 & 4.0 & 10.6 \\
\hline Polystyrene (Polystyrene LG, BASF) & 21.3 & 5.8 & 4.3 & 12.7 \\
\hline Saturated polyester (Desmophen 850, Bayer) & 21.5 & 14.9 & 12.3 & 16.8 \\
\hline Terpene resin (Piccolyte S-1000, Penn. Ind. Chem.) & 16.5 & 0.4 & 2.8 & 8.6 \\
\hline Water (with organic liquids) & 19.5 & 17.8 & 17.6 & 14.7 \\
\hline
\end{tabular}

\subsection{Changes in Mutual Solubility with Aging}

During aging, chemical reactions change the polarity of the bio-oil components. For example, esterification converts highly polar organic acid and alcohol molecules into esters with relatively low polarity and extremely polar water. The formation of acetals shifts the composition away from acetaldehyde hydrates, releasing the water of hydration and the water formed with the acetal. Acetals are in the relatively nonpolar family of ethers. Thus, the polarity of the organic material is decreased when the water content is increased. This increasing difference in polarity among the compounds in the aged bio-oil increases the tendency for phase separation. Although ethyl acetate was used to extract the phenolics and other aromatics from bio-oil (Chum and Black 1990; Chum and Kreibich 1991), adding only 10\% ethyl acetate to bio-oil allowed more severe aging to take place before phase separation than did similar amounts of alcohols or ketones (Diebold and Czernik 1997).

With the formation of larger molecules during aging, their mutual solubility decreases. All these things work to increase the probability that phase separation will occur into a light, highly polar aqueous phase and a less polar heavier organic phase. Additional lighter waxy phases and heavier sludge phases also form during storage because of the decrease in mutual solubility during aging (Diebold and Czernik 1997).

\subsection{Micelles, Suspensions, and Emulsions}

As the aging bio-oil becomes saturated with respect to large, low-polarity molecules, there is thought to be a segregation of polar molecules from less polar molecules, with multifunctional molecules between to form micelles, analogous to petroleum fuel oils (Radlein 1999). The lowpolarity molecules can be attracted to the surface of suspended char particles, which act as condensation nuclei. 
When micelles form, the initial liquid phase separation is in the form of very small droplets with very large surface areas. The initial droplets aggregate and then coalesce into larger droplets with smaller surface areas, until there are enough multipolarity molecules to form a stable coating on the droplet surfaces. Depending on the nature and quantity of the multipolarity molecules, the two-phase liquid mixture can stabilize before or after the droplets become large enough to plug filters or phase separate. The multipolarity molecules stabilize the emulsion. Molecules that are particularly good at stabilizing emulsions are called emulsifiers. Small solid particles at the interface of the droplets can help stabilize the emulsion (Friberg and Jones 1994).

Emulsifiers are commonly ionic or nonionic. The ionic emulsifiers are metal soaps or sulfurcontaining detergents, neither of which would form desirable combustion products. Consequently, the nonionic emulsifier is of interest for bio-oil. Nonionic emulsifying materials consist of linear block copolymers; each block has a different solubility characteristic. Each block of the copolymer is long enough to form a loop or a tail into one phase or form a "train" at the interface. An example of such a copolymer is formed by alternating blocks of poly (ethylene glycol) and poly alkyl aryl ether (Friberg and Jones 1994).

Only a very small fraction of bio-oil is soluble in typical diesel fuels. Some mixtures of bio-oil in \#2 diesel oil have been stable emulsions for more than 90 days. The emulsifiers were nonionic, with hydrophilic to lipophilic block ratios between 4 and 18. The emulsifiers were derived from block copolymers of fatty acids and polyoxyethylene glycol, or fatty acids, sorbitol, and polyoxyethylene glycol or polyethoxyethylene glycol with long aliphatic chains. Mixtures as high as $40 \%$ bio-oil were emulsified with diesel fuel, using a combination of two emulsifiers, each at the $1 \%$ level. The emulsions were clear phase, implying micelles that were too small to refract light (sub-micron) (Ikura et al. 1998).

Extending the useful life of bio-oil, as an apparently single-phase liquid during aging, appears feasible by using emulsifying agents. The use of emulsifiers, e.g., lipophilic-hydrophilic block copolymers, may be advantageous to stabilize bio-oil as a stable emulsion during aging. If the resulting emulsion is aqueous-phase continuous, it would probably have a low viscosity similar to the aqueous phase.

\subsection{Off-Gassing during Aging}

Depending on the production procedure, the headspace gases that evolve during aging could be pyrolysis gases that were selectively absorbed by the bio-oil in the condensation train during production. For example, cold methanol is commercially used to absorb $\mathrm{CO}_{2}$ from gas streams in the Rectisol process. At $10^{\circ} \mathrm{C}$ and atmospheric pressure, 5 volumes of $\mathrm{CO}_{2}$ can be absorbed per volume of methanol (Kohl and Riesenfeld 1974), or a little more than $1 \mathrm{wt} \% \mathrm{CO}_{2}$. The pyrolysis gases would be desorbed with a rise in temperature or with a chemical change in the bio-oil that reduced their solubility. For example, the reaction of methanol to form esters and acetals could reduce the solubility of $\mathrm{CO}_{2}$ in bio-oil. The desorbing $\mathrm{CO}_{2}$ would tend to strip the volatile esters and acetals, as well as other absorbed gases, from the bio-oil. 


\subsection{COMPARISONS OF THE STORAGE INSTABILITY MECHANISMS OF BIO-OILS AND PETROLEUM OILS}

Petroleum-derived fuel oils consist principally of hydrocarbons, including saturated aliphatics (paraffins), unsaturated aliphatics (olefins), saturated ring compounds (naphthenes), and unsaturated ring compounds (aromatics). These hydrocarbon families have decreased mutual solubility as their molecular weight increases. Many compounds in petroleum fuel oils have several families represented in a single large molecule; e.g., a long aliphatic chain attached to an aromatic such as heptyl benzene. This multifunctionality increases the mutual solubility of the hydrocarbons. Except for the olefins, hydrocarbons are relatively stable under storage conditions (Mushrush and Speight 1995).

Crude petroleum typically has very low olefin levels. Refinery operations to lower the molecular weight and viscosity of petroleum include visbreaking, thermal cracking, coking, and catalytic cracking. These cracking reactions cause unsaturated or olefinic fragments of the original crude oil to form (Meyers 1996; Gary and Handwerk 1994).

Crude petroleum has varying amounts of elements other than carbon and hydrogen, depending on the source, principally oxygen, sulfur, nitrogen, vanadium, iron, and nickel. The metals are typically not volatile and are concentrated in the tar fractions used for residual fuel oils, asphalt, and petroleum coke. The other heteroatoms can be removed from the distillates by hydrogenation, a process that also saturates the olefins. Highly refined fuels such as gasoline and diesel fuel contain very small amounts of heteroatoms, e.g., oxygen, sulfur, and nitrogen. With heavier, less refined fuel oils, the relative amounts of heteroatoms increase (Mushrush and Speight 1995).

The storage stability of hydrocarbon fuels is a function of their heteroatom and olefin contents. Many organic sulfur compounds tend to dimerize. Oxygen and nitrogen compounds act as catalysts to polymerize olefins. This has been particularly troublesome in hydrocarbon fuels derived from oil shale and coal. The oxygen may have been in the original crude oil, or it may have been originally absorbed from the atmosphere. Once in the oil, dissolved oxygen can react with hydrocarbons to form carboxylic acids, or with olefins to form hydroperoxides and peroxides. The formation of hydroperoxides is key to many instability problems in petroleum fuels (Mushrush and Speight 1995).

The olefinic polymers formed during aging have a lower volatility and do not evaporate in carbureted gasoline fuel systems, leaving behind deposits called gums. Heteroatoms make up a disproportionately large amount of such deposits. In heavier fuels that are atomized rather than evaporated, the olefinic polymers increase the viscosity and difficulty of atomization. In extreme cases of polymerization during storage, the fuel becomes saturated with the polymers and sludge forms on the bottom of the storage tank (Mushrush and Speight 1995).

As a fuel oil becomes saturated with various polymers having different solubilities, they form heterogeneous molecular aggregations or micelles. The nucleus of a micelle contains the insoluble hydrocarbon family, typically an aromatic asphaltene. If there are enough multifunctional compounds (typically oxygenated aromatics, called resins) to coat the nucleus of the micelle, a stable suspension of the colloidal micelles can form. In a complex mixture such as fuel oils, several layers of compounds can have different mutual solubilities in a micelle. If the micelles in a stable suspension are small enough to pass through filters, they do not create operational problems to the fuel oil user (Friberg and Jones 1994). 
Changes in temperature can destabilize the emulsion. Incompatibility, when two fuel oils are mixed, can also destabilize the emulsions. An unstable emulsion passes sequentially through micelle flocculation or aggregation, agglomeration into larger droplets, and gravitational separation, i.e., sludge formation. Incompatibility can also occur if two fuel oils are mixed that cause a component to phase separate (Mushrush and Speight 1995).

Additives to increase the stability of petroleum fuel oils include emulsifying agents to maintain stable emulsions. Naturally present phenols in low concentrations act as antioxidants, but at higher levels they participate in oxidative coupling and sludge formation. Antioxidant additives such as zinc dialkyldithiophosphate, aromatic amines, and alkylated phenols are used to stabilize lubricating oils. Sulfur compounds act as free-radical traps, but also participate in crosslinking reactions. Excluding air from storage tanks is suggested to reduce oxidative aging effects (Mushrush and Speight 1995).

\subsection{SUMMARY}

Bio-oil is an ill-defined mixture of water, char, and oxygenated organic compounds that include organic acids, aldehydes, esters, acetals, hemiacetals, alcohols, olefins, aromatics, phenolics, proteins, and sulfur compounds. The actual composition of a bio-oil is a complex function of feedstock, pyrolysis technique, char removal system, condensation system, and storage conditions.

These compounds can react during storage to produce oligomers and polymers that have an increased viscosity and reduced solubility in the bio-oil. In particular, there is evidence to suggest that during storage of bio-oil:

- Acids and alcohols react to form esters and water.

- Aldehydes react with water to form hydrates.

- Aldehydes react with alcohols to form hemiacetals, acetals (ethers), and water.

- Aldehydes react to form oligomers and resins.

- Aldehydes react with phenolics in the acidic bio-oil to form novolak resins and water.

- Aldehydes react with proteins to form dimers.

- Mercaptans react to form dimers.

- Olefins polymerize to form oligomers and polymers.

- Atmospheric oxygen reacts with many organics to form peroxides that catalyze the polymerization of olefins and the addition of mercaptans to olefins.

The organic acids and the elements commonly found in the char can act as catalysts for many of these reactions. Bio-oils with lower char contents tend to have lower aging rates.

The potential reactions within bio-oil can be stabilized with solvents and hydrogenation. Adding inexpensive methanol or ethanol stabilizes bio-oil made from softwoods and hardwoods. Compared to neat bio-oil, the viscosity increase rate decreased by a factor of 17 with $10 \%$ methanol, making the mixtures relatively stable even at elevated temperatures. The small residual aging effects may be primarily due to olefinic-addition reactions. These effects will be important only for long-term storage conditions and would be minimized with the proper antioxidant or stabilizer.

Unfortunately, complete hydrogenation to remove oxygen is relatively expensive. Mild hydrogenation to saturate the olefins and convert aldehydes to alcohols is expected to be less expensive, but reportedly causes phase separation and drastically increases the viscosity of the 
organic phase. The use of antioxidants to prevent the olefinic and sulfur-based polymerization reactions may be more cost effective than hydrogenation to stabilize bio-oil.

The small amount of air in the headspace of storage containers $90 \%$ full does not appear to contain enough oxygen to affect the aging rate of bio-oils. However, if mixing is done in containers open to the atmosphere, bio-oil may absorb enough oxygen to form enough organic peroxides to affect aging rates. Preventing the exposure of bio-oil to oxygen in the atmosphere is prudent. Adding a small amount of antioxidant may be a good precautionary measure to prevent the effects of oxygen, e.g., oxygen that may infiltrate the storage tank as it "breathes" air during its daily cycle of expansion and contraction caused by heating and cooling.

Gas evolution during aging has been reported by several research groups. How much pyrolysis gas had been adsorbed by the bio-oil and how much was actually produced by aging reactions is not clear. Changes in gas solubility in the bio-oil can be due to temperature changes and to changes in the bio-oil composition. The chemical reactions that produce $\mathrm{CO}_{2}$ are probably not responsible for the increase in molecular weight and viscosity during aging.

The concepts used to describe mutual solubility, phase separation, and cosolvents for petroleumderived fuel oils appear to be qualitatively useful to describe bio-oil. In particular, the concepts of micelles and emulsions are useful in understanding phase separation in bio-oils. With some research, non-ionic block polymers can probably be identified that can be used as additives to make stable emulsions of bio-oil as it ages and phase separates. Ideally, these stable emulsions would have the low viscosity of the aqueous phase with the viscous tars in suspension (aqueous continuous).

\subsection{CONCLUSIONS AND RECOMMENDATIONS}

Adding low molecular weight solvents at the $10 \%$ level has a remarkably stabilizing effect on bio-oils made from hardwoods and softwoods. Adding reactive solvents shifts the stoichiometry from polymers to oligomers capped with the reacted solvent group. Because pyrolysis produces many of these volatile solvents in small quantities, the volatiles must apparently be recovered in the condensation train and not lost in the pyrolysis gases used for process fuel to maintain storage stability. The formation of esters in the vapor space of hot spray towers should be investigated to determine whether volatile ester solvents are being formed and lost in the pyrolysis gases.

In addition, some pyrolysis conditions might be optimized to produce more beneficial solvents, e.g., acetals. The goal of future research in pyrolysis should be to produce a bio-oil with low viscosity, a high energy conversion (based on the "lower heating value"), and a low aging rate. Trade-off studies could be conducted concerning the purchase of solvent and any losses in energy conversion required to produce a naturally stable, low-viscosity bio-oil. However, if the volatile content of the bio-oil increases significantly, parameters such as its flash point should be checked to determine whether any safety issues have been compromised.

With $10 \%$ methanol in bio-oil, the viscosity increased only from 20 to $22 \mathrm{cP}$ over a 4-month period when stored at $20^{\circ} \mathrm{C}$. This would extrapolate to a viscosity of $30 \mathrm{cP}$ after storage for 12 months. Ethanol at 20\% had a similar stabilizing effect (Oasmaa et al. 1997; Oasmaa 1999). With $10 \%$ methanol added to bio-oil, the viscosity at $40^{\circ} \mathrm{C}$ rose from about $13 \mathrm{cP}$ to an interpolated 15 $\mathrm{cP}$ after preheating for 12 hours at $90^{\circ} \mathrm{C}$, e.g., to reduce the viscosity for ease of atomization (Diebold and Czernik 1997). This demonstrated stability needs improvement only for extreme storage situations of elevated temperature, extreme preheating environments, or extended periods 
of time. Because biomass must be harvested at least annually, in many cases more stability in storage may be necessary than is provided by $10 \%$ to $20 \%$ of an alcohol.

Because solvents so effectively slow the apparent aging reactions, learning more about the mechanisms involved is important. There may be synergistic effects with combinations of solvents to maximize the cosolubility aspects of the bio-oil solution. Some modeling with the Hansen parameters before actual aging experiments could be worthwhile.

To attain more stability in storage and under severe preheating situations, hydrogenation may be desirable. However, even mild hydrogenation can cause phase separation and increase the viscosity of the organic phase. The low-pressure, very mild hydrogenation of bio-oils to saturate the olefins should continue to be investigated. Optimizing the viscosity and storage stability of the resultant bio-oils, instead of maximizing the amount of oxygen removed, would be the goal of this mild hydrogenation research. In addition, effort should be expended into the use of antioxidants to preclude the need for hydrogenation.

Emulsifying agents need to be developed to prevent tars from settling out from bio-oils during extreme aging. These emulsifiers will probably be nonionic and consist of block polymers, e.g., water-soluble (polar) blocks that alternate with phenolic-soluble (less polar) blocks.

As with petroleum products, developing an "additives package" to address the many sources of bio-oil instability during storage will be advantageous. This is envisioned to include solvents to reduce polymerization by esterification, acetalization, and phenol/formaldehyde reactions, antioxidants to reduce olefin polymerization reactions, and emulsifiers to prevent phase separation problems. This additives package would most likely be a proprietary blend; the ingredients would be trade secrets. However, its effectiveness would make a nice paper; comparisons to neat bio-oil and to bio-oil with methanol would be added.

Because aldehyde hydrates are apparently present in bio-oil, knowing whether the Karl Fischer method analyses report the water present as hydrates or only the free water would be instructive.

Research is needed to determine the composition and relative quantity of gases and vapors produced during the storage of bio-oil made from hardwoods and softwoods, including volatile

oxygenates that have low flash point temperatures. Inadequate venting of a storage tank could lead to a buildup of pressure that could rupture the tank. Any gases vented will need to be deodorized and rendered nontoxic. The catalytic air oxidation of these off-gases appears promising and needs to be investigated.

\subsection{REFERENCES}

Acharya, A.S. and Manning, J.M. (1983) "Reaction of Glycoaldehyde with Proteins: Latent Crosslinking Potential of $\alpha$-Hydroxyaldehydes," Proc. Natl. Acad. Sci. USA, 80, pp. 3590-3594.

Adams, E.W. and Adkins, H. (1925) "Catalysis in Acetal Formation," J. Am. Chem. Soc., 47, pp. $1358-1367$.

Adkins, H. and Nissen, B.H. (1922) "A Study of Catalysis in the Preparation of Acetal," J. Am. Chem. Soc., 44, pp. 2749-2755. 
Adkins, H. and Adams, E.W. (1925) "The Relation of Structure, Affinity, and Reactivity in Acetal Formation," J. Am. Chem. Soc., 47, pp. 1368-1381.

Adkins, H. and Broderick, A.E. (1928a) "Hemiacetal Formation and the Refractive Indices and Densities of Mixtures of Certain Alcohols and Aldehydes," J. Am. Chem. Soc., 50, pp. 499-503.

Adkins, H. and Broderick, A.E. (1928b) "The Rate of Synthesis and Hydrolysis of Certain Acetals," J. Am. Chem. Soc., 50, pp. 178-185.

Adkins, H.; Semb, J.; and Bolander, L.M. (1931) "Some Relationships of the Ratio of Reactants to the Extent of Conversion of Benzaldehyde and Furfuraldehyde to Their Acetals," $J$. Am. Chem. Soc., 53, 1853.

Agblevor, F.A.; Besler, S.; and Evans, R.J. (1994) "Inorganic Compounds in Biomass Feedstocks: Their Role in Char Formation and Effect on the Quality of Fast Pyrolysis Oils," in Proceedings of Biomass Pyrolysis Oil Properties and Combustion Meeting, September 26-28, Estes Park, CO, T.A. Milne, ed. National Renewable Energy Laboratory, Golden, CO, NREL-CP-430-7215, pp. 77-89.

Agblevor, F.A.; Besler, S.; and Evans, R.J. (1995) "Influence of Inorganic Compounds on Char Formation and Quality of Fast Pyrolysis Oils," abstracts of the ACS $209^{\text {th }}$ National Meeting, Anaheim, CA, April 2-5.

Andrews, R.G.; Zukowski, S.; and Patniak, P.C. (1997) "Feasibility of Firing and Industrial Gas Turbine Using a Bio-Mass Derived Fuel," in Developments in Thermal Biomass Conversion, A.V. Bridgwater and D.G.B. Boocock, eds., Blackie Academic and Professional, London, pp. 495-506.

Bahkshi, N.N. and Adjaye, J.D. (1994) "Properties and Characterization of Ensyn Bio-Oil," in Proceedings of Biomass Pyrolysis Oil Properties and Combustion Meeting, September 26-28, Estes Park, CO, T.A. Milne, ed., National Renewable Energy Laboratory, Golden, CO, NREL-CP-430-7215, pp. 54-66.

Baker, E.G. and Elliott, D.C. (1988) "Catalytic Hydrotreating of Biomass-Derived Oils," in Pyrolysis Oils from Biomass. Producing, Analyzing and Upgrading, ACS Symposium Series 376, American Chemical Society, Washington, D.C., pp. 228-240.

Barton, A.F.M. (1983) CRC Handbook of Solubility Parameters and Other Cohesion Parameters, CRC Press, Boca Raton, FL, pp. 139-165.

Capener, E.L. and Low, J.M. (1982) "Method and Apparatus for Converting Solid Organic Material to Fuel Oil and Gas," U.S. Patent 4,344,770.

Carey, F.A. (1996) Organic Chemistry, $3^{\text {rd }}$ edition, McGraw-Hill, NY.

Carraza, F.; Rezende, M.E.A.; Pasa, V.M.D.; and Lessa, A. (1994) "Fractionation of Wood Tar," in Advances in Thermochemical Biomass Conversion, A.V. Bridgwater, ed., Blackie Academic and Professional, London, pp. 1465-1474. 
Casanova Kindelan, J. (1994) "Comparative Study of Various Physical and Chemical Aspects of Pyrolysis Bio-Oils Versus Conventional Fuels, Regarding their Use in Engines," in Proceedings of Biomass Pyrolysis Oil Properties and Combustion Meeting, September 26-28, Estes Park, CO, T.A. Milne, ed., National Renewable Energy Laboratory, Golden, CO, NREL-CP-430-7215, pp. 343-354.

Cason, J. (1956) Essential Principles of Organic Chemistry, Prentice-Hall, Inc., Englewood Cliffs, NJ, p. 369.

Chum, H.L. and Black, S.K. (1990) "Process for Fractionating Fast-Pyrolysis Oils, and Products Derived Therefrom," U.S. Patent 4,942,269.

Chum, H.L. and Kriebich, R.E. (1991) "Novolak Resin from Fractionated Fast-Pyrolysis Oils," International Patent Application WO 91/09892.

Conti, L.; Scano, G.; Boufala, J.; and Mascia, S. (1997) "Bio-Crude Oil Hydrotreating in a Continuous Bench-Scale Plant," in Developments in Thermal Biomass Conversion, A.V. Bridgwater and D.G.B. Boocock, eds., Blackie Academic and Professional, London, pp. 622-632.

Conti, L.; Scano, G.; Boufala, J.; and Mascia, S. (1996) "Experiments of Bio-Oil Hydrotreating in a Continuous Bench Scale Plant," in Bio-Oil. Production and Utilization, A.V. Bridgwater and E.N. Hogan, CPL Press, Newbury, UK, pp. 198-205.

Czernik, S. (1994) "Storage of Biomass Pyrolysis Oils," in Proceedings of Biomass Pyrolysis Oil Properties and Combustion Meeting, September 26-28, Estes Park, CO, T.A. Milne, ed., National Renewable Energy Laboratory, Golden, CO, NREL-CP-430-7215, pp. 67-76.

Czernik, S.; Johnson, D.K.; and Black, S. (1994) "Stability of Wood Fast Pyrolysis Oil," Biomass and Bioenergy, 7, No. 1-6, pp. 187-192.

Diebold, J.P.; Scahill, J.W.; Czernik, S.; Phillips, S.D.; and Feik, C.J. (1996) "Progress in the Production of Hot-Gas Filtered Biocrude Oil at NREL," in Bio-Oil Production and Utilization, A.V. Bridgwater and E.N. Hogan, eds., CPL Scientific, Newbury, UK, pp. 66-81.

Diebold, J.P. (1997) A Review of the Toxicity of Biomass Pyrolysis Liquids Formed at Low Temperatures, National Renewable Energy Laboratory, Golden, CO, NREL/TP-43022739, 35 pp. (81 references) Also appears in The IEA Bioenergy Handbook on Biomass Pyrolysis, (1998), T. Bridgwater, S. Czernik, J. Leech, D. Meier, A. Oasmaa, and J. Piskorz, eds., IEA Bioenergy Task XIII Pyrolysis Activity Final Report, Aston University, Birmingham, U.K. Also in The Fast Pyrolysis of Biomass: A Handbook, A. Bridgwater, S. Czernik, J. Diebold, D. Meier, A. Oasmaa, C. Peacocke, J. Piskorz, and D. Radlein, eds., CPL Press, Newbury, UK, pp. 135-163.

Diebold, J.P. and Bridgwater, A.V. (1997) "Overview of Fast Pyrolysis of Biomass for the Production of Liquid Fuels," in Developments in Thermal Biomass Conversion, A.V. Bridgwater and D.G.B. Boocock, eds., Blackie Academic and Professional, London, pp. 5-26. (93 references) Also appears in The IEA Bioenergy Handbook on Biomass Pyrolysis, (1998), T. Bridgwater, S. Czernik, J. Leech, D. Meier, A. Oasmaa, and J. Piskorz, eds., IEA Bioenergy Task XIII Pyrolysis Activity Final Report, Aston University, Birmingham, U.K. Also in The Fast Pyrolysis of Biomass: A Handbook, A. Bridgwater, 
S. Czernik, J. Diebold, D. Meier, A. Oasmaa, C. Peacocke, J. Piskorz, and D. Radlein, eds., CPL Press, Newbury, UK, pp. 14-32.

Diebold, J.P. and Czernik, S. (1997) "Additives to Lower and Stabilize the Viscosity of Pyrolysis Oils During Storage," Energy and Fuels, 11, pp. 1081-1091.

Doerr, R.C.; Wasserman, A.E.; and Fiddler, W. (1966) "Composition of Hickory Sawdust Smoke, Low Boiling Constituents," J. Agr. Food Chem., 14, No. 6, pp. 662-665.

DIPPR (1998) Physical and Thermodynamic Properties of Pure Chemicals: Data Compilation, T.E. Daubert, Danner, R.P., H.M. Sibul, and C.C. Stebbins, eds., AIChE's Design Institute for Physical Property Data, Taylor and Francis, Bristol, PA, 3548 pp.

Dunlop, A.P. and Peters, F.N. (1953) The Furans, ACS Monographs Series, Reinhold Publishing Corp., NY, 400+ pp.

Edgar, G. and Schuyler, W.H. (1924) "Esterification Equilibria in the Gaseous Phase," J. Am. Chem. Soc., 46, pp. 64-75.

Elliott, D.C. (1986) Analysis and Comparison of Biomass Pyrolysis/Gasification CondensatesFinal Report, Pacific Northwest Laboratory, Richland, WA, PNL-5943, UC-61D, pp. 37, 41.

Elliott, D.C. (1994) "Water, Alkali, and Char in Flash Pyrolysis Oils," Biomass and Bioenergy, 7, No. 1-6, pp. 179-186.

Elliott, D.C. and Neuenschwander, G.G. (1997) "Liquid Fuels by Low-Severity Hydrotreating of Biocrude," in Developments in Thermal Biomass Conversion, A.V. Bridgwater and D.G.B. Boocock, eds., Blackie Academic and Professional, London, pp. 611-621.

Etzkorn, W.G.; Kurland, J.J.; and Neilsen, W.D. (1991) “Acrolein and Derivatives," in Kirk and Othmer's Encyclopedia of Chemical Technology, Vol. 1, $4^{\text {th }}$ ed., John Wiley and Sons, NY, pp. 232-251.

Euranto, E.K. (1969) "Esterification and Ester Hydrolysis," in The Chemistry of Carboxylic Acids and Esters, S. Patai, ed., Interscience Publishers, London, p. 507.

Fiddler, W.; Parker W.E.; Wasserman, A.E.; and Doerr, R.C. (1967) “Thermal Decomposition of Ferulic Acid," J. Agric. Food Chem., 15, No. 5, pp. 757-761.

Fraps, G.S. (1901) “The Composition of Wood Oil,” American Chemical Journal, 25, pp. 26-53.

French, R.J. and Milne, T.A. (1994) "Vapor Phase Release of Alkali Species in the Combustion of Biomass Pyrolysis Oils," Biomass and Bioenergy, 7, No. 1-6, pp. 315-325.

Frevel, L.K. and Hedelund, J.W. (1954) “Acetals and Process for Making the Same," U.S. Patent $2,691,684$.

Friberg, S.E. and Jones, S. (1994) "Emulsions," in Kirk and Othmer's Encyclopedia of Chemical Technology. $4^{\text {th }}$ ed., Vol. 9, John Wiley and Sons, NY, pp. 393-413. 
Gagnon, J. and Kaliaguine, S. (1988) "Catalytic Hydrotreatment of Vacuum Pyrolysis Oils from Wood," Ind. Eng. Chem. Res., 27, pp. 1783-1788.

Gary, J.H. and Handwerk, G.E. (1994) Petroleum Refining Technology and Economics, $3^{\text {rd }}$ ed., Marcel Dekker, Inc., NY, 460 pp.

Gerberich, H.R.; Stautzenberger, A.L.; and Hopkins, W.C. (1980) "Formaldehyde," in Kirk and Othmer's Encyclopedia of Chemical Technology, Vol. 11, $3^{\text {rd }}$ ed., John Wiley and Sons, NY, pp. 231-250.

Goos, A.W. and Reiter, A.A. (1946) "New Products from Wood Carbonization," Ind. Eng. Chem., 38, 2, pp. 132-135.

Granger, F.S. (1937) "Condensation of Phenols with Formaldehyde. Resinification of Phenol Alcohols," Ind. Eng. Chem., 29, pp. 860-866.

Guillén, M.D.; Manzanos, M.J.; and Zabala, L. (1995) "Study of a Commercial Liquid Smoke Flavoring by Means of Gas Chromatography/Mass Spectrometry and Fourier Transform Infrared Spectroscopy," J. Agric. Food Chem., 43, pp. 463-468.

Guillén, M.D. and Ibaragoitia, M.L. (1996) "Relationships between the Maximum Temperature Reached in the Smoke Generation Processes from Vitus vinifera L. Shoot Sawdust and Composition of the Aqueous Smoke Flavoring Preparations Obtained," J. Agric. Food Chem., 44, pp. 1302-1307.

Gust, S. (1997a) "Combustion Experiences of Flash Pyrolysis Fuel in Intermediate Size Boilers," in Developments in Thermal Biomass Conversion, A.V. Bridgwater and D.G.B. Boocock, eds., Blackie Academic and Professional, London, pp. 481-488.

Gust, S. (1997b) "Combustion of Pyrolysis Liquids," in Biomass Gasification and Prolysis. State of the Art and Future Prospects, M. Kaltschmitt and A.V. Bridgwater, eds., CPL Press, Newbury, UK, pp. 498-503.

Harvey, M.T. (1944a) "Acid Condensation Product of Formaldehyde and Acid Condensation Polymerization Product of Furfuryl Alcohol and Method for Preparing the Same," U.S. Patent 2,343,973.

Harvey, M.T. (1944b) "Novel Furfural Alcohol-Formaldehyde Acid Condensation Resinous Product and Method for Preparing the Same," U.S. Patent 2,343,972.

Hawley, L.F. (1923) Wood Distillation, The Chemical Catalog Company, Inc., N.Y., pp. 64-72.

Hiatt, R. (1971) "Hydroperoxides," in Organic Peroxides, D. Swern, ed., Wiley Interscience, NY, pp. 1-134.

Hinshelwood, C.N. and Legard, A.R. (1935) "The Factors Determining the Velocity of Reactions in Solution. Molecular Statistics of the Esterification of Carboxylic Acids," J. Chem. Soc., pp. 587-596.

Huffman, D.R. and Freel, B.A. (1997) "RTPTM Biocrude: A Combustion/Emissions Review," in Developments in Thermal Biomass Conversion, A.V. Bridgwater and D.G.B. Boocock, eds., Blackie Academic and Professional, London, pp. 489-494. 
Ikura, M.; Mirmiran, S. Stanciulescu, M.; and Sawatzky, H. (1998) "Pyrolysis Liquid-in-Diesel Oil Microemulsions," U.S. Patent 5,820,640.

Kelley, S.S.; Wang, X-M, Myers, M.D.; Johnson, D.K.; and Scahill, J.W. (1997) "Use of Biomass Pyrolysis Oils for Preparation of Modified Phenol Formaldehyde Resins," in Developments in Thermal Biomass Conversion, A.V. Bridgwater and D.G.B. Boocock, eds., Blackie Academic and Professional, London, pp. 557-572.

Klar, M. (1925) The Technology of Wood Distillation, Chapman \& Hall, London (translated to English by Alexander Rule), pp. 60-72.

Knight, H.B.; Koos, R.E.; and Swern, D. (1954) "New Method for Hydroxylating Long-Chain Unsaturated Fatty Acids, Esters, Alcohols, and Hydrocarbons," J. Am. Chem. Soc., 31, No. 1, pp. 1-5.

Knight, J.A.; Hurst, D.R.; and Elston, L.W. (1977) "Wood Oil from Pyrolysis of Pine BarkSawdust Mixture," in Fuels and Energy from Renewable Resources, D.A. Tillman, ed., Academic Press, New York 1977, pp. 169-194.

Kohl, A.L. and Riesenfeld, F.C. (1974) Gas Purification. $2^{\text {nd }}$ ed., Gulf Publishing Co., Houston, TX, pp. 691-700.

Kopf, P.W. (1996) "Phenolic Resins," in Kirk and Othmer's Encyclopedia of Chemical Technology. Vol. 18, $4^{\text {th }}$ ed., John Wiley and Sons, NY, pp. 604-609.

Leech, J. and Webster, J.A. (1999) "Storage and Handling of Flash Pyrolysis Oil," in Fast Pyrolysis of Biomass: A Handbook, A. Bridgwater, S. Czernik, J. Diebold, D. Meier, A. Oasmaa, C. Peacocke, J. Piskorz, and D. Radlein, eds., CPL Press, Newbury, UK, pp. 66-68.

Lewis, N.G. and Lantzy, T.R. (1989) "Lignin in Adhesives. Introduction and Historical Perspectives," in Adhesives from Renewable Resources, R.W. Hemingway, A.H. Conner, and S.J. Branham, eds., ACS Symposium Series 385, American Chemical Society, Washington, D.C., pp. 13-26.

Lorand, E.J. (1942) “Preparations of Lower Sugars,” U.S. Patent 2,272,378.

Maga, J.A. (1987) "The Flavor Chemistry of Wood Smoke," Food Reviews International, 3(1\&2), pp. 139-183.

Maga, J.A. (1988) Smoke in Food Processing, CRC Press, Boca Raton, FL, 160 pp.

Maggi, R.; Centeno, A.; and Delmon, B. (1996) "Stabilization by Mild Catalytic Hydrogenation of Bio-Oils Produced by Fast Pyrolysis," abstracts of the $9^{\text {th }}$ European Bioenergy Conference, Copenhagen, Denmark, June 24-27, p. 80.

Meier, D. (1999) private communication to the author on May 25. 
Meier, D.; Bridgwater, A.V.; Di Blasi, C.; and Prins, W. (1997) "Integrated Chemicals and Fuels Recovery from Pyrolysis Liquids Generated by Ablative Pyrolysis," in Biomass Gasification and Pyrolysis State of the Art and Future Aspects, A.V. Bridgwater and M.K. Kaltschidtt, eds., CPL Press, Newbury, U.K.

Meier, D.; Crespo Rodriguez, M.I.; Bridgwater, A.V.; Nakos, P.; di Blasi, D.; Prins, W.; Slonso, J.; and Samolada, M. (1998) Catalytic Pyrolysis of Biomass for Improved Liquid Fuel Quality. Publishable Final Report. January 1996-June 1998, Contract JOR CT95-0081.

Meyers, R.A. (1996) Handbook of Petroleum Refining Processes, $2^{\text {nd }}$ Ed., McGraw-Hill, NY, $802 \mathrm{pp}$.

Miles, T.R.; Miles, T.R., Jr.; Baxter, L.L.; Bryers, R.W.; Jenkins, B.M.; and Oden, L.L. (1996) Alkali Deposits Found in Biomass Power Plants. A Preliminary Investigation of Their Extent and Nature, National Renewable Energy Laboratory, Golden, CO, NREL/TP-4338142 or Sandia National Laboratories, Livermore, CA, SAND 96-8225.

Milne, T.A.; Agblevor, F.; Davis, M.; Deutch, S.; and Johnson, D. (1997) "A Review of the Chemical Composition of Fast Pyrolysis Oils, in Developments in Thermal Biomass Conversion, A.V. Bridgwater and D.G.B. Boocock, eds., Blackie Academic and Professional, London, pp. 409-424.

Minné, N. and Adkins, H. (1933) "Structure of Reactants and the Extent of Acetal Formation, " $J$. Am. Chem. Soc., 55, pp. 299-309.

Mushrush, G.W. and Speight, J.G. (1995) Petroleum Products: Instability and Incompatibility, Taylor and Frances, Washington, D.C., 390 pp.

Nelson, W.G. (1930) "Waste-Wood Utilization by the Badger-Stafford Process," Ind. Eng. Chem., 22, No. 4, pp. 312-315.

Oasmaa, A. and Sipilä, K. (1996) "Pyrolysis Oil Properties: Use of Pyrolysis Oil as Fuel in Medium Speed Diesel Engines," Bio-Oil Production and Utilization, A.V. Bridgwater and E.N. Hogan, eds., CPL Scientific Information Services, Ltd, Newbury, UK, pp. 175185.

Oasmaa, A.; Leppämäki, E.; Koponen, P.; Levander, J.; and Tapola, E. (1997) Physical Characterisation of Biomass-Based Pyrolysis Liquids, Technical Research Centre of Finland, VTT Publication 306, 46 pp. plus appendices.

Oasmaa, A. (1999) Private communication to the author on June 23.

Palm, M.; Piskorz, J.; Peacocke, C.; Scott, D.S.; and Bridgwater, A.V. (1993) Fast Pyrolysis of Sweet Sorghum Bagasse in a Fluidized Bed," in Proceedings of the First Biomass Conference of the Americas. Energy, Environment, Agriculture, and Industry. Vol. II, August 30-September 2, Burlington, VT, National Renewable Energy Laboratory, NREL/CP-200-5768, DE93010050, pp. 947-963.

Peacocke, G.V.C.; Russell, P.A.; Jenkins, J.D.; and Bridgwater, A.V. (1994) "Physical Properties of Flash Pyrolysis Liquids," Biomass and Bioenergy, 7, No. 1, pp. 169-177. 
Perry, R.H.; Green, D.W.; and Maloney, J.O., eds. (1997) Perry's Chemical Engineers' Handbook, $7^{\text {th }}$ ed., McGraw-Hill, N.Y., pp. 2-28 to 2-47.

Polk, M.B. and Phingbodhippakkiya, M. (1981) Development of Methods for the Stabilization of Pyrolytic Oils, Municipal Environmental Research Laboratory, U.S. Environmental Protection Agency, Cincinnati, OH, 45268, EPA-600/2-81-201, 74 pp.

Radlein, D.St.A.G.; Piskorz, J.K.; and Majerski, P.A. (1996) "Method of Upgrading Biomass Pyrolysis Liquids for Use as Fuels and as a Source of Chemicals by Reaction with Alcohols," European Patent Application EP 0718392 A1.

Radlein, D. (1999) "The Production of Chemicals from Fast Pyrolysis Bio-Oils," in The Fast Pyrolysis of Biomass: A Handbook, A. Bridgwater, S. Czernik, J. Diebold, D. Meier, A. Oasmaa, C. Peacocke, J. Piskorz, and D. Radlein, eds., CPL Press, Newbury, UK, pp. 164-188.

Radovanovic, M; Venderbosch, R.H.; Prins, W.; and van Swaaij, W.P.M. (1997) "Thermal Stability of Biomass Pyrolysis Liquids: A New Approach," in Biomass Gasification and Pyrolysis. State of the Art and Future Prospects, M. Kaltschmitt and A.V. Bridgwater, eds., CPL Press, Newbury, UK, pp. 460-470.

Riha, W.E. and Wendorff, W.L. (1993) "Browning Potential of Liquid Smoke Solutions: Comparison of Two Methods," J. Food Science, 55, No. 9, pp. 671-674.

Rolfe, A.C. and Hinshelwood, C.N. (1934) "The Kinetics of Esterification. The Reaction between Acetic Acid and Methyl Alcohol," Trans. Faraday Soc., 30, pp. 935-944.

Rossi, C. (1994) "Bio-Oil Combustion Tests at ENEL," in Proceedings of Biomass Pyrolysis Oil Properties and Combustion Meeting, September 26-28, Estes Park, CO, T.A. Milne, ed., National Renewable Energy Laboratory, Golden, CO, NREL-CP-430-7215, pp. 321-328.

Salvi, G. and Salvi, Jr., G. (1991) Pyrolytic Products Utilisation Assessment Study, Commission of the European Communities, Contract No. EN3B-0191-1 (CH).

Sato, H. (1984) “Process for the Production of Carboxylic Acid Esters," U.S. Patent 4,465,852.

Scahill, J.W.; Diebold, J.P.; and Feik, C. (1997) "Removal of Residual Char Fines from Pyrolysis Vapors by Hot Gas Filtration," in Developments in Thermochemical Biomass Conversion, A.V. Bridgwater and D.G.B. Boocock, eds., Blackie Academic and Professional, London, pp. 253-266.

Scott, D.S. and Piskorz, J. (1984) "The Continuous Flash Pyrolysis of Biomass," Can. J. Chem. Eng., 62, pp. 404-412.

Shihadeh, A.L. (1998) Rural Electrification from Local Resources: Biomass Pyrolysis Oil Combustion in a Direct Injection Diesel Engine, $\mathrm{PhD}$ Thesis at the Massachusetts Institute of Technology, p. 34.

Simons, R.M. (1983) in Encyclopedia of Chemical Processing and Design, Volume 19, J.J. McKetta and W.A. Cunningham, eds., Marcel Dekker, N.Y., p. 381. 
Smith, H.A. (1939) "Kinetics of the Catalyzed Esterification of Normal Aliphatic Acids in Methyl Alcohol," J. Am. Chem. Soc., 61, pp. 254-260.

Stamm, A.J. and Harris, E.E. (1953) Chemical Processing of Wood, Chemical Publishing Co., NY, pp. 444-447.

Street and Adkins (1928) "The Effect of Certain Beta Substituents in the Alcohol upon Affinity and Reactivity in Acetal Formation," J. Am. Chem. Soc., 50, 162.

Suida, H. (1931) "Manufacture of Isopropyl- and Homologous Esters of Aliphatic Acids and Isopropyl Alcohol and Homologous Alcohols," U.S. Patent 1,836,135.

Sutton, H.C. and Downes, T.M. (1972) "Rate of Hydration of Formaldehyde in Aqueous Solution," J. Chem. Soc. Chem. Comm., 1, pp. 1-2.

Tiplady, I.R.; Peacocke, G.V.C.; and Bridgwater, A.V. (1996) "Physical Properties of Fast Pyrolysis Liquids from the Union Fenosa Pilot Plant," in Bio-Oil. Production and Utilization, A.V. Bridgwater and E.N. Hogan, eds., CPL Press, Newbury, U.K., pp. 164174.

Tóth, L. and Potthast, K. (1984) "Chemical Aspects of the Smoking of Meat and Meat Products," Advances in Food Research, 29, pp. 87-158.

Vergnet, A.-M. and Villeneuve, F. (1988) "Techniques Analytiques Applicables Aux Gaz et Jus de Pyrolyse de la Biomasse Tropicale," Cahiers Scientifiques Bois et Forets, des Tropiques, Centre Technique Forestier Tropical, Nogent-Sur-Marne, France, No. 9, pp. 3-66.

Walker, J.F. (1953) Formaldehyde, $2^{\text {nd }} e d$., ACS Monograph Series, Reinhold Publishing Corp., NY, 575 pp.

Williams, D.L. and Dunlop, A.P. (1948) "Kinetics of Furfural Destruction in Acidic Aqueous Media," Ind. Eng. Chem., 40, No. 2, pp. 239-241. 


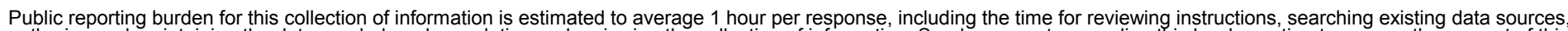

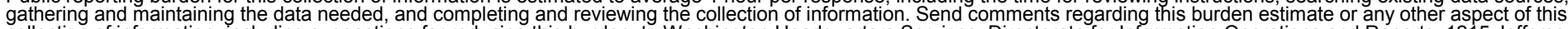

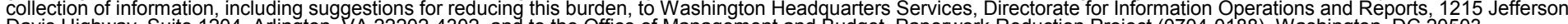

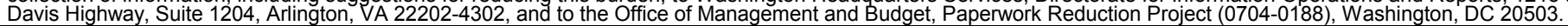

\begin{tabular}{|l|l|l} 
1. AGENCY USE ONLY (Leave blank) & $\begin{array}{l}\text { 2. REPORT DATE } \\
\text { January } 2000\end{array}$ & $\begin{array}{l}\text { 3. REPORT TYPE AND DATES COVERED } \\
\text { Subcontract Report }\end{array}$ \\
\hline
\end{tabular}

\section{TITLE AND SUBTITLE}

A Review of the Chemical and Physical Mechanisms of the Storage Stability of Fast Pyrolysis Bio-Oils

5. FUNDING NUMBERS

BP001010

\section{AUTHOR(S)}

J.P. Diebold

\section{PERFORMING ORGANIZATION NAME(S) AND ADDRESS(ES)}

Thermalchemie, Inc.

57 N. Yank Way

P.O. Box 185134

Lakewood, CO

\section{SPONSORING/MONITORING AGENCY NAME(S) AND ADDRESS(ES)}

National Renewable Energy Laboratory

1617 Cole Boulevard

Golden, CO 80401-3393

8. PERFORMING ORGANIZATION REPORT NUMBER

10. SPONSORING/MONITORING AGENCY REPORT NUMBER

NREL/SR-570-27613

\section{SUPPLEMENTARY NOTES}

12a. DISTRIBUTION/AVAILABILITY STATEMENT

National Technical Information Service

U.S. Department of Commerce

5285 Port Royal Road

Springfield, VA 22161

13. ABSTRACT (Maximum 200 words) Understanding the fundamental chemical and physical aging mechanisms is necessary to learn how to produce a bio-oil that is more stable during shipping and storage. This review provides a basis for this understanding and identifies possible future research paths to produce bio-oils with better storage stability.

14. SUBJECT TERMS

bio-oil, storage stabiliity, pyrolysis

\begin{tabular}{l|l}
$\begin{array}{l}\text { 17. SECURITY CLASSIFICATION } \\
\text { OF REPORT } \\
\text { unclassified }\end{array}$ & $\begin{array}{l}\text { 18. SECURITY CLASSIFICATION } \\
\text { OF THIS PAGE } \\
\text { unclassified }\end{array}$ \\
\hline
\end{tabular}

NSN 7540-01-280-5500
15. NUMBER OF PAGES

16. PRICE CODE OF ABSTRACT unclassified
20. LIMITATION OF ABSTRACT

UL
19. SECURITY CLASSIFICATION 